Aus der Abteilung Nephrologie und Rheumatologie (Prof. Dr. med. G.A. Müller) im Zentrum Innere Medizin der Medizinischen Fakultät der Universität Göttingen

\title{
HGF als anti-fibrotisches Agens: Effekte der Überexpression in renalen Fibroblasten und Tubulusepithelzellen
}

\author{
Inaugural-Dissertation \\ zur Erlangung des Doktorgrades \\ der Medizinischen Fakultät \\ der Georg-August-Universität zu Göttingen
}

\author{
vorgelegt von \\ Cathleen Rogge \\ aus \\ Magdeburg \\ Göttingen 2010
}


Dekan: Prof. Dr. med. C. Frömmel

I. Berichterstatter: Prof. Dr. med. F. Strutz

II. Berichterstatter/in:

III. Berichterstatter/in:

Tag der mündlichen Prüfung: 


\section{Inhaltsverzeichnis}

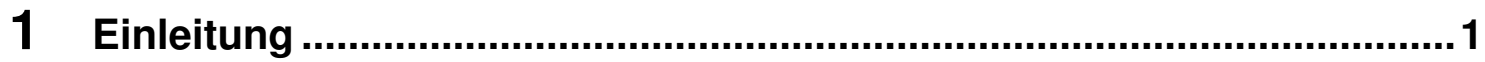

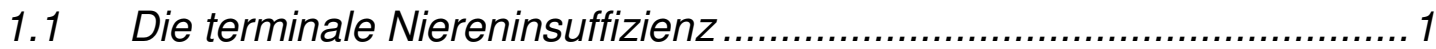

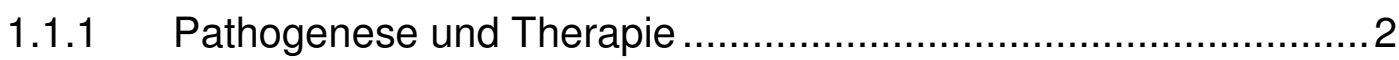

1.2 Die renale Fibrose und das Tubulointerstitium ................................. 3

1.3 Gewebeschädigung, Entzündung und Reparation

- Die renale Fibrose als überschießende Wundheilung - ..................... 5

1.5 Die epithelial-mesenchymale Transition .................................... 8

1.6 TGF- $\beta 1$ das „Schlüsselzytokin“ der renalen Fibrogenese ...................9

$1.7 \quad$ Antifibrotisch wirkende Zytokine ............................................. 10

$1.8 \quad$ Hepatocyte Growth Factor................................................... 11

1.8.1 Struktur, Synthese und biologische Aktivität von HGF ..............11

1.8.2 Hepatocyte Growth Factor in renalen Erkrankungen.................. 14

$1.9 \quad$ Fragestellung und Zielsetzung ............................................... 17

2 Material und Methoden................................................................... 18

$2.1 \quad$ Material............................................................................... 18

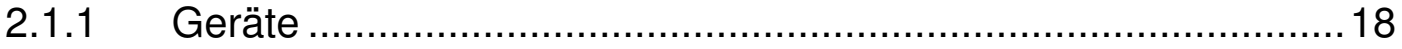

2.1.2 Gebrauchsmaterialien .................................................... 19

2.1.3 Chemikalien .................................................................. 20

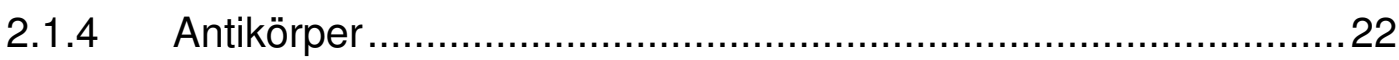

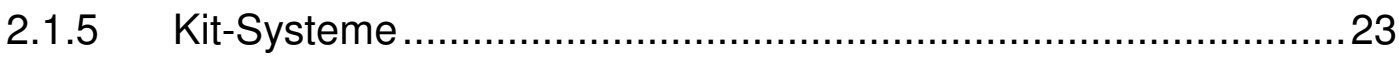

2.1.6 Allgemeine Puffer und Lösungen .......................................24

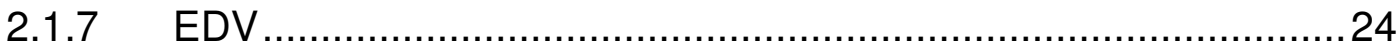

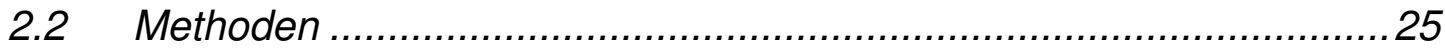

2.2.1 Die Zellreihen TFB-HGF/-3.1 und NP1-HGF ..........................25

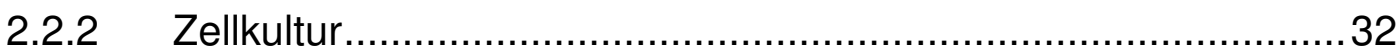

2.2.3 Kryokonservierung und Auftauen von Zellen............................33

2.2.4 Untersuchung der Zellzählung ........................................ 34

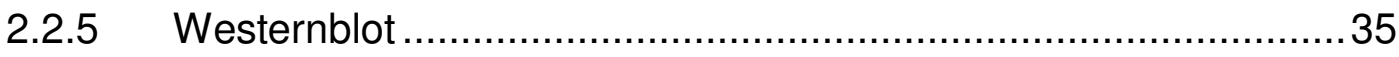


2.2.6 Untersuchung der extrazellulären Matrixdegeneration....

2.2.7 Quantitative Bestimmung von Fibronektin und Kollagen im Zellüberstand

2.2.8 Apoptoseuntersuchung mittels FITC-Annexin-V- Markierung und Durchflusszytometrie 44

2.2.9 Statistische Analysen 45

3 Ergebnisse 46

3.1 Untersuchung zum Nachweis einer HGF-Überexpression 46

3.1.1. PCR zum Nachweis einer HGF- und 3.1-Überexpression nach stabiler Transfektion

3.1.2. Westernblotanlysen zum Nachweis einer HGF-Proteinsekretion nach stabiler Transfektion 46

3.2 Untersuchungen zum proliferativen Effekt von HGF in renalen

Fibroblasten und proximalen Tubulusepithelzellen 47

3.2.1 Proliferationsmessung mit Hilfe eines BrdU-Assays. 47

3.2.2 Zellzählung mittels Trypanblau-Assay..... 50

3.3 Untersuchung zur Wirkung von HGF auf die Synthese Extrazellulärer Matrixproteine 52

3.3.1 Fibronektinsynthese 53

3.4 Analyse der Sekretion extrazellulärer Markerproteine unter dem Einfluss einer HGF-Überexpression 54

3.4.1 Effekt von HGF auf die Sekretion von Fibronektin .....................55

3.4.2 Effekt von HGF auf die Sekretion von Kollagentyp-I ...................56

3.5 Matrixdegeneration unter HGF-Überexpression...............................58

3.5.1 Effekt von HGF auf die Aktivität der Matrix-Metalloproteinase-2 und -9 58

3.6 Untersuchungen zum Einfluss einer HGF-Überexpression auf die durch CsA induzierte Apoptose in renalen Fibroblasten und proximalen Tubulusepithelzellen 61

4 Diskussion 64 
4.1 HGF fördert die Proliferation proximaler Tubulusepithelzellen und renaler Fibroblasten .............................................................................6 66

4.2 HGF hemmt die Produktion extrazellulärer Matrixproteine ................68

4.3 Matrixdegeneration - Induktion und Inhibition von MMP-2 und MMP-9 71

4.4 HGF schützt Tubulusepithelzellen und renale Fibroblasten vor Cyclosporin-A-induzierter Apoptose 73

4.5 Schlussfolgerung und Ausblick................................................ 79

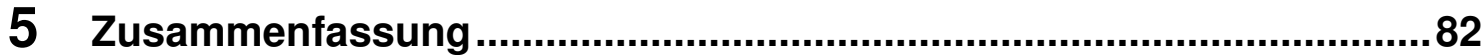

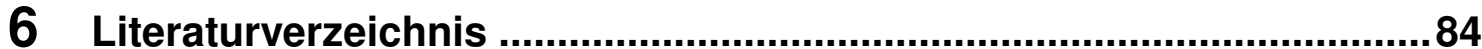

7 Abbildungs- und Tabellenverzeichnis ................................................ 95

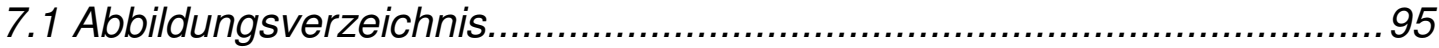

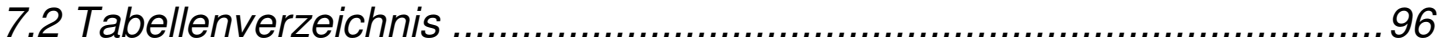




\section{Abkürzungsverzeichnis}

$\begin{array}{ll}\alpha \text {-SMA } & \alpha \text {-Glattmuskelaktin ( } \alpha \text {-smooth-muscle-actin) } \\ \text { ACE } & \text { Angiotensin-Converting-Enzyme } \\ \text { Ang II } & \text { Angiotensin II } \\ \text { APS } & \text { Ammoniumperoxidsulfat } \\ \text { BMP7 } & \text { Bone morphogenic protein 7 } \\ \text { BrdU } & \text { Bromdeoxyuridin } \\ \text { BSA } & \text { Bovine Serum Albumin } \\ \text { CsA } & \text { Cyclosporin A } \\ \text { CSPD } & \text { Disodium3-(4-methoxyspiro(1,2-dioxetane-3,2.(5'- } \\ & \text { chloro)triclo(3,3,1,1)decan)-4-yl)phenylphosphate } \\ \text { CTGF } & \text { Connective Tissue Growth Factor } \\ \text { ddH }{ }_{2} \text { O } & \text { Zweifach destilliertes Wasser } \\ \text { DMEM } & \text { Dulbecco's Modified Eagle Medium } \\ \text { DTT } & \text { Dithiotreitol } \\ \text { ECM } & \text { Extrazelluläre Matrix (Extracellular Matrix) } \\ \text { EDTA } & \text { Ethylendiamintetraessigsäure-Dinatriumsalz } \\ \text { EGF } & \text { Epidermal Growth Factor } \\ \text { EGTA } & \text { Ethylenglycol-bis-( } \beta \text {-aminoethylenether)-NNN'N'- } \\ & \text { tetraessigsäure } \\ \text { ELISA } & \text { Enzyme Linked Immunosorbent Assay } \\ \text { EMT } & \text { Epithelial-Mesenchymale Transformation } \\ \text { FCS } & \text { Foetales Kälberserum } \\ \text { FGF } & \text { Fibroblast Growth Factor } \\ \text { FN } & \text { Fibronektin } \\ \text { FSP-1 } & \text { Fibroblasten-Spezifisches Protein-1 } \\ \text { GFR } & \text { Glomeruläre Filtrationsrate } \\ \text { HGF } & \text { Hepatocyte Growth Factor } \\ \text { HRP } & \text { Horse Radish Peroxydase } \\ \text { INF- } \gamma & \text { Interferon- } \gamma \\ & \end{array}$




$\begin{array}{ll}\text { Kol-I } & \text { Kollagentyp-I } \\ \text { Kol-IV } & \text { Kollagentyp-IV } \\ \text { MMP } & \text { Matrix-Metalloproteinase } \\ \text { PBS } & \text { Phosphat-gepufferte Salzlösung ("phosphate buffered } \\ & \text { sodium") } \\ \text { PMSF } & \text { Phenylmethansulfonsäurefluorid } \\ \text { SDS } & \text { Sodiumdodecylsulfat } \\ \text { TBM } & \text { Tubuläre Basalmembran } \\ \text { TEMED } & \text { Tetramethylethylendiamin } \\ \text { TGF- } \beta 1 & \text { Transforming Growth Factor- } \beta 1 \\ \text { ZO-1 } & \text { Zona-occludens-1 }\end{array}$




\section{Einleitung}

\subsection{Die terminale Niereninsuffizienz}

Die chronische Niereninsuffizienz ist ein weltweites Gesundheitsproblem mit stetig steigender Inzidenz und Prävalenz, sowie schlechter Langzeitprognose und hohen sozioökonomischen Belastungen (Eknoyan et al. 2004). Ursächlich liegen ihr sowohl chronische Nierenerkrankungen, wie beispielsweise die diabetische Nephropathie, Glomerulonephritiden, tubulointerstitielle Erkrankungen, vaskuläre und polyzystische Nephropathien, als auch Systemerkrankungen mit nephrogener Beteiligung zu Grunde. Nach Angaben des Jahresberichtes Quasi-Niere 2005/2006, der ca. 90\% aller deutschen Dialysezentren erfasst, ist die Zahl der Dialysepatienten zwischen 1995 und 2005 um 53\% und die der Nierentransplantierten um 78\% gestiegen (Frei und Schober-Halstenberg 2006). Der Trend zeigt vor allem in den westlichen Industrienationen eine stetig wachsende Inzidenz der großen Volkskrankheiten Diabetes mellitus und arterieller Hypertonus, die die häufigsten Grunderkrankungen der terminalen Niereninsuffizienz darstellen. Ende 2005 wurden in Deutschland ca. 65.000 Patienten mit einem Dialyseverfahren versorgt, wobei mehr als 16.700 Patienten erstmalig in chronische Nierenersatzverfahren aufgenommen wurden. Die ökonomische Bedeutung der chronischen Niereninsuffizienz für das hiesige Gesundheitssystem, ergibt sich aus den hohen Kosten der Nierenersatzverfahren und den Kosten ihrer Folgeerkrankungen. In Deutschland werden für die Dialyse pro Jahr durchschnittlich 50.00060.000 Euro pro Patient veranschlagt. So wurden 2005 allein 3 Milliarden Euro für die Dialysebehandlung ausgegeben, was somit eine erhebliche Belastung für Gesundheitswesen und Volkswirtschaft darstellt. 


\subsubsection{Pathogenese und Therapie}

Unabhängig von der Grunderkrankung münden chronische Nierenerkrankungen in den meisten Fällen in die terminale Niereninsuffizienz. Diese ist geprägt durch die irreversible Verminderung der glomerulären, tubulären und endokrinen Funktion der Niere. Dadurch bedingt kommt es zum Versagen der exkretorischen Nierenfunktion, was zu Störungen des Wasser-, Elektrolyt- und Säure-Basen-Haushaltes führt. Die Abnahme der inkretorischen Funktionen, wie die Sekretion von Erythropoetin, aktivem Vitamin D und Prostaglandinen, verändert die Hämodyamik und resultiert in renaler Anämie und Osteopathie. Bedingt durch die eingeschränkte Ausscheidungsfunktion werden harnpflichtige Substanzen retiniert. Diese können toxische Organschäden verursachen und im Besonderen zur Steigerung des kardiovaskulären Risikos bei niereninsuffizienten Patienten führen. Im Terminalstadium, Stadium V der Niereninsuffizienz, liegt die glomeruläre Filtrationsrate unter $15 \mathrm{ml} / \mathrm{min} /$ $1,73 \mathrm{~m}^{2}$, was im Regelfall eine Nierenersatztherapie in Form von Dialyse oder eine Nierentransplantation notwendig macht (Herold 2007). Wie schnell die renale Funktion abnimmt, ist einerseits von der Grunderkrankung und andererseits von den Progressionsfaktoren abhängig. Zu den wichtigsten Progressionsfaktoren der Niereninsuffizienz zählen die systemische Hypertonie, die Proteinurie, die hohe Eiweiß- und Phosphatzufuhr, sowie die Hyperlipidämidie und die metabolische Azidose. Die therapeutischen Möglichkeiten, auf die Progredienz der Erkrankung Einfluss zu nehmen, sind leider gering. Im Wesentlichen beruhen sie auf der Behandlung der Grunderkrankung und der Progressionsfaktoren. Von entscheidender Bedeutung für das Fortschreiten der Krankheit ist die Einstellung des Blutdruckes, wobei Werte unter $130 \mathrm{mmHg}$ systolisch und $80 \mathrm{mmHg}$ diastolisch angestrebt werden. Präferentiell sollten dazu ACE-Hemmer, bzw. AngiotensinRezeptorblocker eingesetzt werden (Herold 2007). Bei Patienten mit diabetischer Nephropathie ist die Einstellung des Blutzuckers auf normoglykämische Werte absolut notwendig. Auch die Proteinrestriktion 
(Remuzzi und Bertani 1998) und die frühzeitige medizinische Betreuung von chronisch Nierenkranken durch Nephrologen, kann sich positiv auf die Progressionsverzögerung auswirken (Battle et al. 2006). Keine der derzeit angewandten Therapiestrategien führt zu einem Funktionserhalt der Niere, so dass die Nierentransplantation oder die Dialyse bisher die einzigen Therapiemöglichkeiten sind.

\subsection{Die renale Fibrose und das Tubulointerstitium}

Die chronische Niereninsuffizienz ist histologisch durch Glomerulosklerose und tubulointerstitielle Fibrose charkterisiert. Unabhängig von der zu Grunde liegenden Erkrankung kommt es durch den fortschreitenden Krankheitsverlauf zu ausgeprägter Gewebevernarbung, die zur Destruktion des Nierenparenchyms und terminaler Niereninsuffizienz führt. Die Zunahme des Narbengewebes korreliert mit der Funktionsverschlechterung und Abnahme des Glomerulumfiltrats. Insbesondere die tubulointerstitielle Fibrose spielt für die Progression renaler Erkrankungen eine wichtige Rolle. Bohle et al. (1994) demonstrierten, dass die zunehmende Erweiterung des Tubulointerstitiums mit einer progredienten Einschränkung der Nierenfunktion assoziert ist und dass ferner das tubulointerstitielle Volumen mit der Serum-Kreatininkonzentration korreliert. Da der tubulointerstitielle Raum mehr als $80 \%$ des Nierenvolumens ausmacht (Palmer 1997), ist es nicht verwunderlich, dass Veränderungen seiner Struktur einen entscheidenden Einfluss auf die Nierenfunktion haben. Der tubbulointerstitielle Raum besteht aus Interstitium, Tubuli und Gefäßen (Lemley und Kritz 1991). Durch die tubuläre Basalmembran sind die Tubulusepithelzellen vom Interstitium und den anderen Strukturen getrennt. Sie besteht aus der Hauptkomponente, dem Kollagentyp-IV, und anderen Strukturproteinen. Ersteres bildet als Hauptkomponente das Gerüst der tubulären Basalmembran und bewahrt deren strukturelle Integrität (Timpl 1996). Das Interstitium beinhaltet eine lockere 
extrazelluläre Matrix, die hauptsächlich aus Kollagenen (Typ I, Typ III), Fibronektin und Heparansulfatproteoglykan besteht. Sie umgibt interstitielle Fibroblasten und interagiert mit ihnen über Integrine (Zeisberg et al. 2001, Kaissling und Le Hir 1994). Die Fibroblasten, die dabei den grössten Anteil bilden, sind für die Synthese von extrazellulärer Matrix (ECM) verantwortlich (Aumailley und Gayraud 1998). In der gesunden Niere herrscht ein physiologisches Gleichgewicht zwischen Matrixsynthese und Matrixabbau, dieses wird bei chronischen Nierenrerkrankungen gestört.

Auf molekularer Ebene liegt dem Prozess der Nierenfibrose eine exzessive Ablagerung von ECM zu Grunde. Sie geht zunächst mit einer Vermehrung interstitieller Zellen (Bohle et al. 1979, Bohle 1982) und mit der Ausweitung des Interstitium einher, welche mit tubulärer Atrophie und tubulärer Dilatation assoziiert ist (Strutz und Neilson 2003). Dieser Prozess exzessiver Matrixakkumulation ist erstens durch die gesteigerte Synthese von Matrixproteinen wie Fibronektin, Proteoglykanen, KollagenI, -III, -IV, Laminin, Vitronectin, Tenascin und Heparansulfat geprägt. Zweitens wird durch die verminderte Bildung von Gewebsproteinasen, wie z.B. Matrix-Metalloproteinasen (MMP) und die gesteigerte Bildung von Protease-Inhibitoren, wie Tissue Inhibitors of Metalloproteinases (TIMP) und Plasminogen-Aktivator-Inhibitor-Typ-1 (PAI-1), der Matrixabbau gehemmt. Drittens begünstigt die lokale Überexpression von matrixbindenden Rezeptoren, sogenannter Integrine, die Adhäsion von Matrixproteinen (Border und Noble 1994). 


\subsection{Gewebeschädigung, Entzündung und Reparation}

\section{- Die renale Fibrose als überschießende Wundheilung -}

Für das Überleben von Organismen ist die Fähigkeit der Gewebereparation und Regeneration essentiell. Abhängig von Zelltyp und anatomischer Funktion besitzen Zellen ein unterschiedliches Potential, auf Noxen zu reagieren, d.h. sie sind in der Lage, Schädigungen innerhalb bestimmter Grenzen zu tolerieren. Wird diese Toleranzgrenze überschritten, kommt es zur irreversiblen Schädigung der Zellen und Einleitung von Zelltod. Unabhängig vom initialem Insult folgt auf eine Gewebeschädigung immer eine Entzündungsreaktion mit anschließender Wundheilung (Ferguson und O'Kane 2004). Der Entzündungsprozess läuft nach einem allgemeinen Schema ab. Zunächst kommt es zur Bildung und Sekretion unterschiedlicher Mediatoren. Sie bewirken eine Steigerung der vaskulären Permeabilität, die Aktivierung von Endothelzellen und Einwanderung inflammatorischer Zellen (Kofler et al. 2004). Die Entzündungsreaktion ist entscheidend für die zelluläre Regeneration und Deckung von Gewebedefekten mittels Matrixexpansion. Bleibt dieser Prozess zeitlich und lokal begrenzt, kann somit die physiologische Histologie und Funktion wieder hergestellt werden. Vorraussetzungen dafür sind, dass keine weiteren Schädigungen auftreten, Entzündungsmediatoren neutralisiert werden und inflammatorische Zellen abgebaut werden. Häufiger als die vollständige Regeneration ist die unvollständige Geweberegeneration. Gründe dafür sind chronisch einwirkende Noxen oder eine bereits vorliegende ausgeprägte Zerstörung der ursprünglichen Gewebearchitektur. An der Niere führen z. B. Schädigungsreize wie Hypertonie, Hyperglykämie oder chronische Entzündungen zu einer anhaltenden, nicht limitierten Wundheilung. Die dadurch bedingte Matrixüberexpression führt zur destruierenden Narbenbildung und Ausbildung einer Schrumpfniere. Auch in anderen Organen mit chronisch-progressiven Erkrankungen wie z.B. Leberzirrhose, Lungen- und Myokardfibrose, findet diese Form der Gewebeantwort statt (Border und Noble 1994). Alle diese Krankheiten 
gehen mit einer Fibrosierung und dem daraus resultierenden Funktionsverlust des Organs einher.

\subsection{Die renale Fibrogenese}

Das heutige Modell der renalen Fibrogenese ist mit der physiologischen Wundheilung vergleichbar, die sich in drei Phasen einteilen lässt. Hierzu zählen die Induktionsphase, Phase der inflammatorischen Matrixsynthese und Phase der postinflammatorischen Matrixsynthese (Strutz und Neilson 2003). Nach initaler Schädigung reagiert die Niere mit einer Entzündungsreaktion. In der Induktionsphase bewirkt die Sekretion von Chemokinen einen vermehrten Einstrom von Monozyten, Makrophagen und Lymphozyten (Müller et al. 1992). Diesem Chemokingradienten folgend, werden die inflammatorischen Zellen direkt zu dem geschädigten Areal geleitet. Abhängig von der Ätiologie der renalen Schädigung werden entweder glomeruläre oder ins Interstitium eingewanderte Entzündungszellen aktiviert und beginnen mit der weiteren Sekretion schädigender Mediatoren. Die Zytokine stimulieren die Proliferation residenter Fibroblasten und deren Aktivierung zu Myofibroblasten. Des Weiteren fördern sie die Epithelial-Mesenchymale Transition tubulärer Epithelzellen in Matrix-produzierende Zellen. In der sich anschließenden Phase der inflammatorischen Matrixsynthese werden Fibroblasten durch anhaltende Sekretion profibrogener Zytokine durch eingewanderte Entzündungszellen und residente Nierenzellen stimuliert. $\mathrm{Zu}$ den wichtigsten Zytokinen der inflammatorischen Matrixsynthese zählen insbesondere Angiotensin-II (AT-II) und Transforming Growth Factor- $\beta 1$ (TGF- $\beta 1$ ). AT-II ist in der Lage, Tubulusepithelzellen und Fibroblasten zur TGF- $\beta 1$-Sekretion und Kollagensynthese zu stimulieren (Ruiz-Ortega und Edigo 1997). TGF- $\beta 1$ selbst wird als das Schlüsselzytokin der Fibrogenese angesehen. Es wirkt chemotaktisch auf Fibroblasten, fördert deren Transformation zu Myofibroblasten und die Produktion von extrazellulären Matrixproteinen, wie Fibronektin und Kollagen-I. Neben 
der Überproduktion unterstützt die verminderte Matrixdegeneration die exzessive Akkumulation von ECM. Die postinflammatorische Phase unterschiedet sich von der physiologischen Wundheilung durch eine ausbleibende Resolution. Trotz Abklingen des primären inflammatorischen Stimulus persistiert die interstitielle Entzündung. Da das Gleichgewicht zwischen Matrixsynthese und Matrixdegeneration gestört ist, führt dieser Prozess zur fortschreitenden Zerstörung der Organarchitektur, zum Funktionsverlust und schließlich zur terminalen Niereninsuffizienz (Strutz und Neilson 2003).

I Induktionsphase
Freisetzung von Chemokinen und Zytokinen durch tubuläre Epithelzellen
Infiltration von mononukleären Zellen
Freisetzung von profibrogenen Zytokinen
Aktivierung und Proliferation von residenten Fibroblasten
Epithelial-Mesenchymale Transition
II Inflammatorische Phase
Gesteigerte Matrixsythese und -deposition
Kontinuierliche Freisetzung profibrogener Zytokine durch infiltrirende Zellen
III Post-inflammatorische Phase
Einstellung des primären Entzündungsstimulus
Sekretion von profibrogenen Zytokinen durch Tubulusepithelzellen
Autokrine Proliferation aktivierter Fibroblasten

Tab. 1.1:

Mechanismen der renalen Fibrose (Strutz und Neilson 2003, 461) 


\subsection{Die epithelial-mesenchymale Transition}

Die epithelial-mesenchymaleTransition (EMT) ist unerlässlich für die embryonale Entwicklung, die Tumorprogression (Thiery 2002) und die Organfibrose (Lee et al. 2006). Während der EMT kommt es zum Verlust epithelspezifischer Charkteristika und zur Ausbildung eines mesenchymalen Phänotyps von Epithelzellen. Die zellmorphologischen Veränderungen führen zum Verlust intrazellulärer epithelialer Adhäsionsmoleküle, an deren Stelle mesenchymale Zytoskelettmarker exprimiert werden. In der embryologischen Entwicklung ermöglicht die EMT den bereits verankerten Zellen, sich im entwickelnden Organismus neu auszurichten. Im adulten Organismus dient die EMT der raschen Rekrutierung vitaler Zellen mit der Absicht, geschädigtes Gewebe relativ schnell durch epitheliale Zellen zu ersetzen (Iwano et al. 2002). Bei der renalen Fibrose spielt die EMT eine zentrale Rolle (Okada et al. 2000). Neuere Studien zeigen, dass die Akkumulation von Kollagen und anderer Matrixkomponenten nicht allein auf die Aktivierung residenter Fibroblasten zu Myofibroblasten zurückzuführen ist. Diese Fibroblasten stammen zum einen vom Knochenmark ab, zum andern sind sie auf die EMT von Tubulusepithelzellen zurückzuführen (Strutz et al. 1995, Kalluri und Neilson 2003, Neilson 2005). Diese Arbeitsgruppe konnte anhand der Expression von Fibroblasten-spezifischem Protein (FSP1) und $\alpha$-smooth muscle actin (Myofibroblasten-Marker) demonstrieren, dass Tubulusepithelzellen durch Zytokine und Verlust der TBM eine Transition durchlaufen und sich zu Fibroblasten umwandeln können. Während der renalen Fibrogenese läuft die EMT in mehreren Schritten ab. Zu den wichtigsten EMT-Induktoren zählen Wachstumsfaktoren, wie TGF- $\beta 1$, EGF, FGF-2, IL-1 und Enzyme, z.B. MMP-2 oder andere Matrixmetalloproteinasen. In der Initialphase werden die Tubulusepithelzellen durch TGF- $\beta 1$ und MMP-2 aktiviert (Zeisberg et al. 2001). Daraus resultiert zum einen der Verlust der E-CadherinExpression, ein epitheliales Adhäsionsmolekül, das für die Aufrechterhaltung der Zellstruktur verantwortlich ist. Zum anderen 
beginnen die aktivierten Epithelien mit der autokrinen Sekretion von TGF$\beta 1$ und MMP-2, was die weitere Destruktion der TBM und Fortsetzung der EMT begünstigt. Durch die EMT verlieren die Tubulusepithelzellen ihre ursprüngliche apikal-basale Polarität und sind in der Lage sich aus ihrem Zellverband zu lösen und durch die geschädigte Baselmembran in das Interstitium zu migrieren (Zeisberg et al. 2002; Zeisberg und Kalluri 2004). Dort wandeln sie sich zu fusiformen, fibroblastenähnlichen Zellen um (Strutz und Müller 2000). Parallel dazu kommt es zur de-novo-Expression mesenchymaler Marker wie $\alpha$-SMA, Vimentin und FSP-1 (Strutz et al. 1995). Im Interstitium tragen die via EMT entstandenen Fibroblasten entscheidend zur exzessiven Matrixsynthese und deren Deposition und schließlich zur Progression der chronischen Nierenerkrankung bei (Iwano et al. 2002). Ein Teil der migrierten Zellen geht via Apoptose (programmierter Zelltod) zugrunde. Demzufolge scheinen die EMT und die Apoptose am Verlust tubulärer Epithelzellen beteiligt zu sein und wesentlich zur tubulären Atrophie und Krankheitsprogression beizutragen (Zeisberg und Kalluri 2004).

\subsection{TGF- $\beta 1$ das „Schlüsselzytokin“ der renalen Fibrogenese}

Transforming Growth Factor- $\beta 1$ (TGF- $\beta 1$ ) ist ein profibrogenes Zytokin mit multifunktionaler Wirkung und wird als das Schlüsselzytokin der renalen Fibrogenese angesehen (Strutz und Neilson 2003). Studien an transgenen TGF- $\beta 1$ überexpremierenden Mäusen zeigten eine rasche Entwicklung von Glomerulosklerose und interstitieller Fibrose (Kopp und Klotmann 1990). Auch die Verabreichung von externem TGF- $\beta 1$ förderte die Fibrogenese und Expansion renaler Matrix (Border und Noble 1994). Bei Patienten mit chronischen Nephropathien wurden erhöhte TGF- $\beta$ Serumkonzenztrationen gemessen (Negri 2004). Andere Studien beschrieben, dass in vivo und in vitro die Blockade einer Aktivierung von TGF- $\beta 1$ (Isaka et al. 1999) eine verminderte Matrixsynthese und 
Matrixakkumulation zur Folge haben und dass die Neutralisierung dieses Zytokins die renale Fibrose bis zu einem gewissen Maß revidieren kann (Chen et al. 2003). TGF- $\beta 1$ ist ein Zytokin mit chemotaktischer Wirkung auf Fibroblasten und Monozyten. Es vermittelt die Umwandlung von Fibroblasten zu Myofibroblasten und triggert die Synthese extrazellulärer Matrixkomponenten, wie Fibronektin und Kollagentyp-I. Durch die Stimulation von Integrinen auf der Zelloberfläche werden ZellMatrixinteraktionen und die Matrixvernetzung begünstigt. Ferner inhibiert TGF- $\beta 1$ die Expression von Kollagenasen und stimuliert die Synthese von Proteaseinhibitoren (z.B. PAI-1 und TIMP), wodurch die Matrixdegeneration gehemmt wird. Die Induktion der TGF- $\beta 1$-Expression wird durch verschiedene Faktoren hervorgerufen. Dazu gehören Angiotensin-II, Endothelin-1, Insulin-Like Growth Factor-1, Platelet Activating Factor, Thromboxane, aber auch Ischämie, Glukose und zahlreiche Medikamente, wie beispielsweise Cyclosporin A sind dazu in der Lage. TGF- $\beta 1$ wird von residenten Nierenzellen und infiltrierenden Leukozyten sezerniert (Eddy 2000). TGF- $\beta 1$ fungiert über die Bindung an Typ-I- und Typ-II-Rezeptoren, die von den meisten Zellen exprimiert werden. Aktiviertes TGF- $\beta 1$ bindet zunächst an den Typ-II-Rezeptor, der anschließend an den Typ-I-Rezeptor bindet. Dieser Rezeptorkomplex stellt eine Serin/Tyrosin-Kinase dar, der durch die Phosphorylierung von Transkriptionsfaktoren, sogenannte Smad-Proteine, eine intrazelluläre Signaltransduktion aktiviert (Schiffer et al. 2000).

\subsection{Antifibrotisch wirkende Zytokine}

Das grundlegende Problem chronisch progressiver Erkrankungen ist das Ungleichgewicht zwischen pro-fibrogenen und anti-fibrotischen Faktoren, wobei das Verhältnis zu Gunsten der pro-fibrogenen Faktoren verschoben ist. Neben den Zytokinen, die den fibrotischen Gewebeumbau fördern, existieren Antagonisten, anti-fibrotische Zytokine, die diesem Prozess entgegenwirken (Liu 2006). Zu Ihnen gehören z.B. Interferon- $y$, ein 
immunmodulatorisches Zytokin mit inhbitorischen Effekten auf Myofibroblasten und die Kollagenexpression (Strutz et al. 2000; Giannopoulou et al. 2006). Ein anderes Zytokin aus dieser Reihe ist Relaxin. Es ist in der Lage, die Kollagensynthese zu hemmen und Kollagendegeneration zu fördern (Negri 2004). Von besonderer Bedeutung sind derzeitig das Bone Morphogenic Protein 7 (BMP7) und Hepatocyte Growth Factor (HGF). Sie sind in der Lage, die fibrogenen Aktionen von TGF- $\beta 1$ direkt zu antagonisieren (Strutz 2004).

\subsection{Hepatocyte Growth Factor}

Hepatocyte Growth Factor (HGF), ist ein multifunktionelles Polypeptid mit mitogener, motogener, morphogener und antiapoptotischer Wirkung. Der Arbeitsgruppe Nakamura et al. (1987) gelang es, HGF aus Thrombozyten $\mathrm{zu}$ isolieren und dessen Struktur zu beschreiben. In darauf folgenden Studien konnte demonstriert werden, dass HGF ebenfalls von verschiedenen Organen, einschließlich der Niere, exprimiert wird und an einer Vielzahl zellulärer Prozesse beteiligt ist. Neben seinen regenerativen und proliferativen Eigenschaften beschrieben mehrere Arbeitsgruppen, an unterschiedlichen experimentellen Tiermodellen, HGF als einen endogen antifibrotisch wirkenden Faktor, der in der Lage ist, fibrotische Läsionen zu mildern und die Organfunktion zu erhalten (Liu 2004b).

\subsubsection{Struktur, Synthese und biologische Aktivität von HGF}

Das humane HGF, das auf Chromosom 7q11.2-21 kodiert ist, wird als biologisch inaktive Vorstufe, als Einzelstrang, sezerniert und extrazellulär durch eine spezifische Serin-Protease in die biologisch aktive Form gespalten. Bei der aktiven Form des HGF handelt es sich um ein über Disulfidbrücken gebundenes, heterodimeres Glykoprotein, bestehend aus 
einer ca. $69 \mathrm{kDa}$ schweren $\alpha$ - und einer ca. $34 \mathrm{kDa}$ schweren $\beta$ Untereinheit (Matsumoto und Nakamura 2001).

Umfangreiche Studien zeigten, dass HGF verschiedenartige zelluläre Prozesse steuert. Dazu gehören Zellüberleben, Proliferation, Migration und Zelldifferenzierung. Diese verschiedenen biologischen Tätigkeiten werden über einen c-met transmembranen Tyrosinkinase-Rezeptor vermittelt (Matsumoto und Nakamura 2001). Der HGF-Rezeptor wurde 1991 als das Produkt eines, auf Chromosom 7q21-31 gelegenen, c-met Protoonkongens entdeckt (Bottaro et al. 1991). Der 190 kDa schwere cmet Rezeptor ist ein über Disulfidbrücken gebundener Komplex, wobei die extrazellulär gelegene, $50 \mathrm{kDa}$ schwere, $\alpha$-Untereinheit mit der transmembran gelegenen, $145 \mathrm{kDa}$ schweren $\beta$-Untereinheit verknüpft ist (Park et al. 1987). Die $\beta$-Untereinheit besitzt an ihrem intrazellulär gelegenen Ende eine Tyrosinkinasedomäne. Die Bindung von HGF an den c-met Rezeptor induziert, bedingt durch die Aktivierung der Tyrosinkinase, die Autophosphorylierung des intrazellulär gelegenen Rezeptoranteils und bewirkt damit die Rekrutierung von Signalproteinen. $\mathrm{Zu}$ diesen Signalproteinen, die mit den unterschiedlichen biologischen Aktivitäten von HGF assoziiert sind, gehören Phosphatidylinositol 4,5Bisphophonat 3-Kinase (PI3- Kinase), Phospholipase C-y, pp60 ${ }^{\text {src }}$ Tyrosinkinase, Gab-1, Grb2-SoS Komplex, Ras GTPase aktivierendes Protein (Ras-GAP), Shp-2, Crk-2 und STAT-3. Durch die Bindung der Signalproteine an den aktivierten Rezeptor wird eine Signalkaskade induziert. Sie bewirkt die Expression unterschiedlicher Gene und darüber eine spezifische zelluläre Antwort. Beispielsweise reguliert die Induktion des Grb-2/SoS Komplexes, über die Aktivierung von Ras und die Phosphorylierung von ERK, die Zellproliferation (Ponzetto et al. 1994). Die Phosphorylierung von Gab-1, ein Protein, welches den Met-Rezeptor mit Signalproteinen, wie PI-3 Kinase, PLC-y, Shp-2 und Crk-2 verbindet, spielt eine entscheidende Rolle bei der HGF vermittelten Morphogenese und Zellmigration (Scheaper et al. 2000; Weidner et al. 1996). Montesano et al. (1997) demonstrierten eine durch Gab-1-Expression induzierte 
gesteigerte Zellmobilität und Tubulogenese. In einer anderen Studie konnte gezeigt werden, dass HGF zur Phosphorylierung von Adhäsionsmolekülen beiträgt und dadurch die Zell-Matrix-Interaktionen fördert und die Cadherin- vermittelte Zell-Zell-Adhäsion herabsetzt (Matsumo et al. 1994; Watabe et al. 1993). Seine zellprotektiven Effekte vermittelt HGF über zwei verschiedene Signalwege. Einerseits induziert es via Pl-3- Kinase und Akt Proteinkinase B die Phosphorylierung von Bad und somit die Inaktivierung des pro-apoptotischen Proteins, andererseits induziert HGF die Expression des anti-apoptotischen BCL-xL (Liu 1999). Die essentielle Rolle von HGF bei der Organogenese von Säugern wurde an verschiedenen Tiermodellen mit unterbrochener HGF Expression oder c-Met Rezeptorefekt deutlich. In einer Studie von Schmidt et al. 1995 verstarben die HGF defizienten Tiere bereits in utero an einer mangelhaften Leber- und Plazentaentwicklung. HGF ist ebenfalls in die Entwicklung anderer epithelialer Gewebe einschließlich der Lunge und Mamma involviert, sowie an deren Regeneration, Funktionserhalt und Tumorgenese beteiligt.
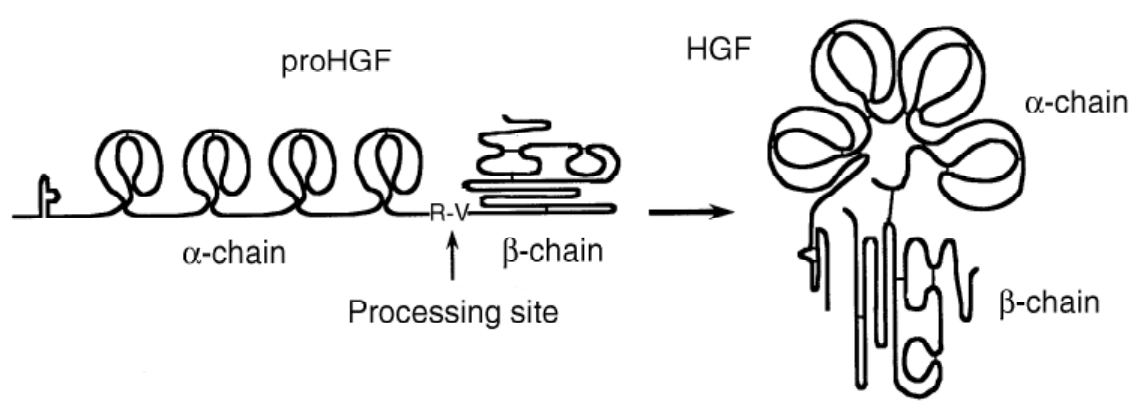

Schematische Strukturen: Prohepatocyte Growth Factor (HGF) und ausgereifter HGF (nach Matsumoto und Nakamura 2001, Seite Abb. 1.1: 2024) 


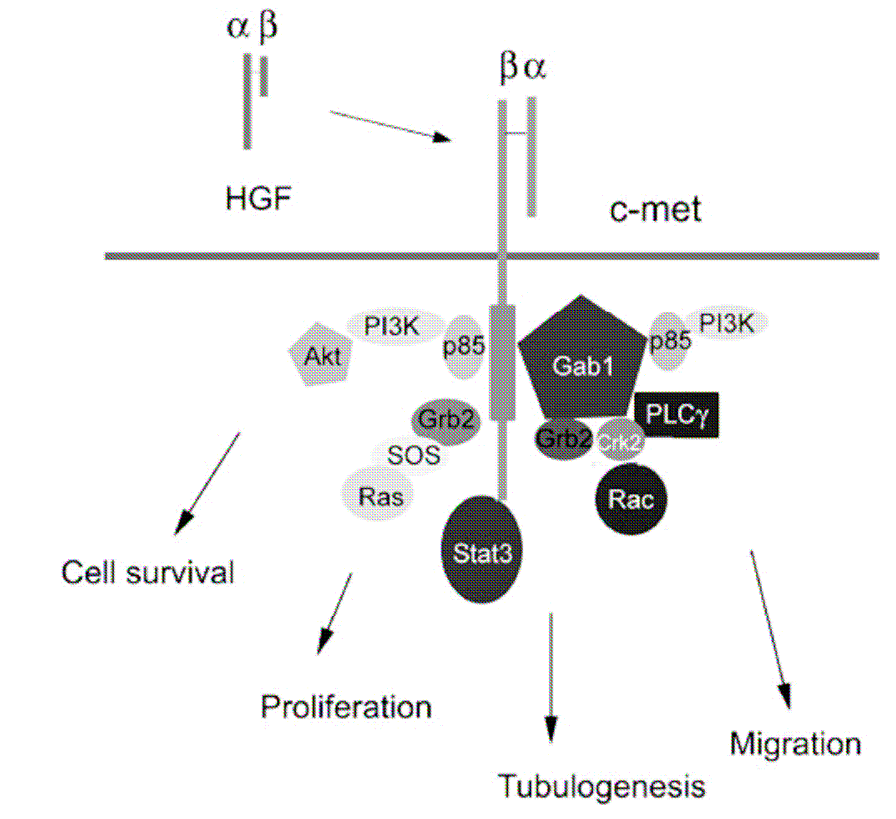

Vereinfachte Darstellung der Hauptsignalwege von HGF in Abb. 1.2: Nierenzellen (nach Liu 2003, F8)

Nach der Bindung von HGF durchläuft der c-met Rezeptor eine Autophosphorilierung in eine Tyrosinkinase Domäne, was zur Rekrutierung verschiedener intrazellulärer Signalgeber, einschließlich der homologen Src-Domäne, der p85/p110 Untereinheiten der Phosphoinositid 3-Kinase (PI-3K), des Grb2/Sos/Ras Komplexes, der Phospholipase C-y (PLC- $y$ ) und dem Multiadapterprotein Gab-1. Diese führen zu diversen zellulären Antworten, wie z.B. Zellüberleben, Proliferation, Migration und Tubulogenese.

\subsubsection{Hepatocyte Growth Factor in renalen Erkrankungen}

HGF wird in der Niere von interstitiellen Zellen, Endothelzellen und Makrophagen produziert. Sein c-Met Rezeptor wird von Tubulusepithelzellen exprimiert. Untersuchungen an verschieden Modellen akuter Nierenschädigung (Vijayan et al. 2001, Liu et al. 1999) beschrieben nach initialer Gewebeschädigung eine systemische, bzw. eine lokal gesteigerte Expression von HGF und c-Met. Die Gabe von exogenem HGF stimulierte die Epithelproliferation und beschleunigte die 
Regeneration nach akuter Schädigung (Liu et al. 1998). Studien an Modellen chronischer Nephropathie bewiesen, dass sowohl die sytemische Applikation von exogenem HGF, als auch der Gentransfer von HGF-cDNA, die renale Fibrosierung mindern kann (Mizuno et al. 1998; Liu und Yang 2006). Die Neutralisierung von endogenen HGF resultiert in forcierter Fibrose (Mizuno et al. 2001). In-vitro-Studien zeigten, dass HGF den pro-fibrotischen Aktionen von TGF- $\beta 1$ entgegen wirkt (Yang $\mathrm{J}$ et al. 2003, Florquin und Rouschop 2003). Daher nimmt man an, dass die Balance zwischen diesen beiden Zytokinen eine entscheidende Rolle bei der renalen Fibrogenese spielt. Abhängig von der Dauer des Insultes kommt es entweder zur Regeneration oder fortschreitender Fibrosierung. Eine limitierte Nierenschädigung führt zum Übergewicht von HGF und resultiert in Gewebereparation und Regeneration. Eine chronische Schädigung verändert das HGF/TGF- $\beta 1$ Verhältnis, zu Gunsten des fibrogenen TGF- $\beta 1$ und führt zur Gewebefibrose (Liu 2004b). Daher richtet sich der Forschungsfokus auf die Entwicklung geeigneter Therapiekonzepte, die HGF Konzentration zu steigern, um seine protektive Wirkung in geschädigtem Gewebe zu verstärken. 


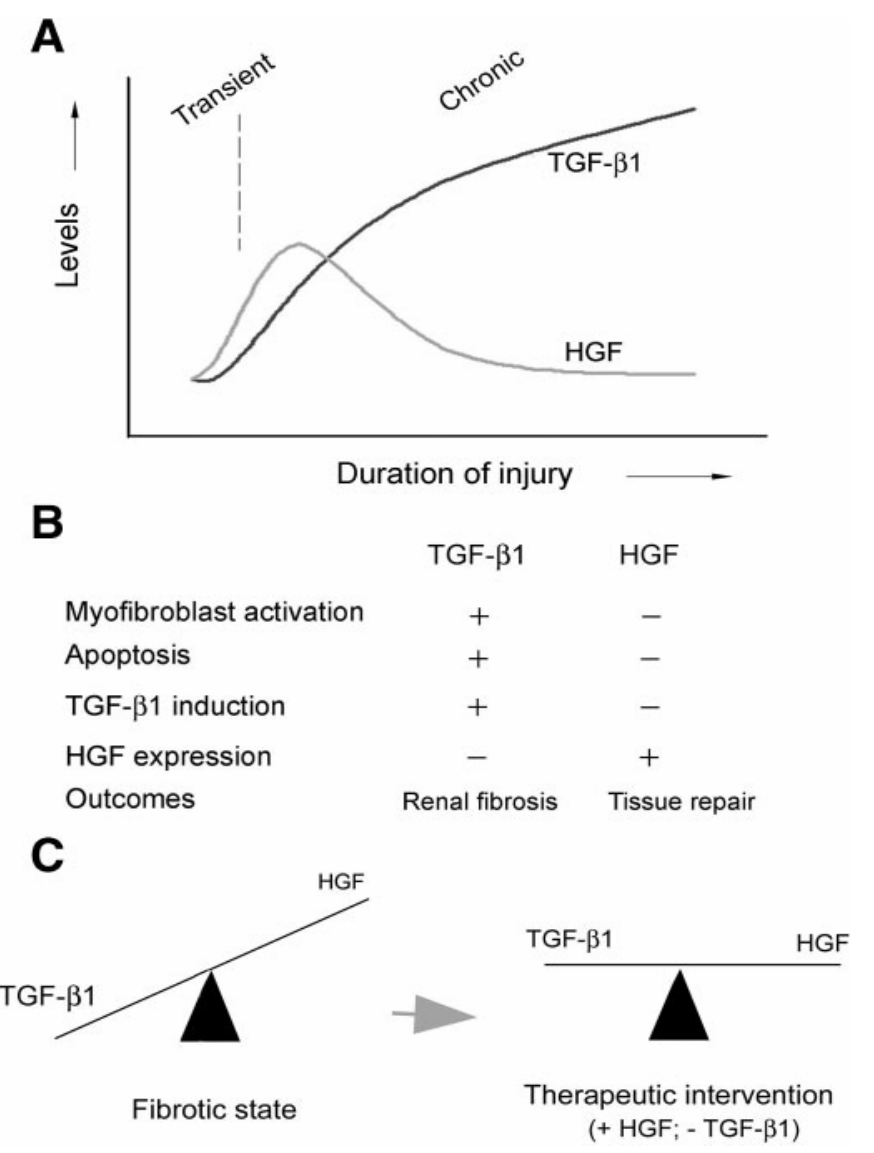

\section{Antagonismus zwischen HGF und TGF- $\beta 1$ in der Pathogenese der}

Abb. 1.3:

\section{Fibrose (nach Liu 2003, F9)}

A: Erklärungsmodell der HGF und TGF- $\beta 1$ in der geschädigten Niere. Die Dauer des Schädigungsstimulus entscheidet darüber, ob das betroffene Gewebe wieder regeneriert oder fibrosiert. Eine transiente Schädigung (gestrichelte Linie) führt zu einem TGF- $\beta 1 / H G F$ Verhältnis, mit Übergewicht des HGF, resultierend in Geweberegeneration und reparation. Wohingegen chronische Schädigung zu einem TGF- $\beta 1 / \mathrm{HGF}$ Verhältnis mit deutlichem TGF- $\beta 1$ Übergewicht führt und die Fibrosierung des Gewebes zur Folge hat.

B: Funktion von TGF- $\beta 1$ und HGF in fibrotischen Nieren. Das Gleichgewicht des TGF- $\beta 1 /$ HGF Verhältnisses. (+ = fördern; - = hemmen) 
C: Therapeutische Strategien renalen Fibrose. In fibrotischen Nieren ist das Gleichgewicht zwischen TGF- $\beta 1 /$ HGF gestört und TGF- $\beta 1$ dominiert. Daher sollten therapeutische Strategien darauf abzielen, die TGF- $\beta 1$ Aktivität zu reduzieren und/oder die HGF Konzentration erhöhen.

\section{$1.9 \quad$ Fragestellung und Zielsetzung}

Vorangegangene Arbeiten demonstrierten, dass sowohl die externe Gabe von HGF (Yang and Liu 2003), als auch die gesteigerte endogene HGFProduktion (Liu et al. 2000) eine interstitielle Fibrosierung am Mausmodell verhindern kann. HGF antagonisiert die TGF- $\beta 1$ Aktivitäten. Seine renotropen Wirkungen beziehen sich auf die Stimulation der Proliferation renaler Zellen, Protektion vor Apoptose, anti-inflammatorischer Wirkung und Modulation der Matrixsynthese- bzw. -Degeneration (Liu 2006). Dabei hat HGF vermutlich einen entscheidenen inhibitorischen Effekt auf die epithelial-mesenchymale Transition (Yang J und Liu 2002). Die Verhinderung der morphologischen Umwandlung tubulärer Epithelzellen könnte eine therapeutische Option für Patienten mit chronisch progredienter Niereninsuffizienz bedeuten.

Da die interne Überexpression eines Zytokins häufig andere Wirkungen hat als die externe Gabe, konzentriert sich die hier vorgelegte Arbeit auf die Effekte der Überexpression von HGF in isolierten murinen renalen Fibroblasten und proximalen tubulären Epithelzellen in vitro.

Es wurden folgende Punkte untersucht:

- Einfluss der Überexpression von HGF auf die Proliferation von Fibroblasten und tubulären Epithelzellen

- Beeinflussung der Matrixsynthese und deren Degradation durch endogene HGF- Produktion

- Apoptoseverhalten unter HGF-Überexpression. 


\section{Material und Methoden}

\subsection{Material}

\subsubsection{Geräte}

Analysewaage, $1213 \mathrm{MP}$

Sartorius, Göttingen

Autoclav

Tecnorma, Ruhberg

$\mathrm{CO}_{2}$ Inkubator Nuaire ${ }^{\mathrm{TM}}$

Nuaire, Plymoth, USA

Digiscan

Durchflusszytometer FACS-Claibur

ASYS Hitech $\mathrm{GmbH}$, Österreich

Eismaschine

Becton Dickinson, USA

Elektrophoresesysstem mit Gelkammer

Mini-Protean ${ }^{\circledR}$ und Blotmodul Mini-

TransBlot $^{\circledR}$

Ziegra, Isernhagen

Entwicklungsmaschine Curix 60

Fluor $S^{{ }^{T M}}$-Multilmager Fluoreszenzreader

Agfa, Leverkusen

BioRad, Heidelberg

für Mikrotiterplatten

Gene Quant

Pharmacia Biotech, Heidelberg

Heizblock

Liebisch, Bielefeld

Kühlzentrifuge, Mikroliterzentrifuge 5402

Eppendorf, Hamburg

Magnetrührer (beheizbar), IKAMAG RCT

IKA Labortechnik, Staufen

Mikroskop, Axioskop

Zeiss, Oberkochen

Mikroskop, Axiovert 100 TV FL

Zeiss, Oberkochen

Mikroskop, Diavert

Leitz, Wetzlar

Mikrolumat LB $96 \mathrm{P}$

E\&G Berthold, Deutschland

Nanopore Wasser-Anlage, Ultrafree 20

Millipore, Eschborn

Netzgerät Power Pack 35/75 für Blot

Phase, Viersen

Netzgerät Power Pack 1000 für

Elektrophorese

BioRad, Heidelberg

pH-Meter, Calimac 766

Jürgens, Hannover 
Photometer, Spectronic Genesys 5

Pipettierhilfe, Pipetus-akku®

Spectralphotometer für Mikrotiter, MR 400

Sterilbank, Hera Save

Stickstoffbank, Chronos ${ }^{\circledR}$ Biosave ${ }^{\circledR}$

Vakuumkonzentrierer BaVaCo Mini 30

Vakuumpumpe

Vortex, VF2

Waage Sartorius excellence

Wippe RT-2S
ThermoScience, USA

Hirschmann Labortechnik, München

Dynatech, Deckendorf

Heraeus, Hanau

Messer, Griesheim

Bachofer, Reutlingen

Baumüller, Marktdrewitz Jancke und Kunkel, Stauffen in $\mathrm{Br}$.

Sartorius, Göttingen

Fröbel, Lindau

\subsubsection{Gebrauchsmaterialien}

Combitips plus $2,5 \mathrm{ml}, 10 \mathrm{ml}$, steril

Einfrierröhrchen Nunc Cryo Tube ${ }^{\mathrm{TM}}$ Vials

FACS- Röhrchen $5 \mathrm{ml}$

Falcon Zellkulturflaschen mit Luftfilter

T12,T25, T75

Falcon ${ }^{\mathrm{TM}}$ Culture Slides

Filterpapier 2MM

Filterpapier für Mini-Trans-Blot ${ }^{\circledR}$ Apparatur

Glaswaren

Mehrkanalpipette, Eppendorf, Research 300

Mikroliterpipetten $(2,5 \mu \mathrm{l}, 10 \mu \mathrm{l}, 100 \mu \mathrm{l}, 200$ $\mu \mathrm{l}, 1000 \mu \mathrm{l})$

Mikroliterplatten Falcon ${ }^{\circledR}$ Mikrotest $^{\mathrm{TM}} 96$

Becton Dickinson, USA

Mikroliterplatten Microlite ${ }^{\circledR}$ 2, 96

Vertiefungen

Dynex Technologies, Chandilly, USA

Mikrotiterplatten Microflour 2 Black;

Thermo

Neubauer Zählkammer

Labsystem, USA

Parafilm „M“

Saaringia, Deutschland

American National Can ${ }^{\mathrm{TM}}$

Eppendorf, Hamburg

Nalge Nunc, Naperville USA

Sarstedt, Nümbrecht

Becton Dickinson, USA

Becton Dickinson USA

Whatmann, Wiesloch

BioRad, Heidelberg

Schott, Mainz

Eppendorf, Hamburg

Eppendorf, Hamburg 
Pasteurpipetten

Pipetten $2 \mathrm{ml}, 5 \mathrm{ml}, 10 \mathrm{ml}, 25 \mathrm{ml}$

Pipettenspitzen 2,5 $\mu \mathrm{l}, 10 \mu \mathrm{l}, 100 \mu \mathrm{l}, 1000$ $\mu \mathrm{l}$

Röhrchen $15 \mathrm{ml}$ (steril), $50 \mathrm{ml}$

Röntgenfilm Kodak X-Omat

Skalpelle

Spritzten $2 \mathrm{ml}, 5 \mathrm{ml}, 10 \mathrm{ml}$

Zellkulturflaschen $75 \mathrm{~cm}^{2}$

Zellschaber

Zymographiegele 10\% Gelatine

12-Well Kulturplatten
Brand, Deutschland

Sarstedt, Nümbrecht

Eppendorf, Hamburg

Sarstedt, Nümbrecht

Kodak, Stuttgart

pmf, Köln

Braun, Melsungen

Sarstedt, Nümbrecht

Sarstedt, Newton, USA

BioRad, München

Costar $^{\circledR}$, Cambridge

\subsubsection{Chemikalien}

4,6-Diamin-2 -phenyllindol-dihydrochlorid Boehringer, Mannheim (DAPI)

Aceton

Merck, Darmstadt

Acrylamid/ Bis 30\%

BioRad, München

Ammoniumpersulfat (APS)

Fluka, Buchs, Scheiz

$\beta$-Mercaptoethanol

Sigma, Deisenhofen

BM-Chemiluminescense ELISA Substrat

Roche, Mannheim

Bovines Serumalbumin (BSA)

Bradford Reagenz für Proteinassay

Paesel \& Lorei, Hanau

Brij-35

BioRad, München

Sigma, Deisenhofen

Bromphneolblau

Calciumchlorid $\left(\mathrm{CaCl}_{2}\right)$

Sigma, Deisenhofen

Coomassie R-250

Merck, Darmstadt

Merck, Darmstadt

Cyclosporin A

Novartis, Schweiz

Dimethylsulphoxid (DMSO)

Serva, Heidelberg

Dinatriumhydrogenphosphat $\left(\mathrm{Na}_{2} \mathrm{HPO}_{4}\right)$

Merck, Darmstadt 
Dithiotreitol (DTT)

DMEM-Medium

$E C L+$ Westernblotting Detection System

E. coli Bakterien (XL-10 Gold, ultracompetent cells, )

Essigsäure

Ethanol

Ethylene-glyccol-bisN,N'N'N'-tetraacetic acid (EGTA)

Ficoll

Foetales Kälberserum (FCS), US-Standard

Glycerol

Glyzin

Humanes Fibronektin

Humanes Kollagentyp-I

Hygromycin

IMDM-Medium

Kaliumdihydrogenphosphat $\left(\mathrm{KH}_{2} \mathrm{PO}_{4}\right)$

Kollagenase Typ VII

Kupfer-II-Sulfat

L-Ascorbinsäure

L-Glutamat

Magermilchpulver

Methanol

Molekulargleichgewichtsstandard Rainbow ${ }^{\circledR}$, Low Range, High Range, Full Range

Mowiol

M-Plasmocin

Natriumchlorid $(\mathrm{NaCl})$

Natriumdeoxycholat

Natriumdodecylsulfat (SDS)
Sigma, Deisenhofen Gibco BRL, Paisley, GB

Amersham Pharmacia, Braunschweig

Stratagene, Basel, Schweiz

Merck, Darmstadt

Roth, Karlsruhe

Sigma, Deisenhofen

Sigma-Aldrich, USA

Gibco BRL, Paisley, GB

Sigma, Deisenhofen

Sigma, Deisenhofen

Sigma, Deisenhofen

Sigma, Deisenhofen

Merck, Darmstadt

Gibco BRL, Paisley, GB

Merck, Darmstadt

Sigma, Deisenhofen

Merck, Darmstadt

Sigma, Deisenhofen

Biochrom, Berlin

Merck, Darmstadt

Merck, Darmstadt

Amersham, Pharmacia,

Braunschweig

Sigma, Deisenhofen

Paesel \& Lorei, Hanau

Merck, Darmstadt

Sigma, Deisenhofen

Serva, Heidelberg 
Natriumvanadat

Natronlauge $(\mathrm{NaOH}) 1 \mathrm{M}$

Nitrozellulosemembran, Hybond ECL

p-Aminopopionitril

Phenylmethansulfonsäurefluorid (PMSF)

Ponceau S

Rinderserumalbumin (BSA)

RPMI-Medium

Salzsäure $(\mathrm{HCl}) 1 \mathrm{~N}$

Tergitol (NP-40)

TES

Tetramethylethylendiamin (TEMED)

Tris-Base

Triton X-100

Trypan-Blau

Trypsin-EDTA 1x

Tween ${ }^{\circledR} 20$

Wasserstoffperoxyd $\left(\mathrm{H}_{2} \mathrm{O}_{2}\right)$

Xylencyanoblau
Sigma, Deisenhofen

Merck, Darmstadt

Amersham Pharmacia, Braunschweig

Sigma, Deisenhofen

Boehringer, Mannheim

Sigma, Deisenhofen

Paesel \& Lorei, Hanau

Gibco BRL, Paisley, GB

Merck, Darmstadt

Sigma, Deisenhofen

Sigma, Deisenhofen

Sigma, Deisenhofen

Sigma, Deisenhofen

Sigma, Deisenhofen

Biochrom Seromed, Berlin

Gibco BRL, Paisley, GB

Boehringer, Mannheim

Merck, Darmstadt

Sigma, Deisenhofen

\subsubsection{Antikörper}

\begin{tabular}{|l|l|l|}
\hline Antikörper & Anwendung & Herkunft \\
\hline Anti-Kaninchen HPR & WB & $\begin{array}{l}\text { Amersham Pharmacia, } \\
\text { Braunschweig }\end{array}$ \\
\hline Anti-Ziege HPR & WB & Santa Cruz Biotechnology, USA \\
\hline Anti-Maus HPR & WB & $\begin{array}{l}\text { Amersham Pharmacia, } \\
\text { Braunschweig }\end{array}$ \\
\hline Anti-Kaninchen-IgG-Ap & ELISA & Chemicon International, USA \\
\hline Anti-Ziege-IgG-AP & ELISA & Boehringer, Mannheim \\
\hline
\end{tabular}




\begin{tabular}{|l|l|l|}
\hline $\begin{array}{l}\text { Kaninchen Anti-human- } \\
\text { Fibronektin }\end{array}$ & ELISA, WB & Sigma, Deisenhofen \\
\hline Ziege Anti-ß3-Aktin & WB & Santa Cruz Biotechnology, USA \\
\hline
\end{tabular}

\subsubsection{Kit-Systeme}

BD ApoAlert ${ }^{\mathrm{TM}}$ Annexin V \& Apo 2.7

Enthält:

Annexin V-FITC $(20 \mu \mathrm{g} / \mathrm{ml}$ Tris-NaCl)

$1 \times$ Binding Buffer

Propidium lodid $(50 \mu \mathrm{g} / \mathrm{ml}$ in $1 \times$ Binding Buffer $)$
Biosience Clontec, Becton Dickinson. USA

\section{Cell proliferation ELISA system (Version 2) RPN Amersham Pharmacia, 250 Braunschweig}

Enthält:

\begin{tabular}{l|l}
\begin{tabular}{l|l} 
5-Brom-2-deoxyurifin (BrdU) in PBS \\
Fixierlösung
\end{tabular} & $\begin{array}{l}\text { Verdünnungslösung für Antikörper } \\
10 \times \text { PBS als Waschpuffer } \\
\text { Blockier Reagenz }\end{array}$ \\
Maus-Anti-BrdU HRP, Fab Fragmente & $\begin{array}{l}\text { Tertramethylbenzidin (TMB) in 15\% } \\
\text { Dimethylsulphoxid (DMSO) (v/v) }\end{array}$
\end{tabular}

\section{Quiagen $^{\circledR}$ Maxi-Präparationskit Quiagen, Hilden}

Enthält:

\begin{tabular}{l|l} 
Puffer 1 & Puffer TE \\
Puffer 2 & LyseBlue (Indikator) \\
Puffer 3 & RNase A \\
Puffer QBT & Filterpatronen \\
Puffer QC & Ausfällapparat \\
Puffer QF &
\end{tabular}




\subsubsection{Allgemeine Puffer und Lösungen}

\begin{tabular}{ll} 
Substanz & Menge \\
\hline \hline $\mathrm{KH}_{2} \mathrm{PO}_{4}$ & $1,44 \mathrm{~g}$ \\
$\mathrm{Na}_{2} \mathrm{HPO}_{4}$ & $7,59 \mathrm{~g}$ \\
$\mathrm{NaCl}$ & $90,0 \mathrm{~g}$ \\
$\mathrm{ddH}_{2} \mathrm{O}, \mathrm{pH} 7,4$ & ad $1000 \mathrm{ml}$ \\
\hline
\end{tabular}

Tab. 2.1: Phosphat-gepufferte Lösungen (PBS) 10x

\begin{tabular}{ll} 
Substanz & Menge \\
\hline \hline Tris-Base & $60,5 \mathrm{~g}$ \\
$\mathrm{NaCl}$ & $87,5 \mathrm{~g}$ \\
$\mathrm{ddH}_{2} \mathrm{O}, \mathrm{pH} \mathrm{7,6}$ & ad $1000 \mathrm{ml}$ \\
\hline
\end{tabular}

Tab.2.2: $\quad$ Tris-gepufferte Lösung (TBS) 10x

\subsubsection{EDV}

Microwin $^{\mathrm{TM}}$ 3.0 Software Becton Dickinson Microtec Laborsysteme, Paint A Overath

Gate Plus Software Becton Dickinson, USA

Multi Analyst ${ }^{\mathrm{TM}}$ Software

BioRad, München

MC 200 Chip Software

Zeiss, Oberkochen

Statistica $^{\mathrm{TM}}$ Statistik Software

Stat Soft, Hamburg 


\subsection{Methoden}

\subsubsection{Die Zellreihen TFB-HGF/-3.1 und NP1-HGF}

In der vorliegenden Arbeit wurde eine proximale Tubulusepithelzellinie (NP1) und eine murine renale Fibroblastenzellinie (TFB) verwendet. Dabei stammen die NP1-Zellen aus isolierten Tubuli von C57BL/6J Mäusen, charakterisiert durch Immunzytochemie (Strutz et al. 2003). Die TFB-Zellen sind tubulointerstitielle Fibroblasten aus Mäusenieren (Alvarez et al. 1992). Die Etablierung HGF produzierender Zellen erfolgte in beiden Zellinien durch stabile Transfektion eines Expressionsvektors. Das Plasmid pcDNA3.1hygro(+) ist ein 5,6 kb Vektor. Er enthält einen CMV Promotor, multiple Klonierungsstellen (forward +, reverse -) zur Erleichterung der Klonierung, ein Hygromycinresistenzgen als eukaryonten Marker und ein Ampicillinresistenzgen zur Selektionierung stabiler Zellinien. Das Plasmid pcDNAHGF enthält einen CMV Promotor und humane HGF cDNA. Die humane HGF-cDNA (2,3 kb), die zuvor aus Placenta isoliert wurde (Hartmann et al. 1992), wurde als Insert in das BamH I-Fragment, ein Polylinker, des pcDNA3.1hygro(+) Vektors (Invitrogen), kloniert. 


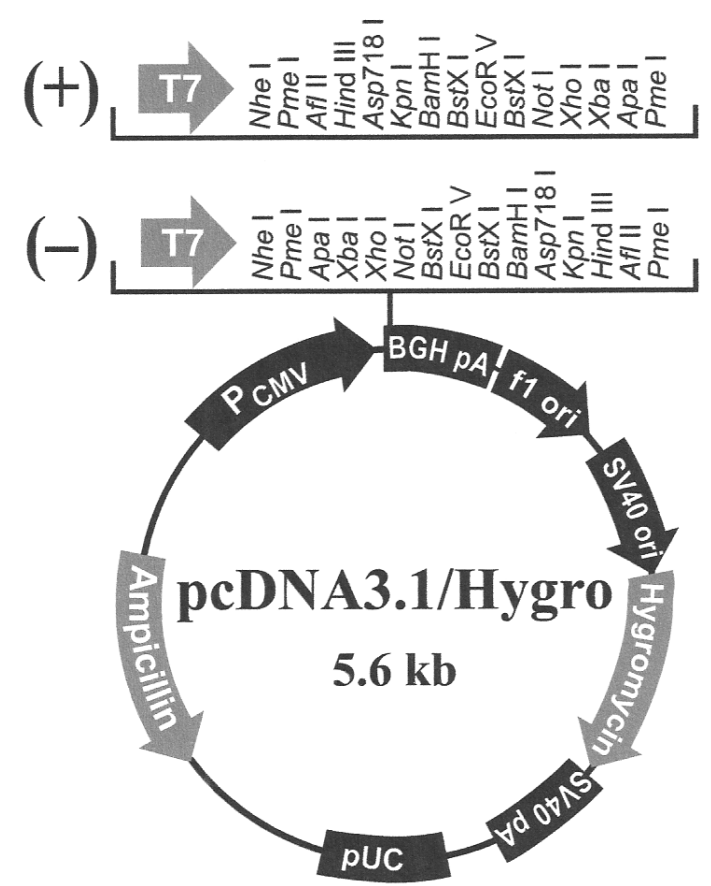

Abb. 2.1: pcDNA3.1/Hygro (+) Vector-Karte, Invitrogen, (www-invitrogen.com)

\subsubsection{Transfomation}

Für die Transformation wurden $100 \mu \mathrm{l}$ kompetenter E. coli-Bakterien (XL10 Gold, ultracompetent cells, Stratagene) mit $1 \mu \mathrm{l}$ des jeweiligen Plasmids (pcDNAHGF/pcDNA3.1) für 30 min auf Eis inkubiert. Um den Durchtritt der Plasmid-DNA in die Zellen zu ermöglichen, wurde die Zellmembran zuvor durch Hitzeschock permeabel gemacht. Dafür wurden die Zellen für $35 \mathrm{~s}$ in $42^{\circ} \mathrm{C}$ warmen Wasserbad erhitzt und anschließend auf Eis für zwei Minuten heruntergekühlt. Danach wurde dem Ansatz 900 $\mu \mathrm{l}$, auf $42^{\circ} \mathrm{C}$ vorgewärmtes, SOB Medium hinzugefügt und für eine Stunde auf dem Schüttler bei $230 \mathrm{rpm}$ und $37^{\circ} \mathrm{C}$ inkubiert. Anschließend wurden je $250 \mu \mathrm{l}$ der Bakteriensuspension auf Selektiv-Agarplatten ausgesät und bei $37^{\circ} \mathrm{C}$ über Nacht inkubiert. Da die Transformation nur bei einem Bruchteil der Bakterien stattfindet, werden durch die Verwendung von Hygromycin, alle nicht transformierten Zellen in ihrer Zellwandsynthese 
gehemmt und an einer weiteren Vermehrung gehindert. Die transformierten Zellen sind durch das Plasmid mit dem enthaltenen Hygromycin- Resistenzgen geschützt. Die auf dem Selektiv-Agar wachsenden Bakterien haben demzufolge das Plasmid aufgenommen.

\subsubsection{Isolierung von Plasmid-DNA}

Für die präparative Isolierung der Plasmid-DNA wurde eine MaxiPräparation durchgeführt. Dafür wurde von der frisch ausgestrichenen Selektiv-Agarplatte mit einer sterilen Öse vorsichtig eine Bakterienkolonie entnommen. Diese wurde in $100 \mathrm{ml}$ LB-Hygromycin-Medium resuspendiert und für $24 \mathrm{~h}$ bei $37^{\circ} \mathrm{C}$ im Schüttler (300 rpm) inkubiert. Die Bakteriensuspension wurde danach bei $6000 \mathrm{rpm}$ und $4^{\circ} \mathrm{C}$ für $15 \mathrm{~min}$ zentrifugiert. Das gewonnene Pellet wurde mit einem Quiagen ${ }^{\circledR}$ MaxiPräparationskit (Quiagen, Hilden) nach Herstellerangaben aufgearbeitet. Das Pellet wurde zunächst in $10 \mathrm{ml}$ Puffer P1 Lösung $(100 \mathrm{~g} / \mathrm{ml}$ RNAse A, $50 \mathrm{mM}$ Tris-Cl, pH 8,0, $10 \mathrm{mM}$ EDTA) resuspensiert. Anschließend wurden der Suspension 10 ml Lysis-Puffer, P2 (200 mM NaOH, 1\% SDS) zugesetzt, der Ansatz resuspensiert und für $5 \mathrm{~min}$ bei RT vorsichtig geschwenkt. Nach Zugabe von $10 \mathrm{ml}$ gekühltem Neutralisationspuffer P3 (3 M K-Acetat, $\mathrm{pH} 5,5$ ) und 30 min Inkubation auf Eis, wurde die Zellsuspension auf einen QIA-Filter gegeben und bei $10 \mathrm{~min}$ bei RT inkubiert und anschließend der Überstand mittels Stempel durch den Filter gedrückt. Der Quiagen-Tip wurde zunächst mit $10 \mathrm{ml}$ QBT-Puffer äquibrilliert und mit niedriger Geschwindigkeit herunterzentrifugiert. Danach wurde das Zelllysat auf die Quiagen-Tip-Säule gegeben, gewartet bis der Überstand diese gemäß der Schwerkraft durchlaufen hat und das Lysat klar war. Anschließend wurde die Säule mit $200 \mathrm{ml}$ QC-Puffer gewaschen und die DNA mit $15 \mathrm{ml}$ QF-Puffer eluiert. Danach wurden 70\% des DNA-Eluats mit $10,5 \mathrm{ml}$ Isopropanol präzipiert, gemischt und für 30 min bei $4^{\circ} \mathrm{C}$ bei $30.000 \mathrm{rpm}$ zentrifugiert. Nach erneutem Waschen des DNA-Pellets in $70 \%$ Ethanol und 10 min Zentrifugation (15.000 rpm) bei 
$4^{\circ} \mathrm{C}$, wurde der Ethanolüberstand vorsichtig abgeschüttet und das Pellet für 5-10min bei RT luftgetrocknet und in $200 \mu \mathrm{ITE}, \mathrm{pH} 8,0$ resuspendiert.

Die quantitative Bestimmung der DNA-Konzentration erfolgte photometrisch in einem UV-Spektrometer über die $\mathrm{OD}_{260}$.

\subsubsection{Restriktion der DNA}

Die Restriktion der DNA erfolgte nach Angaben der Enzymhersteller und unter Benutzung der mitgelieferten oder empfohlenen Puffer. Die eingesetzte Enzymmenge und die Dauer der Restriktion wurden dabei auf die DNA Qualität abgestimmt. Routinemäßig wurde für die analytische Restriktion eine Menge von $3 \mu \mathrm{g}$ pcDNA -3.1 und pcDNA HGF 0,5-1 $\mu \mathrm{l}$ der entsprechenden Restriktionsenzyme verwendet. Diese wurden mit destilliertem Wasser auf ein Volumen von $30 \mu \mathrm{l}$ gebracht und für $1-2 \mathrm{~h}$ bei $37^{\circ} \mathrm{C}$ inkubiert. Die Reaktion wurde mit 5x Blue Run gestoppt.

\subsubsection{Analyse der Plasmide mittels Agarose-Gelelektrophorese}

Nach der enzymatischen Restriktion wurden die DNA-Fragmente mittels Gelelektrophorese ermittelt. Dazu wurden die Reaktionsansätze mit 10x DNA-Probenpuffer versetzt und auf ein 0,8\% Agarosegel geladen. Um die DNA-Banden durch UV-Licht-induzierte Fluoreszenz sichtbar zu machen, wurde der DNA der interkalierende Farbstoff Ethidiumbromid in einer Konzentration von $0,5 \mu \mathrm{g} / \mathrm{ml}$ zugesetzt. Die Elektrophorese erfolgte bei 80 V. Als Größenstandard diente ein $1 \mathrm{~kb}$ Marker.

$\begin{array}{ll}25 \% & \text { Ficoll } 400.000 \\ 0,4 \% & \text { Xylencyanoblau } \\ 0,4 \% & \text { Bromphenolblau }\end{array}$

Tab. 2.3: 10x DNA-Probenpuffer 
$40 \mathrm{mM} \quad$ Tris-Base

$50 \mathrm{mM} \quad$ EDTA

$5 \mathrm{mM} \quad$ Na-Acetat

$32 \mathrm{mM}$ Essigsäure

Tab. 2.4: 1x TAE-Laufpuffer

\subsubsection{Stabile Transfektion von TFB und NP1}

Die stabile Transfektion der TFB- und NP1-Zellen erfolgte mit der Kalziumchlorid-Methode. Bei dieser Methode nutzt man die Fähigkeit der Zellen, Kalziumphosphatkristalle zu phagozytieren. Auf diese Weise kann kopräzipierte Plasmid-DNA in die Zellen eingebracht werden. Dabei wird zunächst die freie DNA mit Kalziumchlorid behandelt, so dass zwischen der negativ geladenen DNA und der positiv geladenen Zellmembran weniger abstoßende Kräfte bestehen. Bei einem kurzem Hitzeschock (41$43^{\circ} \mathrm{C}$ für $60-90 \mathrm{~s}$ ), öffnen sich die Membranen, so dass die DNA in die Zellen gelangen kann.

Für die stabile Transfektion wurden die NP1- und TFB-Zellen, je 2,5 x 104 auf 6-Wellplatten ausgesät und in $1 \mathrm{ml}$ DMEM ohne Zusätze über $24 \mathrm{~h}$ kultiviert. Vier Stunden vor der Transfektion erfolgte ein Mediumwechsel. $30 \mu \mathrm{g}$ Plasmid-DNA wurden einer Reaktionlösung bestehend aus $500 \mu \mathrm{l}$ 2,5 $\mathrm{M} \mathrm{CaCl}_{2}$-Lösung (2,5 $\mathrm{M} \mathrm{CaCl}_{2}$ 1:10 in Ampuwa) und $50 \mu \mathrm{l}$ PBS zugesetzt und gevortext. Nach 20 min Inkubation bei RT wurde die $\mathrm{CaCl}_{2}$ -DNA Lösung unter Schwenken tropfenweise in das Kulturmedium auf die Zellen gegeben. Nach $24 \mathrm{~h}$ Inkubation bei $37^{\circ} \mathrm{C}$ im Mediumwechsel die noch im Medium verbliebene $\mathrm{DNA} / \mathrm{CaPO}_{4}$-Präzipitate entfernt wurden. Nach Absaugen des alten Mediums wurden die Zellen zweimal mit PBS gewaschen, mit $3 \mathrm{ml}$ Trypsin von der Schale abgelöst, mehrfach resuspendiert und in Falcon-Röhrchen überführt. Anschließend wurden 
sie für 5 min bei $1000 \mathrm{rpm}$ und $4^{\circ} \mathrm{C}$ zentrifugiert. Das entstandene Pellet wurde in $7 \mathrm{ml}$ Selektivmedium (DMEM + $200 \mu \mathrm{g} / \mathrm{ml}$ Hygromycin B) für eine Primärkultur in $75-\mathrm{cm}^{2}$-Flaschen ausgesät. Die Subkultivierung der Zellreihen erfolgte gemäß der unter 2.2.1 beschriebenen Methode. Mittels Westernblot-Analysen und PCR wurde die Überexpression von HGF und 3.1 verifiziert.

\subsubsection{Polymerasekettenreaktion}

Die PCR ist eine in-vitro-Technik, mit deren Hilfe sich gezielte DNAAbschnitte amplifizieren lassen (Mullis et al. 1986). Sie läuft in Zyklen ab, wobei ein Zyklus aus folgenden Schritten besteht: erstens der Denaturierung der DNA bei $94^{\circ} \mathrm{C}$, zweitens der Hybridisierung der Primer mit der Einzelstrang-DNA und drittens der Taq-Polymerase-vermittelten DNA-Synthese bei $72^{\circ} \mathrm{C}$. Durch Wiederholung des angegebenen Zyklus (30 bis 40x) lässt sich eine Vervielfältigung der DNA etwa um den Faktor $10^{6}$ bis $10^{7}$ erreichen. Mit Hilfe des Enzyms Reverse-Transkriptase lassen sich zusätzlich RNA-Sequenzen in cDNA umschreiben (RT-PCR), die dann wiederum mittels PCR amplifiziert werden können. Anhand dieser Methode sollte die Transfektion verifiziert und die Genexpression von HGF und GAPDH, als „housekeeping“-Gene, in NP1- bzw. TFB-Zellen bestimmt werden.

\section{RNA Isolierung}

Die NP1- und TFB-Zellen wurden zuerst in einer Konzentration von (0,7 x $10^{6} /$ Flasche) in 25-cm²-Kulturflaschen mit DMEM/10\% FCS ausgesät und über $48 \mathrm{~h}$ kultiviert. Nach dreimaligem Waschen der adhärenten Zellkultur mit PBS wurde je $1 \mathrm{ml}$ RNA Bee den Flaschen zugefügt. Danach wurden die Zellen mit einem Zellschaber vom Flaschenboden abgelöst und in ein Eppendorfcup überführt. Anschließend wurden 0,2 $\mathrm{ml}$ Chloroform hinzugegeben, vorsichtig vermischt und 5 min auf Eis belassen, dann für 
$15 \mathrm{~min}$ bei $14.000 \mathrm{U} / \mathrm{min}$ und $4^{\circ} \mathrm{C}$ zentrifugiert. Schließlich wurde das RNA-Pellet mit 70\% Ethanol gewaschen, luftgetrocknet und in Nukleasefreiem Wasser aufgenommen. Die RNA-Konzentration wurde photometrisch (Gene Quant II, Pharmacia Biotech) anhand einer Eichgeraden bestimmt.

Für die Untersuchung der Genexpression von HGF und 3.1 wure ein PCR-Kit (Amersham) verwendet. Oligo-dt, Superscript/RNAse $\mathrm{H}$ und NTP's stammen von der Firma Gibco-Invitrogen. Folgende Primer wurden verwendet: HGF (396bp), R\&D, UK, GAPDH (310bp); MWG, Deutschland

Die RT-PCR in wurde in folgenden Arbeitsschritten durchgeführt:

$3 \mu \mathrm{g}$ RNA $+1 \mu$ l Oligo dT $+1 \mu$ ldNTP-Mix $\rightarrow 10$ min bei $70^{\circ} \mathrm{C}$, dann 3 min bei $4^{\circ} \mathrm{C}$

$2 \mu \mathrm{l}$ RT-Puffer $+1 \mu \mathrm{l}$ DTT $+2 \mu \mathrm{l} 25 \mathrm{mM}$ $\mathrm{MgCl}_{2}+0,5 \mu \mathrm{l}$ RNAse-Out hinzugeben $\rightarrow 5 \min$ bei $42^{\circ} \mathrm{C}$

$1 \mu$ Superscript/RNAse $H$ hinzugeben $\rightarrow 50$ min bei $42^{\circ} \mathrm{C}$, dann $15 \min$ bei $70^{\circ} \mathrm{C}$, dann 20 min bei $37^{\circ} \mathrm{C}$

Der nachfolgende PCR-Ansatz hatte folgende Zusammensetzung:

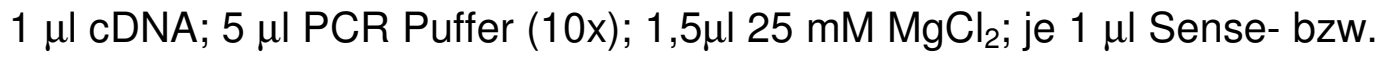
Antisense-Primer; $1 \mu \mathrm{l}$ dNTP; 0,5 $\mu \mathrm{l}$ Taq-Polymerase; $39 \mu \mathrm{l}$ Nukleasefreies $\mathrm{H}_{2} \mathrm{O}$.

Die PCR wurde in einem Cycler für 30-35 Zyklen wie oben beschrieben durchgeführt. Dabei wurde die Primer-Hybridisierung jeweils bei $56^{\circ} \mathrm{C}$ vorgenommen. Die amplifizierte cDNA wurde nun mit Hilfe eines Agarosegels $(0,45 \mathrm{~g}$ Agarose $+30 \mathrm{ml}$ TAE-Puffer $+2,5 \mu \mathrm{l}$ Ethidiumbromid) unter $80 \mathrm{~V}$ Gleichspannung in TAE-Puffer (2,0 M Tris, 5,71\% eiskalte Essigsäure, 0,05 M EDTA) elektrophoretisch aufgetrennt. Dafür wurde sie mit einem Probenpuffer (Bio Rad) versetzt. Als Marker wurde ein Längenstandard der Firma MBI eingesetzt. Anschließend wurde das Gel unter UV-Licht eingescannt (BioRad Fluor S Multilmager) und densiometrisch ausgewertet. 


\subsubsection{Zellkultur}

Das Arbeiten mit den Zellkulturen war an die von Freshney (1990) beschriebenen Methoden angelehnt. Die Zellen wurden als Monolayer Zellkultur in $75-\mathrm{cm}^{2}$-Flaschen in einem Brutschrank mit wasserdampfgesättigter und $5 \% \quad \mathrm{CO}_{2}$ angereicherter Luft bei $37^{\circ} \mathrm{C}$ gehalten. Die kontinuierliche Kultur der NP1- und TFB-Zellen erfolgte in Dulbecco's modified Eagle's Medium (DMEM), dem 10\% fötales Kälberserum (FCS), 0,5 mM/ml L-Glutamin, 0,02\% Plasmocin und 200 $\mathrm{ng} / \mathrm{ml}$ Hygromycin B zugesetzt wurden. Zweimal pro Woche wurden die Zellen je nach Bedarf ausgedünnt. Die für die Subkultivierung benötigten Lösungen wurden vor Gebrauch im Wasserbad bei $37^{\circ} \mathrm{C}$ temperiert. Sämtliche verwendeten Materialien wurden dampfautoklaviert (25 min, $120^{\circ} \mathrm{C}$ ) und steril verpackt aufbewahrt. Vor jedem Arbeitsgang erfolgte eine Hände- und Arbeitsplatzdesinfektion mit 70\%igem Ethanol. Alle zellbiologischen Arbeiten wurden unter der Sterilbank durchgeführt. Zum Subkultivieren wurde das Nährmedium abgesaugt und der Zellrasen mit PBS gewaschen. Zum Ablösen vom Flaschenboden wurden die Zellen mit Trypsin-EDTA bei $37^{\circ} \mathrm{C}$ für 4 min inkubiert. Danach wurden sie vorsichtig aus der Flasche gespült und durch langsames Resuspendieren in ein 50 $\mathrm{ml}$ Zentrifugenröhrchen überführt. Im Anschluss wurde die Zellsuspension für $3 \mathrm{~min}$ bei $1000 \mathrm{U} / \mathrm{min}$ zentrifugiert und das Zellpellet nach Absaugen des Überstandes mit $12 \mathrm{ml}$ Kulturmedium resuspendiert. Nach Bestimmung der Zellzahl mittels Neubauerzählkammer wurden die Zellen, in der gewünschten Verdünnung (siehe Tab.2.5) in neue Kulturflaschen ausgesät. 


\begin{tabular}{|l|l|l|l|l|}
\hline Kulturflaschen & $\begin{array}{l}\text { Zellzahl bei } \\
\text { Aussaat: }\end{array}$ & $\begin{array}{l}\text { Zellzahl bei } \\
\text { Konfluenz }\end{array}$ & $\begin{array}{l}\text { Wachstums- } \\
\text { medium: }\end{array}$ & $\begin{array}{l}\text { Trypsin zum } \\
\text { Ablösen: }\end{array}$ \\
\hline $12,5 \mathrm{~cm}^{3}$ & $\sim 0,3 \times 10^{6}$ & $\sim 1-2 \times 10^{6}$ & $2-4 \mathrm{ml}$ & $1,5 \mathrm{ml}$ \\
\hline $25 \mathrm{~cm}^{3}$ & $\sim 0,7 \times 10^{6}$ & $\sim 3 \times 10^{6}$ & $5-6 \mathrm{ml}$ & $2 \mathrm{ml}$ \\
\hline $75 \mathrm{~cm}^{3}$ & $\sim 2,1 \times 10^{6}$ & $\sim 9 \times 10^{6}$ & $10-12 \mathrm{ml}$ & $4 \mathrm{ml}$ \\
\hline
\end{tabular}

Tab. 2.5: $\quad$ Maße und Volumina zur Subkultivierung von Zellen

\subsubsection{Kryokonservierung und Auftauen von Zellen}

Die Kryokonservierung der Zellen erfolgte einerseits zum Schutz vor Zellverlust durch Kontamination, andererseits zur Minimierung des genetischen Drifts in kontinuierlichen Zellenlinien, sowie deren Veränderung durch Alterung und Transformation.

Hierfür wurden die Zellen zunächst abtrypsiniert und resuspendiert. Anschließend wurden 0,8 $\mathrm{ml}$ dieser Zellsuspension und 0,8 $\mathrm{ml}$ eines Einfriermediums (DMEM/FCS/DMSO 40/40/20 v/v/v) gemischt, in ein Kryoröhrchen gegeben und bei $-80^{\circ} \mathrm{C}$ in einer Styroporschachtel eingefroren. Nach $24 \mathrm{~h}$ Lagerung bei $-80^{\circ} \mathrm{C}$ folgte die endgültige Einlagerung der Zellen in einen Stickstofftank $\left(-196^{\circ} \mathrm{C}\right)$. Der Zusatz des DMSO zum Einfriermedium erfolgte zum Schutz der Zellen vor Zerstörung durch Eiskristalle.

Zum Auftauen der Zellen wurden die Kryoröhrchen kurz im Wasserbad bei $37^{\circ} \mathrm{C}$ angetaut. Das flüssige Medium und der Eiskern wurden dann in $10 \mathrm{ml}$ gekühltes DMEM/20\% FCS gegeben und durchmischt. Anschließend folgten zwei Waschschritte in Medium und die Aussaat der Zellen in 12,5-cm²-Zellkulturflaschen. 


\subsubsection{Untersuchung der Zellzählung}

\subsubsection{Proliferation mittels BrdU}

Die mögliche mitogene Wirkung einer HGF-Überexpression auf NP1- und TFB-Zellen, wurde mit Hilfe eines BrdU-Proliferationsassay untersucht. Der BrdU-ELISA ist ein nicht radioaktiver Test, bei dem die Proliferation über den Einbau von 5'-Brom-2'-deoxy-Uridin (BrdU) in die zelluläre DNA bestimmt wird (Gratzner 1982). Die Zellen werden nach der Inkubation mit BrdU lysiert und fixiert. Über die Antikörperbindung an BrdU und anschließendem Substratumsatz, des Farbreagenz Tetramethylbenzidin (TMB), wird die Menge an eingebautem BrdU im ELISA Reader bei 450 $\mathrm{nm}$ ermittelt. In der vorliegenden Arbeit wurde mit einem modifizierten Kit (Cell proliferation ELISA-System, Version 2, Amersham) gearbeitet. Für diesen Assay wurden die NP1- und TFB-Zellen in 96-Well Mikrotiterplatten (Microfluor 2 Black; Thermo Labsystem, USA) in Konzentrationen von 1000 Zellen pro Well ausgesät und über Nacht in DMEM/10\% FCS kultiviert. Anschließend erfolgte eine $24 \mathrm{~h}$ Ruhigstellung der Zellen in serumfreiem Medium. Danach wurden die Zellen für 24, 48 bzw. $72 \mathrm{~h}$ in folgenden Medien kultiviert: DMEM/ 1\% FCS und DMEM + 10\% FCS, je $100 \mu \mathrm{l} /$ Well. Alle Ansätze erfolgten in Tripletts. Nach der entsprechenden Inkubation wurden die Zellen bei $37^{\circ} \mathrm{C}$ für $4 \mathrm{~h}$ mit BrdULabellingreagenz (im Verhältnis 1:1000 mit den jeweiligen Inkubationsmedien verdünnt) inkubiert. Daraufhin wurden die Platten vorsichtig ausgeklopft und mit $200 \mu \mathrm{l} /$ Well Fixative für $30 \mathrm{~min}$ bei RT beschichtet. Nach erneutem Ausklopfen der Platte, wurden die unspezifische Bindungsstellen mittels $200 \mu \mathrm{l} /$ Well Blockierlösung (30 min bei RT) belegt. Anschließend folgte eine 90-minütige Inkubation mit dem Sekundärantikörper Peroxidase labelled anti-BrdU, der zuvor in einer Antikörper-Verdünnungslösung (Antibody-Dilution-Solution), im Verhältnis 1:100 verdünnt wurde. Nach drei weiteren Waschschritten mit einem Waschpuffer (1:10 mit dd $\mathrm{H}_{2} \mathrm{O}$ ) erfolgte die Detektion mittels $100 \mu \mathrm{l} /$ Well TMB (Peroxydasesubstrat). Die photometrische Messung der optischen 
Dichte wurde mit Hilfe eines Digiscan (ASYS Hitech GmbH, Österreich) bei $450 \mathrm{~nm}$ durchgführt.

\subsubsection{Zellzählung}

Um die Ergebnisse des Proliferationsassays zu validieren, wurde die Proliferation mittels Zellzählung untersucht. Die Art der Kultivierung entsprach der des BrdU-ELISAs. Nach 24, 48 und 72 h wurden die Zellen mit Trypsin-EDTA abgelöst, anschließend mit Trypan-Blau 0,5\% (w/v) gefärbt und unter Verwendung der Neubauer-Zählkammer (Saaringa, Deutschland) gezählt.

\subsubsection{Westernblot}

\subsubsection{Proteinisolierung}

Zur Isolierung von Proteinen aus Zellkulturen wurden die Zellen $(0,7 \mathrm{x}$ $10^{6} /$ Flasche) zuerst in $25-\mathrm{cm}^{2}-$ Kulturflaschen mit DMEM/10\% FCS ausgesät und über Nacht kultiviert. Für die Untersuchung zum Einfluss einer HGF-Überexpression auf die Bildung extrazellulärer Matrixproteine wurden die NP1-und TFB-Zellen für $48 \mathrm{~h}$ in DMEM mit nur 1\% FCS kultiviert. Anschließend wurden die Zellen zweimal mit 3,5 ml PBS gewaschen. Zur Proteinisolierung wurden 1,5 ml Lysispuffer, dem zuvor Phenylmethansulfonsäurefluorid zur Hemmung endogener Proteasen zugesetzt wurde, in die Kulturflaschen gegeben und für 10 min auf Eis belassen. Mittels Zellschaber wurden dann die Zellen vom Flaschenboden gelöst, das Zelllysat mittels Pipette abgesaugt, in ein 15-ml-Tube überführt und bei $4^{\circ} \mathrm{C}$ für $10 \mathrm{~min}$ bei $1000 \mathrm{U} / \mathrm{min}$ zentrifugiert. Aus dem Überstand wurde mit der Methode nach Bradford (1976) die Proteinkonzentration bestimmt. Das Prinzip dieser Methode beruht auf der Verschiebung des Absorptionsmaximums von $465 \mathrm{~nm}$ zu $595 \mathrm{~nm}$ durch die Bindung von Coomassie-Blau an Proteine. Zwischen der Intensität 
des gebildeten Farbkomplexes und der Proteinkonzentration besteht ein proportionaler Zusammenhang. Für die Messung wurden $50 \mu \mathrm{l}$ Probe bzw. Lysispuffer als Leerwert, mit 2,45ml Bradford- Reagenz (1:4 in $\mathrm{dd}_{2} \mathrm{O}$, filtriert) versetzt und $10 \mathrm{~min}$ bei $\mathrm{RT}$ inkubiert. Anschließend wurde die Proteinkonzentration am Photometer (Spectronic Genesys 5) bei 595nm gemessen und anhand einer Eichgeraden des Proteinstandards, bestimmt.

\begin{tabular}{ll} 
Substanz & Menge \\
\hline \hline Natriumdeoxycholat & $0,4 \mathrm{~g}$ \\
Nonidet P 40 & $1 \mathrm{ml}$ \\
EGTA & $1,9 \mathrm{~g}$ \\
Tris $1 \mathrm{M}, \mathrm{pH} 7,4$ & $1 \mathrm{ml}$ \\
$\mathrm{dd} \mathrm{H}_{2} \mathrm{O}, \mathrm{pH} 7,4$ & ad $100 \mathrm{ml}$ \\
\hline
\end{tabular}

Direkt vor der Lyse: 1:500 (v/v) PMSF [3\% PMSF (w/v) in Isopropanol] zusetzen

\section{Tab. 2.6: Lysispuffer}

\subsubsection{SDS-Page-Gelelektrophorese}

Zur Auftrennung der gewonnenen Proteine hinsichtlich ihrer Größe, wurde die diskontinuierliche SDS-PAGE (Sodium Dodecyl Sulfate PolyacrylamidGelelektropherese) nach Laemmli (1970) angewandt. Dabei wandern die durch SDS (Sodiumdodecylsulfat) denaturierten und negativ geladenen SDS-Protein-Komplexe durch die Gelmatrix. Diese stellt ein dreidimensionales Netzwerk dar, dessen Porengröße durch den prozentualen Anteil an Polyacrylamid bestimmt wird. Die Diffusionsgeschwindigkeit der Proteine im Gel ist von ihrer relativen Molekülmasse abhängig, dementsprechend wandern kleine Moleküle schneller als grosse. Durch die Zugabe von Mercaptoethanol werden 
Protein-Protein-Wechselwirkungen, durch die Öffnung von Disulfidbrücken, aufgehoben.

\begin{tabular}{lll} 
Substanz & Trenngel & Sammelgel \\
\hline $\mathrm{ddH}_{2} \mathrm{O}$ & $4,8 \mathrm{ml}$ & $6,1 \mathrm{ml}$ \\
$1,5 \mathrm{M}$ Tris $\mathrm{HCl}, \mathrm{pH}$ & \\
8,8 & $2,5 \mathrm{ml}$ & $2,5 \mathrm{ml}$ \\
$10 \%$ SDS $(\mathrm{w} / \mathrm{v})$ & $100 \mu \mathrm{l}$ & $100 \mu \mathrm{l}$ \\
Acrylamid/Bis (30\%) & $2,5 \mathrm{ml}$ & $1,3 \mathrm{ml}$ \\
$10 \%$ APS (w/v) & $50 \mu \mathrm{l}$ & $50 \mu \mathrm{l}$ \\
TEMED & $5 \mu \mathrm{l}$ & $10 \mu \mathrm{l}$
\end{tabular}

Tab. 2.7: Zusammensetzung der Gele

Zur Herstellung der Gele wurden die entsprechenden Lösungen frisch angesetzt und anschließend in eine vorbereitete Elektrophoreseapparatur gegossen. Damit das Gel auspolymerisieren konnte, wurde es für 30 min luftdicht mit Isopropanol überschichtet. Nach Entfernung des Isopropanols wurde das Sammelgel aufgegossen und ein Probenkamm mit 10 Taschen von oben zwischen die Glasplatten gesteckt. Zunächst wurden $50 \mu \mathrm{g}$ der zu analysierenden Proben mit Aceton ausgefällt (10 min auf Eis) und lyophilisiert. Anschließend wurden die Pellets mit $25 \mu \mathrm{l}$ Probenpuffer versetzt, resuspendiert und für zwei Minuten im Heizblock bei $93^{\circ} \mathrm{C}$ denaturiert. Im Anschluss wurden die Geltaschen, mit Hilfe einer Hamilton-Spritze, mit je 50 mg Protein beladen. Zusätzlich zu den Proben wurde ein geeigneter Molekulargewichtsstandard auf das Gel aufgetragen (Rainbowmarker ${ }^{T M}$ Amersham), der zuvor im Verhältnis 1:1 mit Probenpuffer vermengt wurde. Die Elektrophorese fand bei $140 \mathrm{~V}$ in einem Mini-Protean 2 System (BioRad, München) im Eisbad statt bis das Bromphenolblau den unteren Gelrand erreicht hatte. 


\subsubsection{Elektophoretischer Proteintransfer (Blotting)}

\begin{tabular}{ll} 
Substanz & Menge \\
\hline \hline Tris-Base & $3,30 \mathrm{~g}$ \\
Glycin & $14,4 \mathrm{~g}$ \\
Methanol & $100 \mathrm{ml}$ \\
$\mathrm{ddH}_{2} \mathrm{O}$ & ad $1000 \mathrm{ml}$ \\
\hline
\end{tabular}

Tab. 2.8: Transferpuffer

Die in der SDS-Gelektrophorese aufgetrennten Proteine wurden zunächst nach der Methode von Towbin et al. (1979) auf eine Nitrocellulosemembran geblottet. Zur Vorbereitung wurden WhatmanFilter und Nitrocellulosemembranen in der Größe des Gels zurechtgeschnitten und $15 \mathrm{~min}$ in Transferpuffer vorinkubiert. Anschließend wurde das zu blottende Acrylamidgel auf die Membranen gelegt. Die übereinander geschichteten Materialien wurden dann mit dem Blot-Nassmodul zusammengebaut. Nach dem Einsetzen der Blotkassette in die mit Transferpuffer gefüllte Blotkammer wurde der als Kathode fungierende Deckel der Blotkammer aufgesetzt und die Elektroden an ein Netzgerät angeschlossen. Der Transfer erfolgte über Nacht bei $30 \mathrm{~V}$ Gleichspannung und $4^{\circ} \mathrm{C}$. Um den Erfolg des Transfers zu kontrollieren, wurde eine reversible Ponceaufärbung durchgeführt. Dazu wurden die Membranen für $10 \mathrm{~min}$ bei RT in Ponceau-Lösung eingefärbt und anschließend in zwei Schritten je 5 min in 5\%iger Essigsäure wieder entfärbt.

\subsubsection{Blockieren der Membranen}

Damit die Antikörper spezifisch an die gesuchten Proteine binden können, müssen unspezifische Bindungsstellen blockiert werden. Hierfür wurden die Nitrocellulosemembranen über Nacht bei $4^{\circ} \mathrm{C}$ in einer Blockierlösung 
$(\mathrm{pH} 7,4)$ inkubiert. Das ermöglicht, dass die Antikörper ausschließlich mit ihrem spezifischen Antigen reagieren. Dadurch werden Hintergrundsignale bei der späteren Filmentwicklung minimiert.

\begin{tabular}{ll} 
Substanz & Konzentration der Lösung \\
\hline \hline Magermilchpulver & $5 \%(\mathrm{w} / \mathrm{v})$ \\
Tween 20 & $0,2 \%(\mathrm{v} / \mathrm{v})$ \\
in PBS, $\mathrm{pH} 7,4$ &
\end{tabular}

Tab. 2.9: Blockierlösung

\subsubsection{Detektion}

Das Prinzip des Western-, bzw. Immunoblots beruht auf einer immunologischen Antikörperreaktion. Dabei bindet ein primärer Antikörper an ein auf die Membran transferiertes Protein. Dieser spezifische Antikörper wird anschließend durch einen mit Meerrettich-Peroxidase (HRP) konjugierten sekundären Antikörper gebunden. Für die Inkubation der Antikörper wurde eine Antikörper-Grundlösung aus PBS und 3\% BSA und eine Waschlösung, bestehend aus PBS/ 0,5\% Tween 20, hergestellt. Die Membranen wurden zuerst $1 \mathrm{~h}$ bei RT mit einem Primärantikörper inkubiert, danach dreimal $10 \mathrm{~min}$ in der Waschlösung gereinigt und anschließend für $1 \mathrm{~h}$ bei RT mit einem Sekundärantikörper inkubiert. Im Anschluss erfolgte nochmals ein dreimaliger Waschvorgang von je 10 $\min$.

\begin{tabular}{lll} 
Antigen & Spezies, Bezeichnung & Inkubation in 3\% BSA/ PBS \\
\hline \hline Human Fibronektin & Kaninchen, polyklonal & $1: 5000$ \\
Anti- $\beta$-Aktin & Ziege, polyklonal & $1: 1000$ \\
Anti-human HGF & Maus, polyklonal & $1: 1000$
\end{tabular}

Tab. 2.10: Primärantikörper 
Spezies,

\begin{tabular}{lll} 
Antigen & Bezeichnung & Inkubation in 3\% BSA/ PBS \\
\hline \hline Anti-Kaninchen HRP & Esel, polyklonal & $1: 3000$ \\
Anti-Ziege HPR & Esel, polyklonal & $1: 5000$ \\
Anti-Maus HPR & Schaf, polyklonal & $1: 5000$
\end{tabular}

Tab. 2.11: Sekundärantikörper

Im Anschluss an die Antikörperinkubation folgte die Detektion mittels „ECL ${ }^{+}$Western blotting detection Kit“ (Amersham, Braunschweig) gemäß dem Protokoll des Herstellers. Die entsprechenden Signale waren nach 20-60 s auf dem Röntgenfilm sichtbar.

\subsubsection{Untersuchung der extrazellulären Matrixdegeneration}

Matrix-Metalloproteinasen (MMPs) sind endogene Proteasen, die die Fähigkeit besitzen, extrazelluläre Matrix, einschließlich der Basalmembranen, aufzuspalten. Sie sind an vielen physiologischen und pathologischen Gewebsumbauprozessen beteiligt. Um zu untersuchen, welchen Einfluss HGF auf die Aktivierung von MMPs hat, wurden GelZymographien nach Quesada et al. (1997) durchgeführt. Dies ist eine sensitive Methode für die Bestimmung der Enzymaktivität von MMPs. In diesem Versuch werden, je nachdem welche Proteasen untersucht werden sollen, Casein- oder Gelatingele verwendet, in denen die Proben elektrophoretisch aufgetrennt werden. Diese Gele dienen den Proteasen als Substrat und werden nach Aktivierungs-, Entwicklungs-, Färbe- und Entfärbeschritten als helle Banden im Gel sichtbar. Aus der Breite und Intensität der Banden kann man semiquantitativ auf die Proteaseaktivität der MMPs schließen. Die Identifikation der MMPs erfolgte anhand eines Zymographiemarkers und der Lage der Banden. 


\subsubsection{Bestimmung von Matrix-Metalloproteinasen}

Für diesen Versuch wurden NP1- und TFB-Zellen, in einer Konzentration von 9000 Zellen/Well auf einer 12 Well-Platte in DMEM/10\% ausgesät. Anschließend wurden die Zellen $24 \mathrm{~h}$ mit serumfreien Medium beruhigt und für weitere $48 \mathrm{~h}$ in $1,5 \mathrm{ml} /$ Well in DMEM/ 1\% FCS kultiviert. Die Mediumüberstände wurden im Anschluss in Eppendorfgefäße überführt und mittels Vakuumkonzentrierer (Ba Va Co Mini 30, Bachofer) auf ca. 1/3 ihres ursprünglichen Volumens konzentriert. Um die Volumenunterschiede ausgleichen zu können, die durch die Konzentrierung entstehen, wurde das Probengewicht vor und nach der Zentrifugation bestimmt. Anschließend wurden die Proben im Verhältnis 1:1 mit Probenpuffer verdünnt und auf das Gel aufgetragen. Da es in diesem Versuch um den Nachweis der Gelatinasen MMP-2 und MMP-9 ging, verwendeten wir 10\% Gelatinegele (BioRad, München). Als MMP Standard wurde ein Gelatinase-Standard (Chemicon International, USA) verwendet. Die elektrophoretische Auftrennung der Proben erfolgte bei $120 \mathrm{~V}$ in einem Mini-Protean 2 System (BioRad, München).

\begin{tabular}{|c|c|c|c|}
\hline Substanz & Menge & Substanz & Menge \\
\hline $\mathrm{ddH}_{2} \mathrm{O}$ & $2,15 \mathrm{ml}$ & Tris-Base & $15,0 \mathrm{~g}$ \\
\hline $0,5 \mathrm{M}$ Tris- $\mathrm{HCl}, \mathrm{pH}$ & & & \\
\hline 6,8 & $1,25 \mathrm{ml}$ & Glycin & $72,0 \mathrm{~g}$ \\
\hline Glycerol & $2,50 \mathrm{ml}$ & SDS & $5,0 \mathrm{~g}$ \\
\hline $10 \%$ SDS & $4,0 \mathrm{ml}$ & $\mathrm{ddH}_{2} \mathrm{O}, \mathrm{pH} 8,3$ & ad $500 \mathrm{ml}$ \\
\hline $1 \%$ & & Tab. 2.13: & Laufpuffer \\
\hline Bromphenolblau & $0,1 \mathrm{ml}$ & & \\
\hline
\end{tabular}

Tab. 2.12: Probenpuffer 


\begin{tabular}{lll} 
Substanz & Konzentration & Menge \\
\hline \hline Tris-Base & $50 \mathrm{mM}$ & $6,06 \mathrm{~g}$ \\
$\mathrm{NaCl}$ & $200 \mathrm{mM}$ & $11,7 \mathrm{~g}$ \\
$\mathrm{CaCl}_{2}$ (dehydriert) & $5 \mathrm{mM}$ & $0,56 \mathrm{~g}$ \\
$30 \%$ Brij-35 & $0,02 \%$ & $0,67 \mathrm{ml}$ \\
$\mathrm{ddH}_{2} \mathrm{O}$ & & ad $1000 \mathrm{ml}$ \\
\hline
\end{tabular}

Tab. 2.14

Entwicklungspuffer, $\mathrm{pH}$ 7,5

Nach der Elektrophorese wurde das fertige Gel für 45 min bei $37^{\circ} \mathrm{C}$ in Renaturierungspuffer (Triton X-100, Sigma, Deisenhofen) ad 1 Liter ddH2O eingelegt und anschließend über Nacht bei ebenfalls $37^{\circ} \mathrm{C}$ in Entwicklungspuffer inkubiert. Am nächsten Tag wurde das Gel in einem Färbepuffer (40\% Methanol, 10\% Essigsäure und Coomassie-Blau R- 250 (Merck, Darmstadt) für eine Stunde bei $37^{\circ} \mathrm{C}$ gefärbt und schließlich in der gleichen Lösung ohne Farbstoff bis zum Sichtbarwerden der Banden entfärbt. Zur endgültigen Aufklarung der Banden und Lagerung wurden die Gele in einen Konservierungspuffer (10\% Essigsäure, $100 \mathrm{~g}$ Glycin, ad $1000 \mathrm{ml} \mathrm{ddH2O)} \mathrm{gegeben.} \mathrm{Die} \mathrm{densitometrische} \mathrm{Auswertung} \mathrm{erfolgte}$ mittels Multi-AnalystTM Softwear und Bio Rad Fluor STM Multimanager.

\subsubsection{Quantitative Bestimmung von Fibronektin und Kollagen im Zellüberstand}

Mit Hilfe des ELISAs wurde untersucht, welchen Effekt die Überexpression von HGF auf die Kollagen- und Fibronektinsyntese von TFB- und NP1-Zellen hat. Hierfür wurde die Konzentration der Kollagentyp-I- und Fibronektin-Proteinsekretion in den jeweiligen Zellüberständen bestimmt (Bornstein et al. 1990). Der ELISA erfolgte in folgenden Schritten: Bindung des Fibronektins, bzw. Kollagens an eine Kunststoffmatrix, Detektion des Proteins mittels Primärantikörper, Bindung 
eines AP-konjugierten Sekundärantikörpers und anschließende Chemiluminiszenzmessung.

\subsubsection{Fibronektin ELISA}

Für die Gewinnung der Überstände wurden die NP1- und TFB-Zellen (9000 Zellen/ Well) in 12 Well-Platten (Costar; Cambridge) ausgesät, über Nacht in DMEM/ 10\% FCS kultiviert und am nächsten Tag in serumfreiem Medium für $24 \mathrm{~h}$ beruhigt. Anschließend erfolgte eine $48 \mathrm{~h}$ Kultivierung in 1,5 ml/Well in DMEM/ 1\% FCS. Im Anschluss wurden die Zellüberstände gewonnen, im Verhältnis 1:1 mit Aqua dest. verdünnt und je $100 \mu$ auf eine 96 Well-Mikrotiterplatte (MicroliteTM, Dynex Technology, USA) pipettiert. Die Platten wurden über Nacht bei $37^{\circ} \mathrm{C}$ inkubiert. Zusätzlich wurde eine Standardverdünnungsreihe $(1 \mathrm{pg} / \mathrm{ml}-100 \mathrm{ng} / \mathrm{ml}$ rekombinantes Fibronektin, Sigma) zur Ermittlung der Standardkurve auf die Platten pipettiert. Die Auftragung der Proben erfolgte in Tripletts. Am nächsten Tag wurden die Platten auf einer Unterlage ausgeklopft, für 30-40 min bei RT luftgetrocknet und zur Blockierung unspezifischer Bindungsstellen für $1 \mathrm{~h}$ bei RT in PBS/ 3\% Magermilchpulver inkubiert. Nach einmaligem Waschen mit PBS erfolgte die Inkubation mit dem Primärantikörper, AntiFibronektin (Sigma), 1:5000 in $10 \mathrm{ml}$ PBS/ 1\% BSA ( $1 \mathrm{~h}$ bei RT). Im Anschluss wurden die Platten dreimal mit PBS/ 0,05\% Tween gewaschen und mit dem Sekundärantikörper, Anti- Rabbit-AP (Chemicon), 1:1000 in PBS/ $1 \%$ BSA ( $1 \mathrm{~h}$ bei $\mathrm{RT}$ ), beschichtet. Danach erfolgte erneut ein dreimaliges Waschen mit PBS/0,05\% Tween. Für die Detektion, wurden im Abstand von $4 \mathrm{~s}$ (in anschließender Messreihenfolge) je $100 \mu \mathrm{l} /$ Well BM Chemilumineszenz-ELISA Substrat (Roche, Grenzach, Whylen) einpipettiert. Nach 15 min konnte die Lumineszenz im Mikrolumat LB 96 P (EG\&G, Berthold, Deutschland) gemessen werden. Die Fibronektinkonzentration wurde anhand der Standardkurve durch Micro WinTM 3,0 Softwear (Mikrotek Laborsysteme, Overath, Deutschland) berechnet. 


\subsubsection{Kollagentyp-I ELISA}

Der Einfluss der HGF-Überexpression auf die Kollagen-Synthese wurde mit Hilfe des ELISAs bestimmt. Die Arbeitsschritte des Kollagentyp-I ELISA entsprechen im Wesentlichem den unter 2.2.7.1 aufgeführten. Sie unterschieden sich in der Verwendung anderer Antikörper: Primärantikörper (Anti-Kollagen Typ I, Southern Biotechnologies, USA), im Verhältnis 1:1000 verdünnt, Sekundärantikörper (Anti- Ziege- AP, Boehringer Mannheim, Deutschland) 1:1000 verdünnt. Als Standard diente in diesem Versuch Kollagentyp-I (rekombinant, Sigma, Deisenhofen) in der Konzentration $1 \mathrm{pg} / \mathrm{ml}$ bis $100 \mu \mathrm{g} / \mathrm{ml}$.

\subsubsection{Apoptoseuntersuchung mittels FITC-Annexin-V- Markierung und Durchflusszytometrie}

Um den Effekt von HGF auf das Apoptoseverhalten renaler Zellen zu untersuchen, wurden FACS (Fluorescence activated cell sorting)Analysen durchgeführt. In diesem Experiment wurde ein modifiziertes Annexin-V Kit (BD ApoAlert ${ }^{\mathrm{TM}}$ Annexin $\mathrm{V}$ \& Apo 2,7- PE, Bioscience Clontech, USA) verwendet. TFB- und NP1-Zellen wurden in einer Konzenration von $0,7 \times 10^{6}$ in $25 \mathrm{~cm}^{3}$ Kulturflaschen ausgesät, über Nacht in DMEM 10\% FCS kultiviert und am folgenden Tag für $24 \mathrm{~h}$ in serumfreien Medium beruhigt. Zur Apoptoseinduktion wurden die Zellen für $48 \mathrm{~h}$ mit Cyclosporin $\mathrm{A}$ (CsA) in den Konzentrationen 100, 500 und $1000 \mathrm{ng} / \mathrm{ml}$ stimuliert. Nach erfolgter Stimulation wurden die Zellen mit Trypsin-EDTA in Suspension gebracht und zentrifugiert (4000 U/min, 5 min). Anschließend wurden sie in DMEM 10\% FCS gewaschen, erneut zentrifugiert, in Bindungspuffer resuspendiert und in FACSProbenröhrchen überführt. Im letzten Arbeitsschritt wurden die Zellen für 15 min mit Annexin V-FITC $(20 \mu \mathrm{g} / \mathrm{ml}$ in Tris- $\mathrm{NaCl})$ und Propidiumjodid (PJ) $(50 \mu \mathrm{g} / \mathrm{ml}$ in $1 \times$ Bindungspuffer) bei RT und Dunkelheit inkubiert. Die 
Analyse der Zellen erfolgte mittels Durchflusszytometer (FACS-Calibur, Becton Dickinson, USA) bei einer Wellenlänge von $488 \mathrm{~nm}$.

\subsubsection{Statistische Analysen}

Alle Werte wurden als Mittelwert \pm Standardfehler angegeben. Dabei wurde eine Varianzanalyse (ANOVA) der logarithmierten Daten in einem allgemein linearen Modell durchgeführt (GLM Procedure; SAS System Software) um statistische Unterschiede zwischen den als Positivkontrolle verwendeten, HGF überexprimierenden TFB- und NP1-Zellen und den als Negativkontrolle benutzten, HGF negativen TFB- und NP1-Zellen, zu ermitteln. Weitere Analysen wurden paarweise mit Hilfe des ContrastStatements durchgeführt. Dazu wurde bei signifikanter Varianz ein F-Test durchgeführt (Positivkontrolle vs. Negativkontrolle) und mittels HolmProzedur für multiple Tests eine Staffelung des Signifikanzniveaus vorgenommen. 


\section{Ergebnisse}

\subsection{Untersuchung zum Nachweis einer HGF- Überexpression}

3.1.1. PCR zum Nachweis einer HGF- und 3.1-Überexpression nach stabiler Transfektion

Um nachzuweisen, dass nach stabiler Transfektion mit pcDNA-HGF die TFB- und NP1-Zellen HGF-DNA expremieren wurden PCR auf HGF durchgeführt. In den Zellreihen TFB-HGF und NP1-HGF konnte eine entsprechene Genexpression nachgewiesen werden

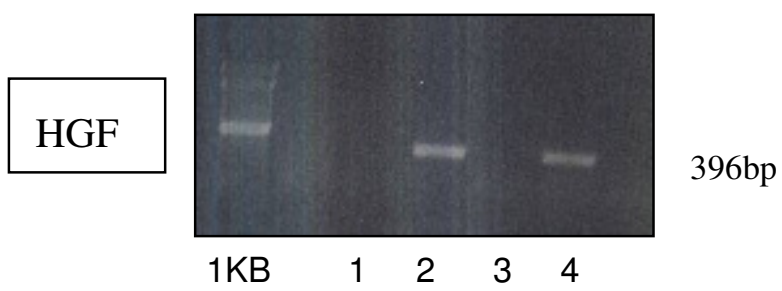

Abb. 3.1: PCR-Gelektrophorese auf HGF- bei 1: TFB-3.1, 2: TFB-HGF, 3: NP1-3.1, 4: NP1-HGF

3.1.2. Westernblotanlysen zum Nachweis einer HGF-Proteinsekretion nach stabiler Transfektion

Zum Nachweis einer HGF-Proteinsekretion durch HGF-Überexpression, wurden aus den transfizierten Zellreihen Proteine isoliert und mittels Westernblot analysiert. 


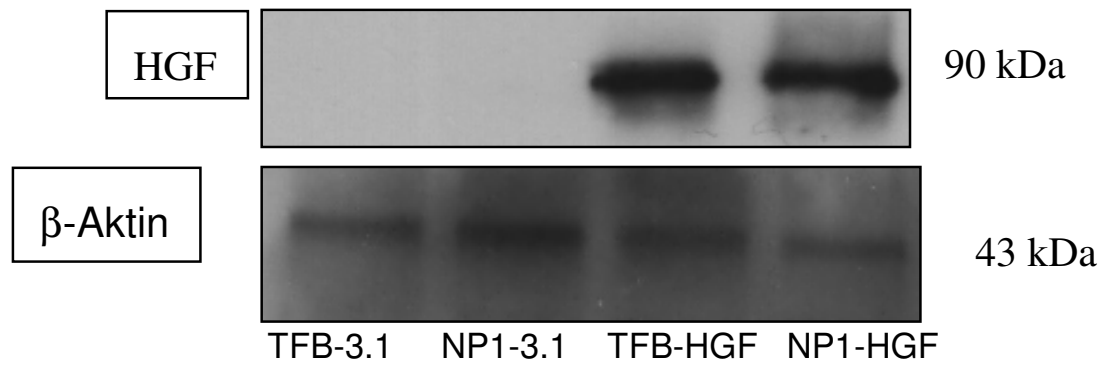

Abb. 3.2: Dargestellt ist ein Westernblot. Er zeigt die HGFProteinexpression der HGF-überexpremierenden Zellen (TFBHGF, NP1-HGF). Die Kontrollzellreihen (TFB-3. 1, NP1-3.1) sind für HGF negativ. Unten ist ein Westernblot auf $\beta$-Aktin der gleichen Probe abgebildet. Er dient dem Nachweis gleicher Proteinkonzentration.

\subsection{Untersuchungen zum proliferativen Effekt von HGF in renalen Fibroblasten und proximalen Tubulus- epithelzellen}

Vorangegangene Arbeiten hatten einen proliferativen Effekt von HGF in vivo auf Tubulusepithelzellen in Modellen akuter und chronischer Nierenschädigung nachweisen können (Liu 2004b). Seine mitogene Wirkung konnte ebenfalls an anderen Zelltypen und Zellen anderer Organe bestätigt werden (Vargas et al. 2000). Eine mitogene Wirkung konnte ebenfalls an verschiedenen Zelltypen unterschiedlicher Organe bestätigt werden. In der vorliegenden Arbeit sollte die Wirkung einer HGFÜberexpression in vitro u.a. auf die Proliferation von renalen Fibroblasten und proximalen Tubulusepithelzellen untersucht werden.

\subsubsection{Proliferationsmessung mit Hilfe eines BrdU-Assays}

Der Einfluss von HGF auf die Mitoserate renaler Fibroblasten (TFB) und proximaler Tubulusepithelzellen (NP1) sollte mit Hilfe eines BrdU-ELISA untersucht werden. Bei diesem Test wird die Proliferation der Zellen über den Einbau von 5-Brom-2deoxy-Uridin in die zelluläre DNA bestimmt. 
Hierfür wurden die HGF-überexprimierenden NP1- und TFB-Zellen auf 96-Wellplatten (1x $10^{3}$ Zellen/Well) ausgesät und für 24, 48 und $72 \mathrm{~h}$ kultiviert. Als Negativkontrolle dienten die mit einem Kontrollvektor transfizierten NP1- und TFB-Zellen.

Es konnte in beiden Zellinien eine Steigerung der Proliferationsrate durch die Überexpression von HGF nachgewiesen werden. Die Proliferationsteigerung der HGF-überexprimierenden TFB-Zellen betrug in DMEM/ 1\% FCS nach $24 \mathrm{~h}$ das 1,36fache (136 $\pm 24 \%$ ), nach $48 \mathrm{~h}$ das 1,38 fache (138 $\pm 27 \%$ ) und nach $72 \mathrm{~h}$ das 1,49 fache $(149 \pm 32 \%)$ der Negativkontrolle. In DMEM/10\% FCS zeigte sich eine vergleichbare Proliferationssteigerung, nach $24 \mathrm{~h}$ entsprach die Zellvermehrung dem 1,41 fachen $(1,41 \pm 0,13)$ nach $48 \mathrm{~h}$ dem 1,49fachen $(1,49 \pm 0,14)$ und nach $72 \mathrm{~h}$ dem 1,57fachen $(1,57 \pm 0,32)$ der Ausgangszellzahl der Kontrolle. Eine Zeitabhängigkeit der Proliferationssteigerung konnte nicht eindeutig nachgewiesen werden. Die Steigerung der Proliferation der HGF-überexprimierenden NP1-Zellen betrug in DMEM/ 1\% FCS nach 24 h das 1,23fache $(1,23 \pm 0,11)$, nach 48 h das 1,30 fache $(1,30 \pm 0,08)$ und nach $72 \mathrm{~h}$ das 1,38fache $(1,38 \pm 0,36)$ der Negativkontrolle. In DMEM/ $10 \%$ FCS zeigte sich bei der gleichen Zellreihe eine zeitabhängige Zunahme der Proliferationssteigerung. Nach $24 \mathrm{~h}$ entsprach der Wachstumszuwachs der NP1-HGF Zellen dem 1,21fachen $(1,21 \pm 0,08)$, nach $48 \mathrm{~h}$ dem 1,36fachen $(1,36 \pm 0,12)$ und nach $72 \mathrm{~h}$ dem 1,64fachen $(1,64 \pm 0,36)$ der Kontrolle. 


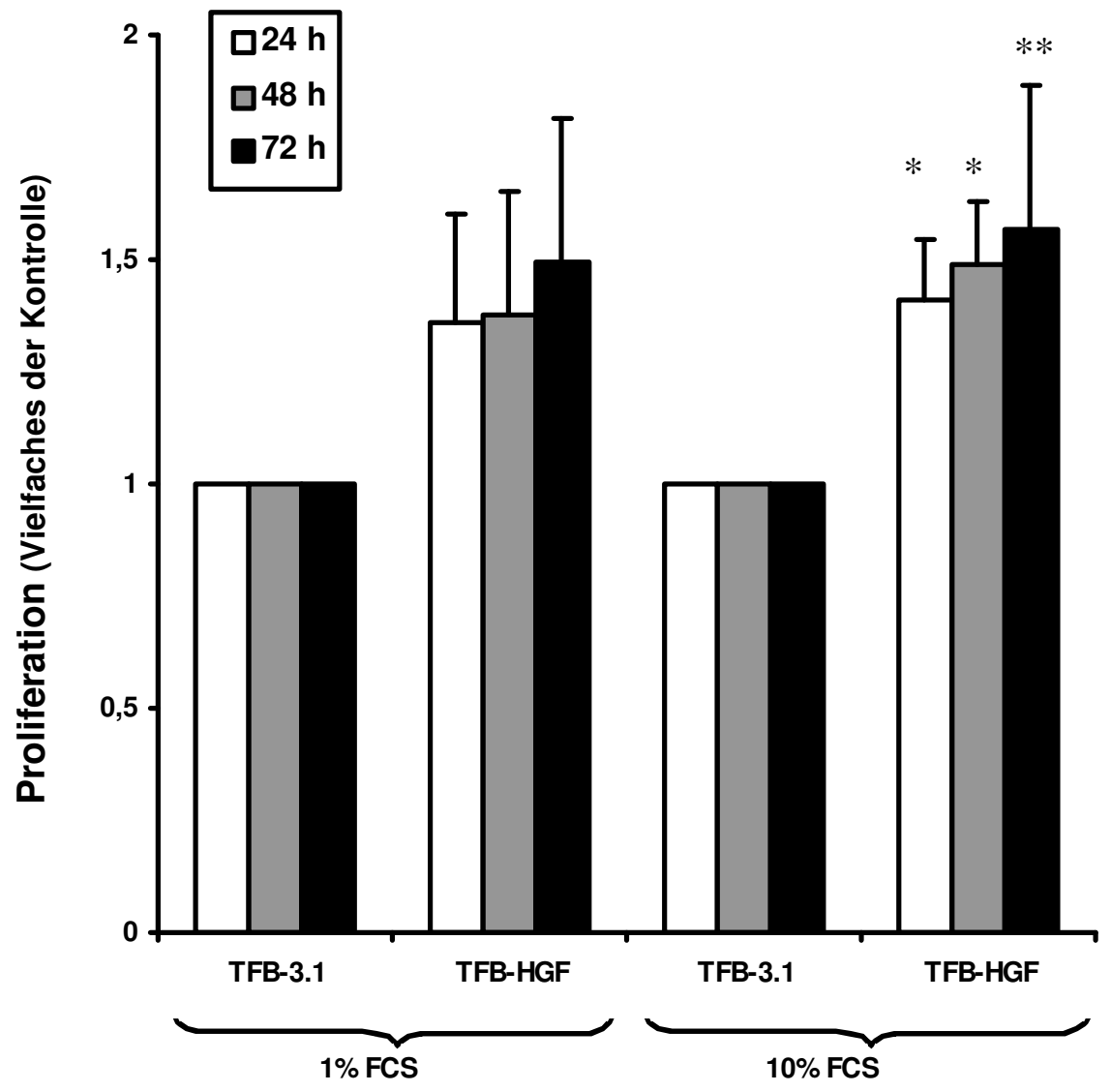

Abb. 3.3: Bestimmung der Proliferation von TFB-Zellen nach Überexpression von HGF und nach 24, 48 und $72 \mathrm{~h}$ Inkubation mit 1\% und 10\% FCS. Die TFB-3.1 Zellen dienten jeweils als Negativkontrolle (MW \pm SE, $n=$ 5). HGF stimulierte signifikant die Proliferation der TFB-Zellen nach 24 h Inkubation. $\left({ }^{*}=p<0,05\right.$ vs Negativkontrolle, $\left.{ }^{* *}=p<0.005\right)$. 


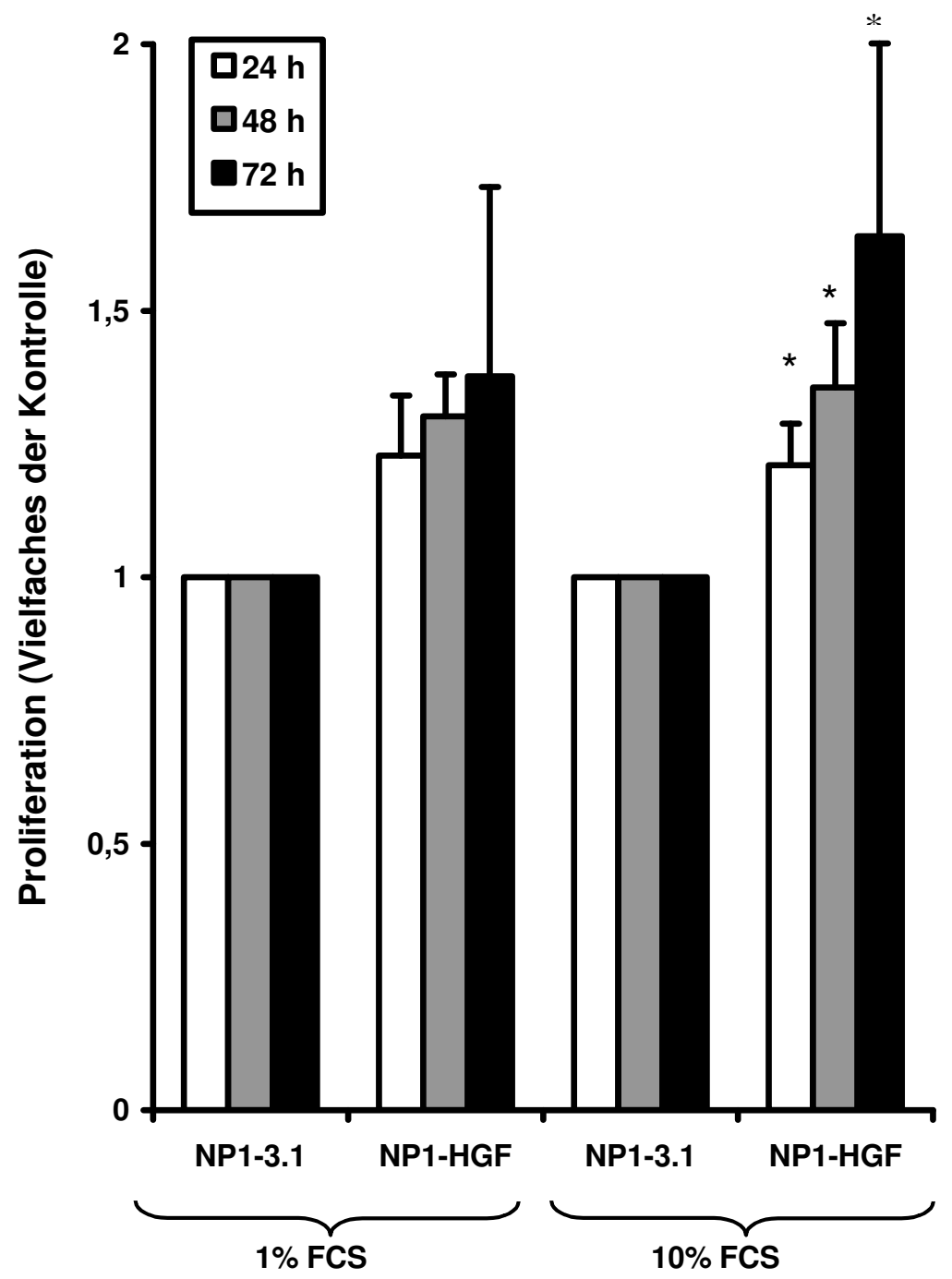

Abb.3.4: Bestimmung der Proliferation von NP1-Zellen nach HGF Überexpression und nach 24, 48 und $72 \mathrm{~h}$ Inkubation mit 1\% und 10\% FCS. Die NP1-3.1Zellen dienten jeweils als Negativkontrolle (MW $\pm S E, n=5$ ). In DMEM/ 10\% FCS steigerte HGF signifikant zeitabhängig die Proliferation der NP1Zellen gegen die Negativkontrolle $\left(^{*}=p<0,05\right.$ vs Negativkontrolle)

\subsubsection{Zellzählung mittels Trypanblau-Assay}

Der im BrdU-Proliferationsassay gezeigte proliferationssteigernde Effekt von HGF auf Tubulusepithelzellen und renalen Fibroblastenzellen, sollte durch eine zweite Methodik verifiziert werden. Hierzu wurde die Zellzahl nach Stimulation für 24, 48 und $72 \mathrm{~h}$ mit Hilfe eines Trypanblau-Assays 
bestimmt. Es konnte gezeigt werden, dass die Zellzahl in der Tat mit den Ergebnissen des Proliferationsassays korrelierte.

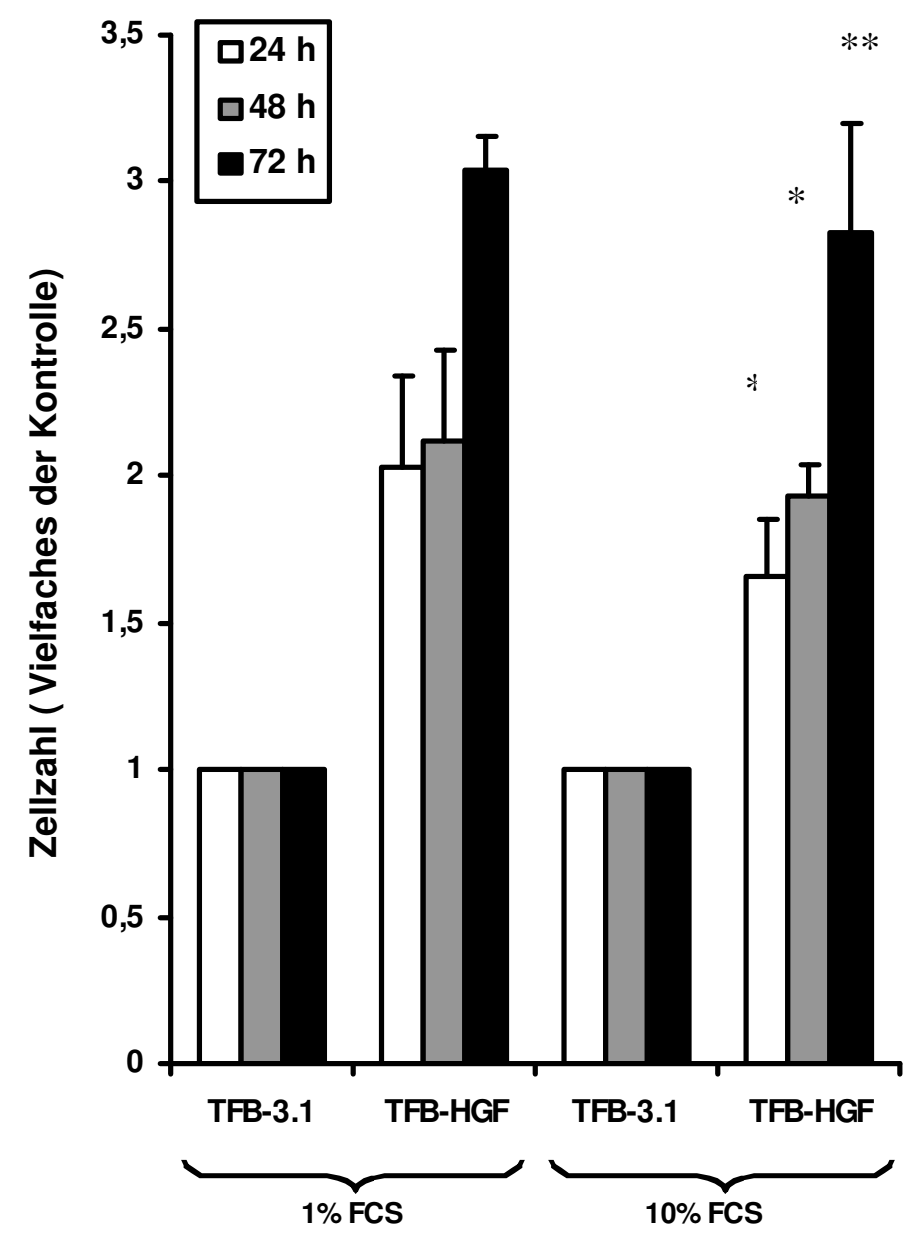

Abb. 3.5: Bestimmung der Proliferation mittels Zellzählung von TFB-HGF Zellen nach 24, 48 und $72 \mathrm{~h}$ Inkubation mit 1\% und 10\% FCS. Die TFB-3.1 Zellen dienten jeweils als Negativkontrolle (MW $\pm \mathrm{SE}, \mathrm{n}=$ 5). HGF stimulierte signifikant die Proliferation der TFB-Zellen nach $24 \mathrm{~h}, 48 \mathrm{~h}, 72 \mathrm{~h}$ Inkubation in $10 \%$ FCS. $\left(^{*}=p<0,05\right.$ vs Negativkontrolle, $\left.{ }^{* \star}=p<0.005\right)$. 


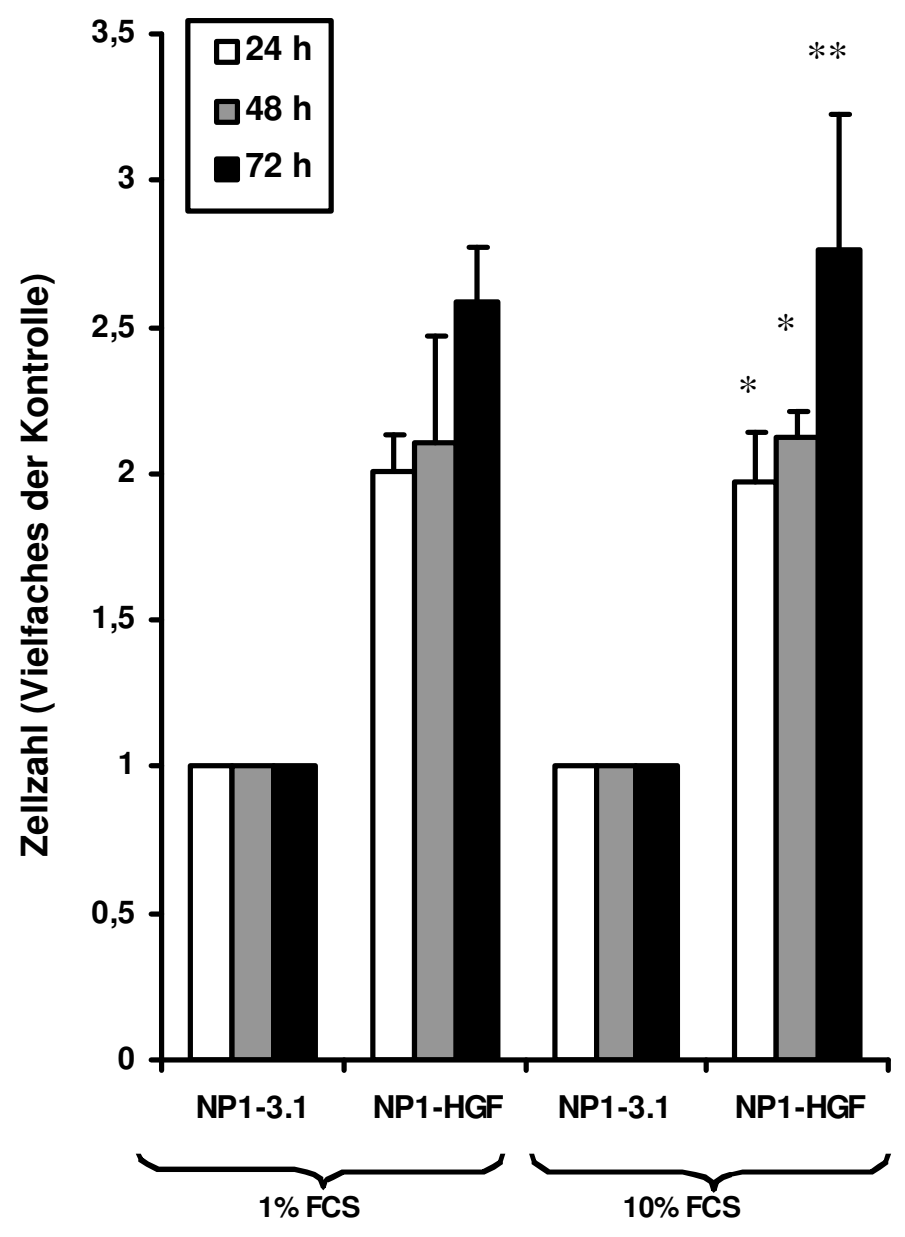

Abb. 3.6: Bestimmung der Proliferation mittels Zellzählung von NP1-HGF Zellen nach 24, 48 und $72 \mathrm{~h}$ Inkubation mit $1 \%$ und $10 \%$ FCS. Die NP1-3.1 Zellen dienten jeweils als Negativkontrolle (MW \pm SE, $n=$ 5). HGF stimulierte signifikant die Proliferation der NP1-Zellen nach $24 h, 48 h, 72 h$ Inkubation in $10 \%$ FCS. $\left(^{*}=p<0,05\right.$ vs Negativkontrolle, $\left.p^{\star}=<0,05,{ }^{\star *}=p<0.005\right)$.

\subsection{Untersuchung zur Wirkung von HGF auf die Synthese extrazellulärer Matrixproteine}

Nachdem in den Vorversuchen ein proliferativer Effekt von HGF sowohl in renalen Fibroblasten als auch in proximalen Tubulusepithelzellen gezeigt werden konnte, sollte darüber hinaus die Wirkung einer endogenen HGFÜberexpression auf die Synthese und Akkumulation extrazellulärer 
Matrixproteine (ECM) untersucht werden. Die Synthese und Deposition dieser Proteine stellt neben der Proliferation und Aktivierung von Fibroblasten eines der Hauptcharakteristika der renalen Fibrogenese dar (Strutz und Neilson 2003).

\subsubsection{Fibronektinsynthese}

Beispielhaft für die ECM wurde in der vorliegenden Arbeit die Wirkung einer HGF-Überexpression auf die Synthese von Fibronektin in proximalen Tubulusepithelzellen und renalen Fibroblasten untersucht. Fibronektin ist ein Protein der interstitiellen Matrix. Bei der renalen Fibrose spielt es eine wichtige Rolle, da es zum einen vermehrt gebildet wird. Zum anderen ist Fibronektin in der Lage den Fibrosierungsprozess durch die Induktion von TGF- $\beta 1$ (Fava und McClure 1987) und chemotaktische Wirkung auf Entzündungszellen aufrechtzuerhalten (Eddy 2000).

Ein möglicher Einfluss einer HGF-Überexpression auf die Fibronektinsynthese von Tubulusepithelzellen und renalen Fibroblasten wurde mittels Westernbblot auf Proteinebene untersucht. Verglichen mit der Kontrolle bewirkte die Überexpression von HGF bei den TFB-Zellen, eine Inhibition der Fibronektinsynthese um 33,66\%+/-SE(13,17). Bei den NP1-Zellen führte HGF zu einer $28,2 \%+/$-SE $(13,73)$ geringeren Synthese des Proteins verglichen mit den HGF negativen NP1-Zellen (NP1-3.1).

\section{Fibronektin}

\section{B-Aktin}
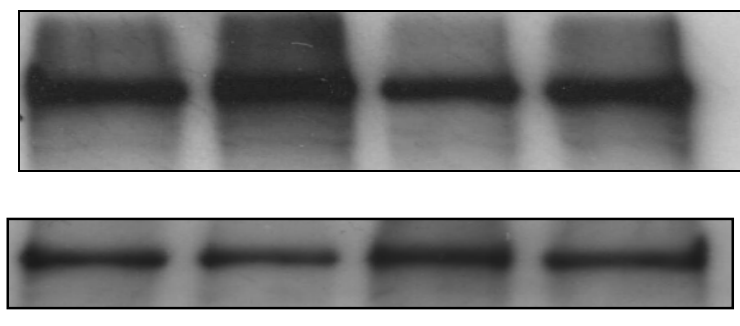

TFB-HGF TFB-3.1 NP1-HGF NP1-3.1
$230 \mathrm{kDa}$

$43 \mathrm{kDa}$

Abb. 3.7: Dargestellt ist ein repräsentativer Blot. Er zeigt die Fibronektinkonzentration der HGF überexprimierenden TFB- und NP1-Zellen, sowie der Kontrollzellreihen TFB-3.1 und NP1-3.1, nach $48 \mathrm{~h}$ Inkubation in DMEM 1\% FCS. Im Bereich von $230 \mathrm{kDa}$ finden sich die Fibronektinbanden. Unten: die gleiche Probe auf $\beta$ Aktin zum Nachweis gleicher Proteinkonzentration 


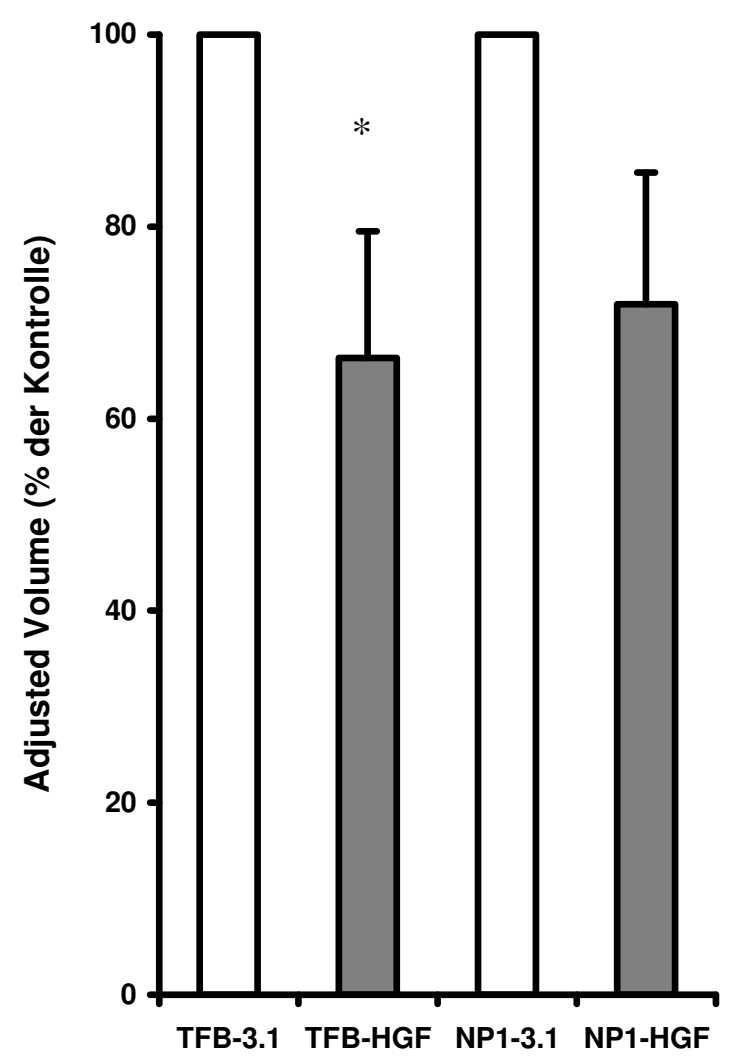

Abb. 3.8: Dichteanalyse der Fibronektinkonzentration. Inhibition der Fibronektinprotein-Synthese durch HGF-Überexpression in TFB- und NP1-Zellen nach $48 \mathrm{~h}$ Inkubation in DMEM/1\% FCS. Als Negativkontrolle dienten TFB-3.1 und NP1-3.1. Die Werte sind als Prozent der Negativkontrolle angegeben (MW $\pm S E, n=5),\left({ }^{*}=p<\right.$ 0,05 vs Negativkontrolle)

\subsection{Analyse der Sekretion extrazellulärer Markerproteine unter dem Einfluss einer HGF-Überexpression}

Mit Hilfe eines semiquantitativen ELISAs wurde die Sekretion der beiden Matrixproteine, Fibronektin und Kollagentyp-I, im Überstand von HGFüberexprimierenden Tubulusepithelzellen (NP1-HGF) und renalen Fibroblasten (TFB-HGF) bestimmt. Als Negtivkontrolle dienten erneut die mit einem Kontrollvektor transfizierten Zellinen (TFB-3.1 und NP1-3.1). 
Die Analysen wurden nach $48 \mathrm{~h}$ Inkubation in DMEM/ 1\% FCS durchgeführt.

\subsubsection{Effekt von HGF auf die Sekretion von Fibronektin}

Wie nach den Vorergebnissen erwartet, ließ sich im Überstand der TFBHGF Zellen eine, im Vergleich zu den TFB-3.1 Kontrollzellen, deutlich geringere Fibronektinkonzentration ermitteln. Die durchschnittliche Fibronektinsekretion der TFB-3.1 Zellen, betrug 1073,68 ng/ml, die der TFB-HGF Zellen dagegen nur 598,47 ng/ml. Damit sezernierten die HGFüberexpremierenden Zellen lediglich die Hälfte der Fibronektinmenge $(55,7 \% \pm 3,1 \mathrm{SE})$ der Kontrollzellen. Der inhibitorische Effekt der HGFÜberexpression auf die Fibronektinsekretion in den TFB-Zellen konnte als statistisch signifikant ermittelt werden. Einen vergleichbar hemmenden Effekt von HGF auf die Fibronektinsekretion zeigte sich ebenfalls in den Tubulusepithelzellen. Hier wurde im Überstand der HGFüberexprimierenden NP1-Zellen (NP1-HGF) eine durchschnittlliche Konzentration von $802,59 \mathrm{ng} / \mathrm{ml}$ gemessen. Bei den NP1-3.1 Kontrollzellen hingegen wurde eine Durchschnittskonzentration von $1324,65 \mathrm{ng} / \mathrm{ml}$ ermittelt, was einer Reduzierung der Fibronektinsekretion um ca. $40 \%$ entspricht $(60 \% \pm 7$ SE der Kontrolle). Die Inhibition der Fibronektinsekretion war auch bei den NP1-Zellen als statistisch signifikant nachweisbar. 


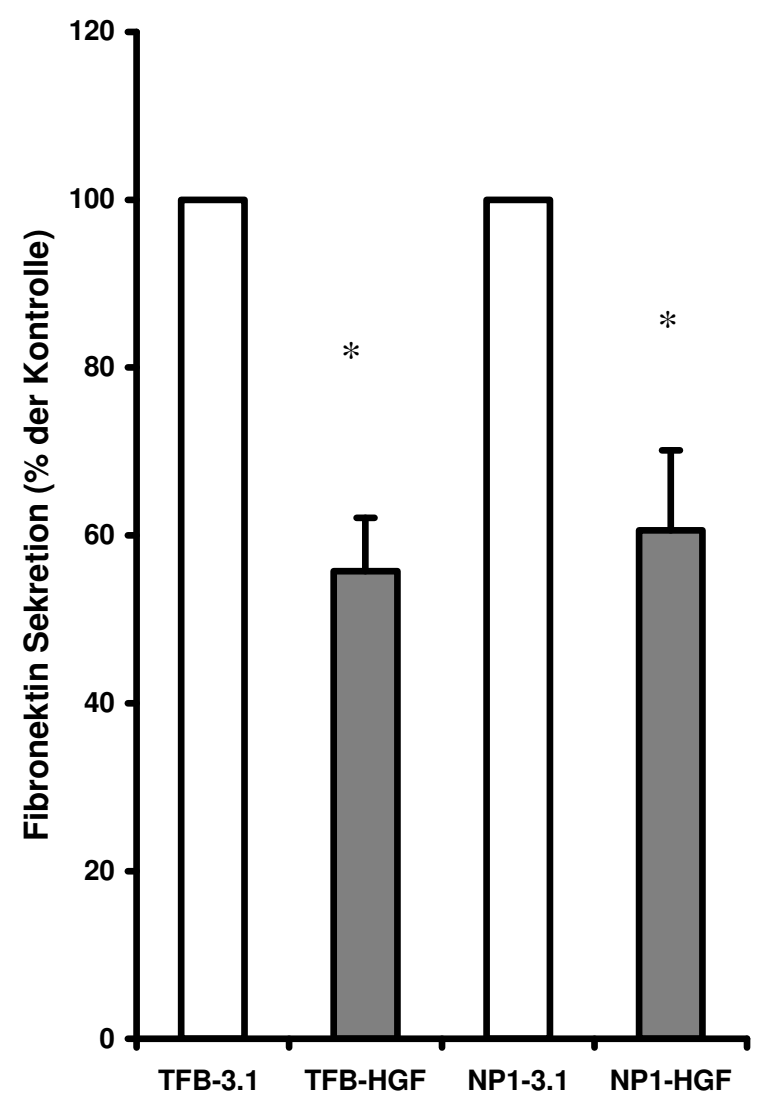

Abb. 3.9: Fibronektinsekretion von HGF-überexprimierenden TFB- und NP1Zellen nach $48 \mathrm{~h}$ Inkubation in DMEM/1\% FCS. Detektion des Fibronektins aus den Zellüberständen mit Hilfe eines quantitativen ELISAs. Die graphische Darstellung der Daten erfolgt als Prozent der Negativkontrolle, TFB-3.1 und NP1-3.1 (MW \pm SE pro $10^{3}$ Zellen, $n=4),\left({ }^{*}=p<0,005\right.$ vs Negativkontrolle)

\subsubsection{Effekt von HGF auf die Sekretion von Kollagentyp-I}

Analog der Experimente zur Fibronektinsekretion sollte ermittelt werden in welchem Maße die HGF-Überexpression einen Einfluss auf die Sekretion von Kollagentyp-I hat. Hierfür wurden ebenfalls ein quantitativer ELISA durchgeführt. Dabei zeigte sich ein sehr viel geringerer inhibitorischer Effekt auf die Sekretion des ECM-Proteins. So lag die Kollagentyp-I Konzentrationen im Überstand der HGF-überexprimierenden NP1- und TFB-Zellen nur gering unter denen der Kontrollzellen. Die 
durchschnittliche Kollagenkonzentration der NP1-HGF Zellen lag bei $234,7 \mathrm{ng} / \mathrm{ml} \pm 2,60$ SE vs $241,2 \mathrm{ng} / \mathrm{ml} \pm 2,67$ SE bei den NP1-3.1 Zellen, jeweils pro $10^{3}$ Zellen. Dieses entspricht einer $2,31 \%$ geringeren Kollagensekretion der HFG überexprimierenden Tubulusepithelzellen. Ähnlich verhielten sich die Kollagenkonzentrationsunterschiede bei den Fibroblasten, $277,91 \mathrm{ng} / \mathrm{ml} \pm 2,48$ SE bei TFB-HGF vs $300,36 \pm 2,44 \mathrm{SE}$ bei TFB-3.1, jeweils pro $10^{3}$ Zellen. Die Hemmung der Kollagensekretion durch HGF-Überexpression betrug hier ca. 7,4 \% der Kontrolle.

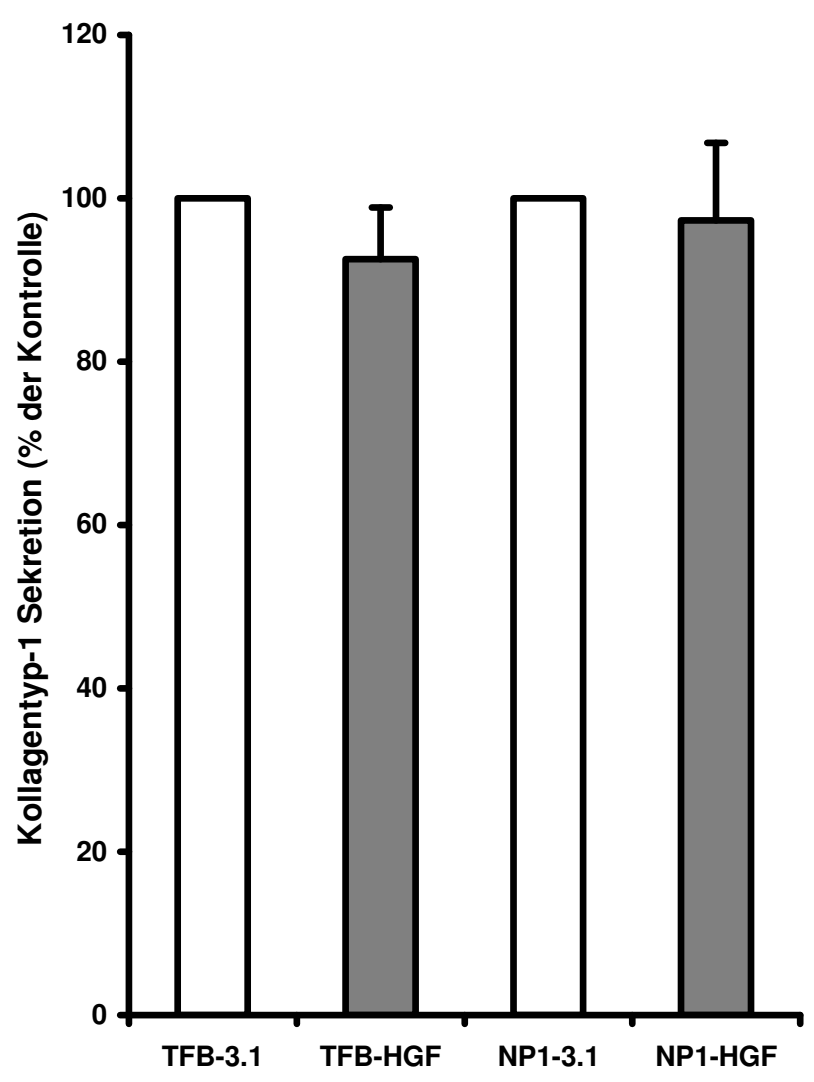

Abb.3.10: Kollagentyp-I-Sekretion von HGF-überexprimierenden TFB- und NP1-Zellen nach 48 h Inkubation mit DMEM/ 1\% FCS. Detektion des Kollagentyp-I aus den Zellüberständen mit Hilfe eines quantitativen ELISAs. Die graphische Darstellung der Werte erfolgte als Prozent der Negativkontrolle, TFB-3.1 und NP1-3.1 $\left(M W \pm\right.$ SE pro $10^{3}$ Zellen, $\left.n=4\right)$ 


\subsection{Matrixdegeneration unter HGF-Überexpression}

Die extrazelluläre Matrix-Homöostase unterliegt der Balance von Synthese und Degeneration extrazellulärer-Matrix-Komponenten. Dieses Gleichgewicht ist bei der renalen Fibrose gestört und führt zur exzessiven Matrixakkumulation (Liu 2006). Die extrazelluläre Matrixdegeneration wird durch eine Familie Zink- und Kalzium-abhängiger, matrixabbauender Enzyme reguliert. Sie sind als Matrix-Metalloproteinasen (MMPs) bekannt (Birkedal-Hanssen 1995). Vorangegangene Studien haben gezeigt, dass HGF in der Lage ist MMPs zu aktivieren und somit die Matrixdegeneration zu fördern (Liu et al. 2000).

\subsubsection{Effekt von HGF auf die Aktivität der Matrix-Metalloproteinase- 2 und -9}

Um zu untersuchen in welchem Umfang die HGF-Überexression einen Einfluss auf die Aktivierung von MMPs hat, wurden in der vorliegenden Arbeit Gel-Zymographien durchgeführt. Mit Hilfe dieser Methode kann die Enzymaktivität anhand ihrer Kollagenaufspaltung abgeschätzt werden (Quesada et al.1997). Hierfür wurden nach $48 \mathrm{~h}$ Inkubation Zellkulturüberstände von TFB-HGF, NP1-HGF, sowie von den mit dem Kontrollvektor transfizierten Zellreihen NP1-3.1 und TFB-3.1 gewonnen. Eine durch HGF-Überexpression gesteigerte Enzymaktivität ließ sich bei den NP1-Zellen, sowohl für MMP-9 als auch MMP-2 nachweisen vs einer geringeren MMP-2 und MMP-9 Aktivität durch HGF-Überexpression bei den TFB-Zellen. In den Zellkulturüberständen von NP1-HGF zeigte sich eine signifikante Aktivitätssteigerung von MMP-2 um 28\% \pm 8 SE und von MMP-9 um 34\% \pm 19 SE im Vergleich zu den NP1-3.1 Kontrollzellen. Bei den renalen Fibroblasten schien die Überexpression von HGF einen gegenteiligen Effekt zu haben. Die von den TFB-HGF-Zellen gewonnenen 
Überstände zeigten eine deutlich verminderte proteolytische Aktivität verglichen mit den Kontrollzellen TFB-3.1. Die Enzymaktivität lag für MMP-2 bei $87 \% \pm 9$ SE und für MMP-9 bei $68 \% \pm 12$ SE der Kontrollzellen (NP1-3.1).

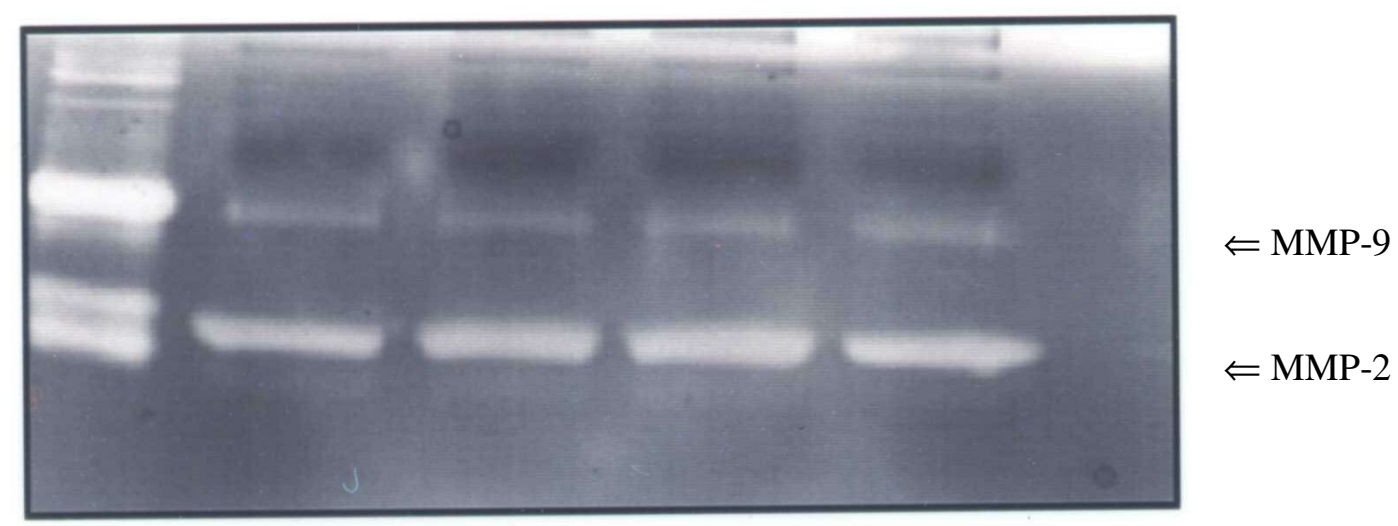

Standard TFB-HGF TFB-3.1 NP1-HGF NP1-3.1

Abb. 3.11: Zymographische Analyse der MMP-2- und MMP-9-Aktivität aus Mediumüberständen kultivierter Tubulusepithelzellen (NP1-HGF, NP1-3.1) und Fibroblasten (TFB-HGF, TFB-3.1). 


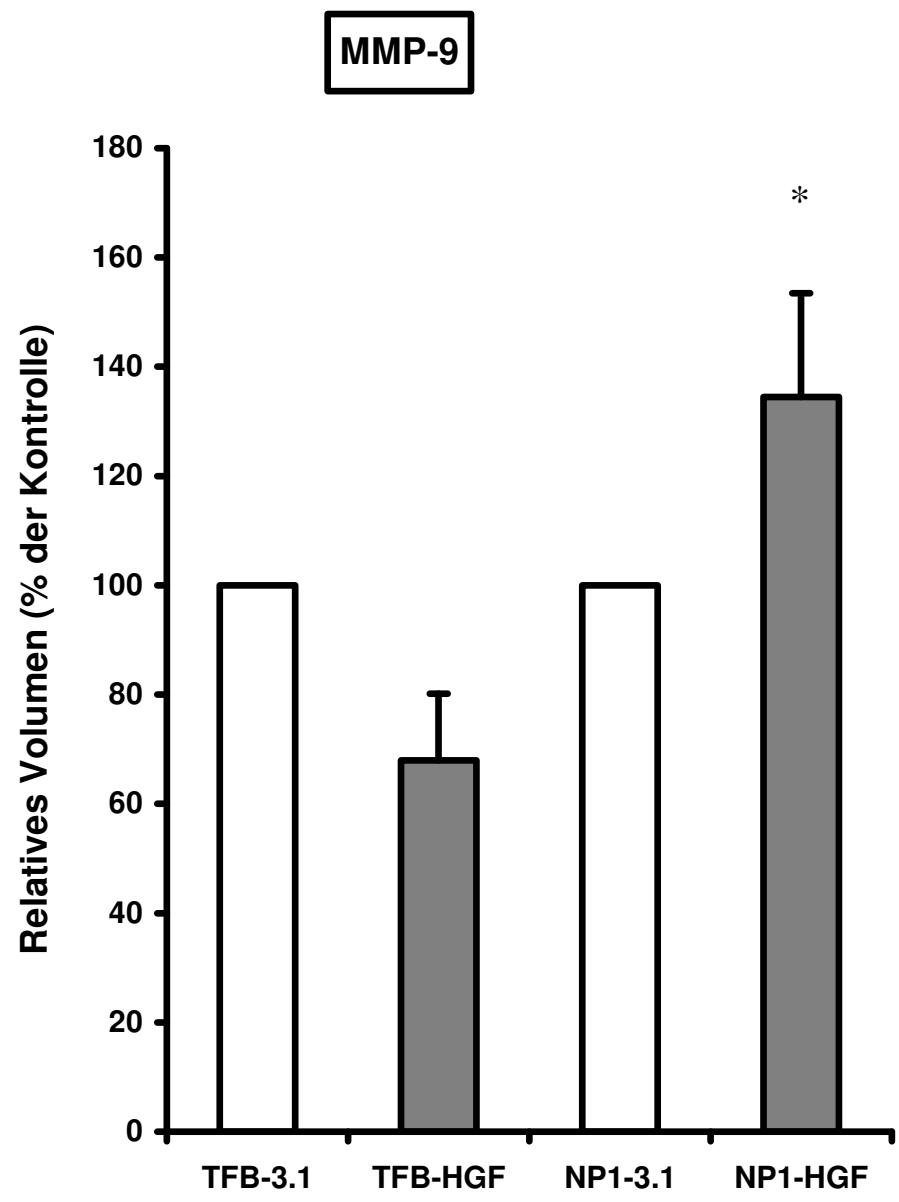

Abb. 3.12 Bestimmung der MMP-9-Enzymaktivität aus Zellüberständen HGFüberexprimierender TFB- und NP1-Zellen und den Kontrollzellreihen TFB-3.1 und NP1-3.1 nach $48 \mathrm{~h}$ Inkubation in DMEM/ 1\% FCS. Die densitometrisch ermittelten Werte, sind als Prozent der Kontrolle angegeben (MW $\pm S E, n=5),\left({ }^{*}=p<0,05\right.$ vs Negativkontrolle) 


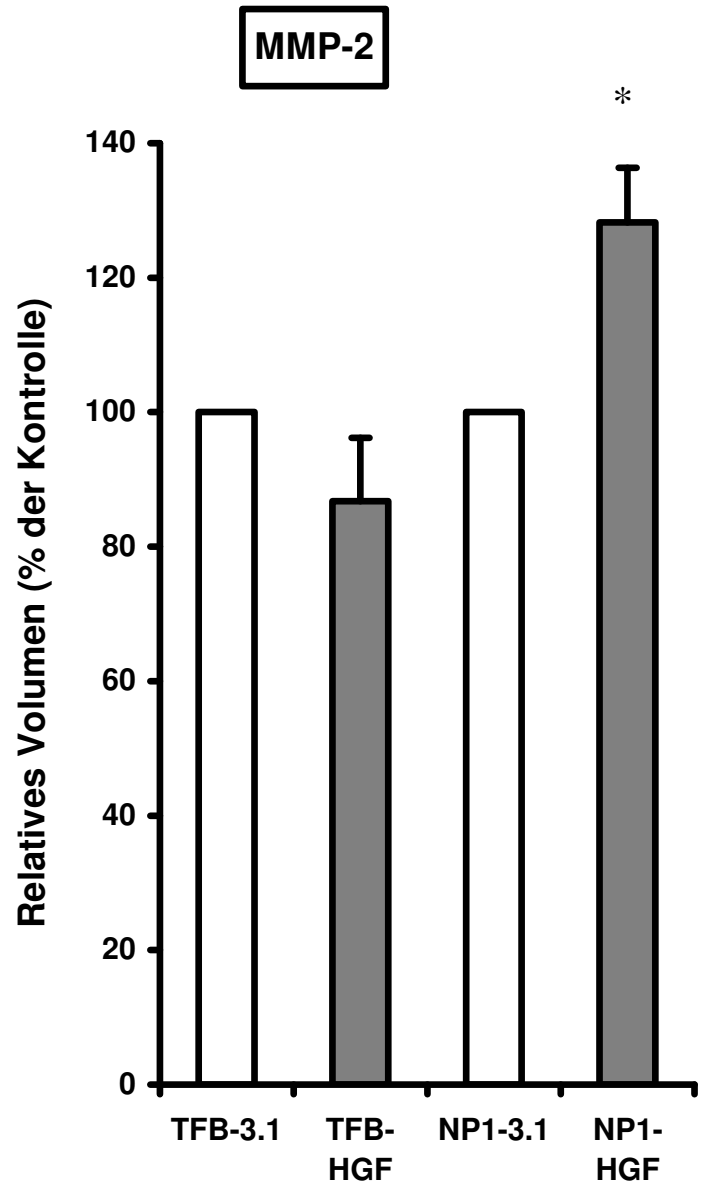

Abb. 3.13: Bestimmung der MMP-2-Enzymaktivität aus Zellüberständen HGFüberexprimierender TFB- und NP1-Zellen und den Kontrollzellreihen TFB-3.1 und NP1-3.1 nach $48 \mathrm{~h}$ Inkubation in DMEM/ 1\% FCS. Die densitometrisch ermittelten Werte, sind als Prozent der Kontrolle angegeben (MW $\pm S E, n=5),\left({ }^{*}=p<0,05\right.$ vs Negativkontrolle)

\subsection{Untersuchungen zum Einfluss einer HGF- Überexpression auf die durch CsA-induzierte Apoptose in renalen Fibroblasten und proximalen Tubulusepithelzellen}

HGF wird unter anderem als Überlebensfaktor bezeichnet. Eine nephroprotektive und antiapoptotische Wirkung konnte in vivo an 
mehreren Modellen akuter und chronischer Nierenschädigung demonstriert werden (Liu 2004).

Um eine mögliche pro- oder antiapoptotische Wirkung einer HGFÜberexpression in unseren Zellkultursystemen zu untersuchen, wurden FACS-Analysen auf Annexin durchgeführt. Hierfür wurden die HGFüberexprimierenden Tubulusepithelzellen (NP1-HGF) und Fibroblasten (TFB-HGF), sowie die als Kontrollzelllinien dienenden NP1-3.1- und TFB3.1 Zellen mit Cyclosporin A (CsA) behandelt. Die CsA-Inkubation erfolgte für $48 \mathrm{~h}$ in der Dosierung 100, 500 und 1000 ng/ml. Nach anschließender Markierung mit Annexin und Propidiumjodid konnten die apoptotischen Zellen mittels FACS (Fluorescence Activated Cell Sorting) -Analyse detektiert und gezählt werden. Unter der CsA-Stimulation kam es in allen Zellinien zur Apoptoseinduktion. Diese fiel bei den HGFüberexprimierenden Zellen geringer aus als bei den Kontrollzellen. Jedoch ließ sich bei der Auswertung keine eindeutige konzentrationsabhängige Apoptoserate eruieren. Die hier ausgeführte Auswertung bezieht sich auf die Messergebnisse der Versuchsreihe, bei der die Zellen für $48 \mathrm{~h}$ mit $500 \mathrm{ng} / \mathrm{ml}$ Cyclosporin A behandelt wurden. Die Ergebnisse zeigten bei den HGF-überexprimierenden Fibroblasten (TFBHGF) eine $42,3 \%(57,7 \% \pm 3,12 \mathrm{SE}$, als \% der Kontrolle) geringere Apoptoserate, gegenüber der Negativkontrolle TFB-3.1. Bei den HGFüberexprimierenden Tubulusepithelzellen (NP1-HGF) ließ sich eine um $58,7 \%(41,3 \% \pm 4,4 \mathrm{SE}$, als \% der Kontrolle) geringere Apoptoserate nachweisen als bei den Kontrollzellen NP1-3.1. Aus diesem Versuch wird eine protektive, bzw. antiapoptotische Wirkungsweise von HGF deutlich. HGF inhibierte sowohl bei den Tubulusepithelzellen als auch bei den Fibroblasten die durch Cyclosporin A-induzierte Apoptose. 


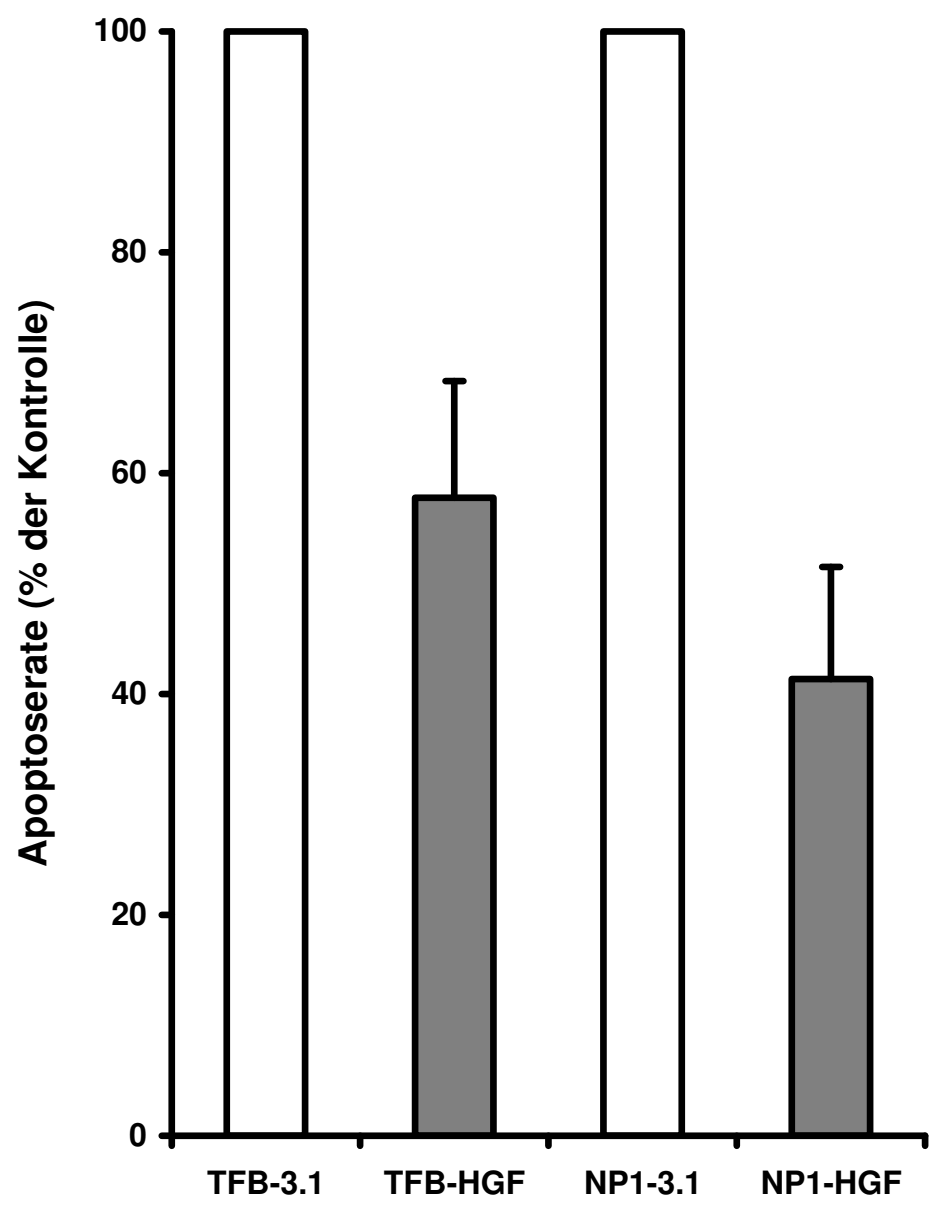

Abb. 3.14: Bestimmung der Apoptoserate von TFB-HGF und NP1-HGF und ihrer Kontrollzellreihen, TFB-3.1 und NP1-3.1, nach 48 h CsAStimulation $500 \mathrm{ng} / \mathrm{ml}$. Die Werte sind als Prozent der Kontrolle angegeben ( $M W \pm S E, n=3)$, ( ${ }^{*}=p<0,005$ vs Kontrolle). 


\section{Diskussion}

Die chronische Niereninsuffizienz ist auch heute noch eine Erkrankung mit limitierten therapeutischen Möglichkeiten. Unabhängig von der primären Ätiologie der Nierenerkrankung führt die chronische Schädigung renaler Zellen zu einem progressiven Organumbau, der durch interstitielle Fibrose, tubuläre Atrophie und Glomerulosklerose geprägt ist (Liu 2006). Die Schädigung der tubulointerstitiellen Zellen induziert die Infiltration von Makrophagen und fördert über die Freisetzung profibrogener Zytokine, die Differenzierung residenter Tubulusepithelzellen und Fibroblasten zu Myofibroblasten. Dieser als Epithelial Mesenchymale Transition (EMT) bezeichnete Mechanismus spielt eine wichtig Rolle für die Resolution und Progression chronisch renaler Erkrankungen (Strutz und Neilson 2003). Während der EMT kommt es zur phänotypischen Umwandlung epithelialer Zellen zu Zellen mit mesenchymalen Eigenschaften (Liu 2004). Dabei verlieren die Zellen inre epitheliale Polarität und zelluläre Integrität, bedingt durch den Verlust ihrer ursprünglichen Zell-ZellKontakte (Zeisberg und Kalluri 2004). Zusätzlich führen Veränderungen in der Aktinstruktur des Zytoskeletts zur de-novo-Expession von $\alpha$-smooth muscle actin ( $\alpha-S M A)$, was die zelluläre Migrationsfähigkeit steigert. Durch die Zerstörung der tubulären Basalmemebran (TBM) migrieren die zu Myofibroblasten aktivierten Zellen ins Interstitium, wo sie zu einer vermehrten Matrixsynthese beitragen (Wahab und Mason 2006) und schließlich zur fortschreitenden Zerstörung der Organstruktur und terminaler Niereninsuffizienz führen. Die EMT wird durch eine Vielzahl von Wachstumsfaktoren, Zytokinen und Metalloproteinasen (MMP) reguliert, die die Zerstörung der TBM in unterschiedlichem Ausmaß bewirken. $\mathrm{Zu}$ den wichtigsten EMT-fördernden Wachstumsfaktoren gehören CTGF und TGF- $\beta 1$. Diesen wirken die gegensinnig regulierten renotropen Wachstumsfaktoren HGF und BMP7 entgegen. 
Vorangegangene Studien zeigten, dass eine Reduktion der TGF- $\beta 1 /$ CTGF Konzentration oder hohe Konzentrationen an HGF/ BMP7 zu einer Krankheitsregression führen können. Daher erhofft man sich, dass der therapeutische Einsatz antifibrotischer Agenzien eine effektive Strategie darstellt, die pathologische ECM-Ablagerung $\mathrm{zu}$ inhibieren und die fibrogenen Mechanismen zu modifizieren. HGF hat multiple biologische Aktivitäten in einer Vielzahl unterschiedlicher Zellen, einschließlich renalen Tubulusepithelzellen, Fibroblasten, Endothelzellen und Mesangiumzelllen. Es ist ein physiologischer Mediator für Geweberegeneration, der während akuter Schädigung und in frühen Stadien chronischer Schädigungsprozesse vermehrt exprimiert wird. Bei anhaltender Gewebeschädigung nimmt die Konzentration an HGF ab und Wachstumsfaktoren mit antagonistischer Wirkung werden überexpremiert. Dies verändert das Gleichgewicht zwischen HGF und profibrotischen Faktoren und verschiebt es zu Gunsten der Letzteren (Liu 2004). Daraus resultiert im weiteren Verlauf eine exzessive Matrixsynthese sowie akkumulation und damit einhergehend eine progressive Fibrose. HGF besitzt mitogene, motogene und morphogene, sowie antiapoptotische und antiinflammatorische Eigenschaften (Liu und Yang 2006). Die Verabreichung des HGF-Proteins als subkutane oder intravenöse Injektion führt zu einer beschleunigten Regeneration nach akuter Nierenschädigung und verzögert die renale Fibrose chronisch geschädigter Nieren (Yang J und Liu 2002). Die klinische Anwendung von exogenem HGF ist nicht unproblematisch, da HGF nur über eine kurze Halbwertzeit verfügt (Kawaida et al.1994) und die HGF-Gaben häufig wiederholt werden müssen. Die Gentherapie stellt eine effektive und ökonomisch vertretbare Alternative dar die Konzentration an exogenen und endogenen HGF zu erhöhen (Liu 2006). Die Folgen der systemischen HGF-Applikation und Wirkungen anhaltender und unphysiologisch hoher HGF-Konzentrationen auf peripheres Gewebe sind noch nicht ausreichend erforscht und müssen kritisch betrachtet werden. Takayama et al. (1997a) beschrieben an transgenen Mäusen mit diffuser HGF- 
Überexpression unerwünschte morphologische und funktionelle Veränderungen, wie Glomerulosklerose, tubuläre Hyperplasie und polyzystische Merkmale, sowie eine erhöhte Inzidenz an Tumorentwicklung. In dem von Fiaschi-Taesch et al. (2004) entwickelten transgenen Mausmodell konnte gezeigt werden, dass die gezielte Überexpression von HGF in proximalen Tubulusepithelzellen keinen nachteiligen Einfluss auf die Entwicklung und Funktion normaler Nieren nimmt und vor akut-ischämisch bedingtem Nierenversagen schützt. Um den Effekt der HGF-Überexpression in renalen Zellen weiter zu untersuchen, wurden in der vorliegenden Arbeit in-vitro-Analysen an nativen proximalen Tubulusepithelzellen und interstitiellen Fibroblasten durchgeführt.

\subsection{HGF fördert die Proliferation proximaler Tubulusepithelzellen und renaler Fibroblasten}

Während der renalen Fibrogenese kommt es vornehmlich durch TGF- $\beta 1$ getriggert zu einem vermehrten Untergang tubulärer Epithelzellen via Apoptose. Die daraus resultierende tubuläre Atrophie ist eines der histologischen Charakteristika der tubulointerstitiellen Nierenfibrose (Strutz und Neilson 2003). An unterschiedlichen Modellen der chronischen Nierenschädigung konnte die antagonistische Wirkungsweise von TGF- $\beta 1$ und HGF auf die Regulation von tubulärer Proliferation und Apoptose nachgewiesen werden (Liu 2004). So führt die akute Gewebeschädigung kurzzeitig zur vermehrten HGF-Sekretion und gesteigerter tubulärer Proliferation. Bei anhaltender Schädigung nimmt sowohl die Proliferationsrate als auch die Konzentration an endogenem HGF ab, im Gegenzug dazu steigt die Konzentration an TGF- $\beta 1$. Die Neutralisation von endogenem HGF bewirkt ein reduziertes tubuläres Wachstum und eine gesteigerte TGF- $\beta 1$ Expression. Andererseits bewirkt 
die Gabe von exogenem HGF eine gesteigerte tubuläre Proliferation und vermindert die TGF- $\beta 1$ Konzentration (Mizuno et al. 2000, 2001).

Um den direkten Einfuss einer HGF-Überexpression auf die Proliferation von proximalen Tubulusepithelzellen (NP1-HGF) zu untersuchen, führten wir Proliferationsanalysen durch. Mittels Bromdeoxyuridin-Inkorporation konnten wir demonstrieren, dass die Überexpression von HGF die Mitoserate der proximalen Tubulusepithelzellen (NP1-HGF) steigert. Die Proliferationsrate der HGF-überexprimierenden NP1-Zellen war bis zu 1,3fach gegenüber den Kontrollzellen (NP1-3.1) gesteigert. Zur Validierung der Ergebnisse der BrdU-Poliferationsassays wurden Zellzählungen durchgeführt.

Diese Ergebnisse zur endogenen HGF-Überexpression bestätigen Arbeiten von Miller et al. (1994) und Kawaida et al. (1994) die an einem Modell der akut ischämischen und akut toxischen Nierenschädigung nachweisen konnten, dass die Verabreichung von rekombinantem HGF die Regeneration und Proliferation von Tubulusepithelzellen fördert. Die Arbeitsgruppe von Dai et al. (2002) demonstrierte an Mäusen mit akuter Nierenschädigung, dass die intravenöse Injektion eines HGF-Gen enthaltenden Plasmids, die Tubulusepithelzellen vor Apoptose schützt und deren Proliferation und Regeneration fördert. Dieser mitogene Effekt von HGF konnte ebenfalls an Modellen chronischer Nierenschädigung nachgewiesen werden. Beispielsweise zeigte die Arbeitsgruppe von Gao et al. (2002) am Modell der chronisch obstruktiven Nephropathie, dass mittels HGF-Gentherapie die Proliferation von Tubulusepithelzellen gesteigert wird. Das lässt vermuten, dass unter pathologischen Bedingungen, HGF durch die Proliferationsinduktion tubulärer Epithelzellen zum Erhalt der zellulären Integrität und der Organarchitektur beitragen kann.

Zusätzlich zu den Proliferationsanalysen an proximalen Tubulusepithelzellen wurde der direkten Einfuß einer HGFÜberexpression auf die Proliferation von interstitiellen Fibroblasten (TFBHGF) untersucht. Mittels Bromdeoxyuridin-Inkorporation konnte gezeigt 
werden, dass die Überexpression von HGF ebenfalls die Mitoserate der renalen Fibroblasten (TFB-HGF) steigert. Verglichen mit den Kontrollzellreihen war die Proliferationsrate bis zu 1,49fach gesteigert. Zur Validierung der Ergebnisse wurden erneut Zellzählungen durchgeführt, die die Ergebnisse der BrdU-Inkorporation bestätigten.

Es gibt mehrere Mechanismen, die die Fibroblastenaktivierung bewirken, eine davon ist die parakrine Stimulation durch profibrogene Wachstumsfaktoren wie z.B. TGF- $\beta 1$, PDGF oder FGF-2 (Zeisberg et al. 2001). Anhand unserer Ergebnisse lässt sich die Frage ableiten, in wie weit die Überexpression von HGF einen profibrogenen Stimulus für TFBZellen darstellt. Bedingt die anhaltende autokrine HGF-Stimulation eine kontinuierliche, nicht limitierte Fibroblastenproliferation und begünstigt demzufolge die Fibrosierung des renalen Gewebes? Da die Fibrogenese nicht nur von der gesteigerten Zellproliferation abhängig ist, sondern ebenfalls durch die exzessive Matrixakkumulation und verminderte Matrixdegeneration bestimmt wird, untersuchten wir des weiteren den Effekt der HGF-Überexpression auf die Bildung extrazellulärer Matrixproteine und Aktivität von Matrix degenerierenden Proteasen.

\subsection{HGF hemmt die Produktion extrazellulärer Matrixproteine}

In den letzten Jahren demonstrierten zahlreiche Studien das antifibrotische Potential von HGF. So konnte an Modellen akuter und chronischer Nierenerkrankungen gezeigt werden, dass sowohl endogenes HGF als auch die Verabreichung von exogenem HGF-Protein die renale Fibrosierung reduziert und den renalen Funktionsverlust verzögert (Liu 2004). Die exzessive Akkumulation extrazellulärer Matrixkomponenten ist das zentrale Ereignis der interstitiellen Fibrose. Sie ist begleitet von tubulärer Atrophie und Expansion des interstitiellen Raumes und mündet in der Destruktion der physiologischen Gewebsarchitektur mit 
einhergehendem renalen Funktionsverlust. Kollagentyp-I, -III, -IV, -V, -VII, $-\mathrm{XV}$, Fibronektin und Laminin gehören dabei zu den für die Fibrogenese relevantesten Matrixproteinen (Eddy 2000). Fibronektin ist ein Matrixprotein, das wichtig für die Zellmigration, Zell-Zell- und Zell-MatrixInteraktionen ist. Darüber hinaus ist es in der Lage die Expression von TGF- $\beta 1$ zu induzieren (Fava und McClure 1987) und chemotaktisch zu wirken (Eddy 2000). Kollagentyp-IV ist in der gesunden Niere eine der Hauptfaserkomponenten der interstitiellen Matrix und der tubulären Basalmembran (Eddy 2000). Im Rahmen der renalen Fibrogenese wird Kollagen vermehrt von aktivierten Fibroblasten, d.h. Myofibroblasten gebildet. Bei der interstiellen Fibrose stellen neben Fibronektin verschiedene Kollagene den größten Anteil der ECM-Komponenten dar (Strutz und Müller 2000).

Um herauszufinden, welchen Effekt eine HGF-Überexpression auf die Bildung extrazellulärer Matrixkomponenten durch renale Fibroblasten und proximale Tubulusepithelzellen hat, wurden Analysen zur Synthese und Expression von Fibronektin durchgeführt. Hierfür wurden die jeweiligen Zellen $48 \mathrm{~h}$ kultiviert und anschließend die Fibronektinexpression mittels Westernblot analysiert bzw. ergänzend die Fibronektinsekretion aus dem Überstand mit einem ELISA gemessen. Anhand dieser Experimente konnte gezeigt werden, dass eine HGF-Überexpression die Fibronektinsynthese und -sekretion, sowohl in renalen Fibroblasten, als auch in proximalen Tubulusepithelzellen inhibiert. Die Fibronektinexpression wurde bei den TFB-Zellen um ca. 34\% und bei den NP1-Zellen um 28\%, verglichen mit den HGF negativen Kontrollzellen suppremiert. Die Fibronektinsekretion wurde noch deutlicher, nämlich um 44\% bei den TFB-Zellen und 39\% bei den NP1-Zellen reduziert.

Diese Ergbnisse stützen die Beobachtungen zur progressiven Fibronektinexpression in einem Modell der chronisch obstruktiven Nierenerkrankung. In diesen Untersuchungen konnte gezeigt werden, dass sowohl eine intravenöse Gabe von HGF-Protein (Yang $\mathrm{J}$ und Liu 
2003) als auch die Injektion eines HGF-Gen enthaltenden Plasmids (Yang $J$ et al. 2001) die Fibronektinexpression um bis zu 48\% unterbinden kann. Ergänzend wurde in der vorliegenden Arbeit der Einfluss einer HGFÜberexpression auf einen weiteren wichtigen Bestandteil der ECM, dem Kollagentyp-I, untersucht. Hierbei zeigte sich lediglich ein geringer suppressiver Effekt von HGF auf die Sekretion von Kollagentyp-I, sowohl durch die Tubulusepithelzellen (8\%) als auch durch die renalen Fibroblasten (3\%).

Unsere Beobachtungen konnten daher vorliegende Untersuchungen zur verminderten Kollagentyp-I Synthese an einem Modell der obstruktiven Nierenschädigung nicht bestätigen. Diese Studien zeigten eine Reduktion der Kollagentyp-I Akkumulation um ein Drittel, sowohl durch Injektion eines HGF-Gen enthaltenden Plasmids (Yang J et al. 2001), als auch durch nachträgliche systemische Gabe eines HGF-Proteins (Yang $\mathrm{J}$ und Liu 2003).

In dem hierfür verwendeten Tiermodel war die Induktion der Nierenfibrose durch operative Obstruktion der Ureteren erfolgt. Infolgedessen nach Ausschüttung verschiedener Mediatoren (TGF- $\beta 1$ ), eine Umwandlung der renalen Fibroblasten und damit eine gesteigerte Sekretion von extrazelluären Matrixproteinen stattfand. Diese stimulierte Umwandlung sowohl der Tubulusepithelzellen, als auch der renalen Fibroblasten lässt sich jedoch in dem vorliegenden Zellkultursystem nicht simulieren, so dass der inhibitorische Effekt von HGF auf die ECM-Synthese zwischen den beiden Systemen nicht komplett vergleichbar ist. Hierbei ist positiv hervorzuheben, dass im vorliegenden Fall der HGF-Überexpression die Fibronektinproduktion ohne einen fibrogenen Stimulus gehemmt wurde, so dass man annehmen kann, dass eine HGF-Überexpression die Fibronektinsynthese auch im Falle eines profibrogenen Stimulus unterdrückt, bzw. die Schwelle, die zu einer vermehrten Fibronektinsynthese führt, hochsetzt. 


\subsection{Matrixdegeneration - Induktion und Inhibition von MMP-2 und MMP-9}

Die Matrixhomöostase befindet sich physiologischer Weise in einer Balance zwischen Matrixproduktion und -Abbau. Es wird angenommen, dass die exzessive Matrixablagerung, wie sie in fibrotischen Nieren zu finden ist, zum einen durch eine Überproduktion an Matrixkomponenten und zum anderen durch ihren mangelnden Abbau verursacht ist. Physiologischerweise produziert das Nierengewebe eine Vielzahl von Proteasen mit proteolytischer Funktion. Dabei spielen das Plasminogen/ Plasmin- und das MMP-System eine wichtige Rolle. Sie sind in der Lage die verschiedenen Matrixproteinkomponenten abzubauen (Liu 2006). In zahlreichen Untersuchungen konnte eine erhöhte Konzentration an Plasminogen Aktivator Inhibitor-1 (PAI-1) und Gewebeinhibitoren von MMP-1 (TIMP) in geschädigten Nieren nachgewiesen werden (Jernigan and Eddy 2000, Shamara et al. 1995). Die MMPs gehören zu einer Großfamilie von mindestens 13 Enzymen, die sich durch ihre Substratspezifität voneinander unterscheiden. Sie werden von Fibroblasten, Endothel-, Epithelzellen und anderen Zellen, wie z.B. Tumorzellen gebildet und als inaktive Proenzyme in den extrazellulären Raum sezerniert, wo sie anschließend von anderen Proteasen aktiviert werden (Löffler und Petrides 1998). Von HGF als Zytokin mit antifibrotischem Potential erhoffte man sich, dass es den Matrixkatabolismus dahingegen modifiziert, dass es in bereits fibrotischen Nieren den Matrixabbau stimuliert und revidiert. Die Arbeitsgruppe von Gong et al. (2003) demonstrierte, dass HGF den Matrixabbau fördert, indem es sowohl Plasminogen/Plasmin, als auch MMP-Mechanismen beeinflusst. Dworkin et al. (2004) wiesen an 2/3 nephrektomierten Ratten nach, dass die Verabreichung von exogenem HGF zu einer vermehrten Expression von MMP-9 und Reduktion von TIMP-2 und PAl-1 führt. Daraus folgerte man, dass HGF durch die Aktivierung 
matrixdegradierender Proteasen den Prozess der Fibrosierung und Matrixablagerung verlangsamen kann.

In der vorliegenden Arbeit wurde die Wirkung einer HGF-Überexpression auf die Induktion bzw. Inhibition einer Matrixdegeneration beispielhaft anhand der Aktivität der Metalloproteinasen-2 und -9 untersucht. Hierfür wurden proximale Tubulusepithelzellen und renale Fibroblasten mit und ohne HGF-Überexpression für 48 h kultiviert, die Überstände abgenommen und die proteolytische Aktivität von MMP-2 und -9 gelzymographisch analysiert. Hierbei konnte für die proximalen Tubulusepithelzellen eine Aktivitätssteigerung von MMP-2 (um 28\%) und MMP-9 (um 34\%) durch HGF nachgewiesen werden. Bei den Fibroblasten bewirkte HGF eine verminderte Aktivität von MMP-2 (um 13\%) und MMP-9 (um 32\%). Die Beobachtungen zur Steigerung der proteolytischen Aktivität von MMP-9 durch HGF in einem renalen Epithelzellkultursystem bestätigen Untersuchungen von Liu et al. (2000). Diese konnten eine 8-fache Steigerung der MMP-9 Expression nach $48 \mathrm{~h}$ Behandlung mit einem rekombinantem HGF in einem HKC-Zellsystem zeigen. Im Gegensatz zur MMP-9 Expression ließ sich dort keine Steigerung von MMP-2 nachweisen, was jedoch auch auf die verschiedenen Zellkultursysteme zurückzuführen sein kann. Der Unterschied in der Wirkung einer HGF-Überexpression auf die MMP-2/9 Aktvität zwischen den renalen Fibroblasten und den Tubulusepithelzellen lässt sich aufgrund der unterschiedlichen Zellarten erklären. So kann im Fall der renalen Fibroblasten eine HGF-Überexpression die verschiedenen Wege der MMP-Aktivierung inhibieren bzw. die Inhibitoren aktivieren.

Die Bedeutung matrixdegenerierender Enzyme in Bezug auf die Reduktion von Matrixablagerungen und damit Limitierung der Fibrogenese, wird anhand neuer Studien kontrovers diskutiert. Yang und Mitarbeiter (2002) demonstrierten an knock-out Mäusen für Tissue Plasminogen Activator (tPA), dass der pathogene Effekt von tPA in der Induktion von MMP-9 liegt. MMP-9 ist am Abbau von Kollagentyp-IV 
beteiligt, dass den wichtigsten Bestandteil der tubulären Basalmembran darstellt. MMP-9 und MMP-2 sind am Abbau der TBM beteiligt und bilden zusammen mit einigen Wachstumsfaktoren, wie TGF- $\beta 1$ die Hauptinduktoren der EMT (Zeisberg und Kalluri 2004). Durch die Zerstörung der strukturellen und funktionellen Integrität der Basalmembran wird vermehrt TGF- $\beta 1$ gebildet, was wiederum die Aktivierung von interstitiellen Fibroblasten und Tubulusepithelzellen zu Myofibroblasten begünstigt. Diese können die geschädigte Membran passieren und in das Interstitium migrieren, wo sie zur vermehrten ECMSynthese und Ablagerung beitragen. Unter dem Aspekt der EMTInduktion durch verstärkte MMP-Aktivität könnte eine HGFÜberexpression durch eine zusätzliche Aktivierung der MMPs die Degeneration der tubulären Basalmembran fördern und den Fibrosierungsprozess damit unterstützen.

\subsection{HGF schützt Tubulusepithelzellen und renale Fibroblasten vor Cyclosporin-A-induzierter Apoptose}

Cyclosporin A ist derzeitig eines der am häufigsten eingesetzten Inmmunsuppressiva. Es wird neben der Therapie von Autoimmunerkrankungen wie z.B. rheumatoider Arthrits, Lupus erythematodes und Proriasis, in der Transplantationsmedizin zur Prävention von Organabstoßungen angewendet. Kurzfristig wirkt sich die Immunsuppression durch CsA günstig auf das Transplantatüberleben aus (Opelz und Dohler 2001). Eine langfristige Anwendung führt jedoch häufig aufgrund seiner Nephrotoxizität zur Transplantatschädigung, bzw. zur chronischen CsA-induzierten Nephropathie, was seine klinische Anwendung limitiert. CsA kann akut zu einer tubulären Schädigung führen (Bobadilla et al. 1998; Wu 2007). Längere CsA-Exposition kann in einer tubulären Atrophie, gestreiften interstitiellen Fibrose und progressiven Nierenschädigung resultieren (Shiab 1996, Shiab et al. 1996). Die 
Mechanismen, die dieser tubulointerstitiellen Schädigung zu Grunde liegen, sind multifaktoriell, wobei der programmierte Zelltod (Apoptose) eine entscheidende Rolle spielt (Thomas et al. 1998). Je nach Schweregrad des Stimulus gehen geschädigte Zellen via Nekrose oder Apoptose zugrunde. Werden im Rahmen einer Gewebeschädigung viele Zellen apoptotisch führt dies im weiteren Verlauf zur Zerstörung des ursprünglichen Gewebes, zunehmender Fibosierung und gesteigerter ECM-Ablagerung (Menè und Amore 1998). Tubulusepithelzellen sind die Angriffsorte ischämisch und toxisch bedingter Apoptose. Healy et al. (1998) demonstrierten, dass CsA direkt toxisch auf Tubulusepithelzellen wirkt und zum Zellzyklusarrest führt. Ferner zeigten sie eine dosisabhängige Apoptose-, bzw. Nekroseinduktion. Nekrose und Apoptose sind zwei verschiedene Formen des Zelltodes, die sich in ihrer Morphologie und in ihrem Mechanismus unterscheiden. Die Apoptose folgt einem genetisch festgelegten Muster und ist durch Zellschrumpfung, Kondensation des Chromatins, Verdichtung der Zellorganellen und DNAFragmentierung charakterisiert. Neben diesen Veränderungen kommt es in der Frühphase der Apoptose zu Umstrukturierungen an der Zellmembran und zur Exposition von zuvor nach intrazellulär gerichteten Phosphatidylserin (Huynh et al. 2002). Im Gegensatz dazu kommt es bei der Nekrose zu einer frühen Zerstörung der Zellmembran (Krammer 2000). Diese Veränderungen führen in der Durchflusszytometrie zu unterschiedlicher Lichtstreuung, was die Unterscheidung zwischen nekrotischen und apoptotischen Zellen ermöglicht (Vermes et al. 1995).

Der Unterschied zwischen beiden Formen ist, daß die Zellmembran in frühapoptotischen Stadien noch intakt ist, während sie schon bei der Nekroseeinleitung die Zellintegrität verliert und durchlässig wird. Zur Evaluierung einer möglichen antiapoptotischen Wirkung von HGF wurden FACS-Analysen nach Apoptoseinduktion durch Cyclosporin A durchgeführt. Hierbei bindet der FITC (Fluoresceinisothiocyanat) markierte Annexin-Antikörper an das in der frühen Apoptose exponierte Phosphatidylserin (Vermes et al. 1995) Da nekrotische Zellen aufgrund 
des Verlustes ihrer Membranintegrität ebenfalls mit Annexin binden können ist eine weitere Differenzierung apoptischer von nekrotischen Zellen notwendig. Dieses erfolgt mittels Gegenfärbung mit Propidiumjodid (PI), das nur die permeable Membran passieren kann und mit der DNA interkaliert. Bei einer fehlenden Färbung liegt somit eine intakte Membranintegrität vor, was eine Nekrose ausschließt.

Das Ziel dieser Analyse war einerseits die zyototoxische Wirkung von CsA auf die beiden Zellreihen, die renalen Firbroblasten und die Tubulusepithelzellen zu untersuchen und anderseits zu ermitteln welchen Einfluss dabei eine HGF-Überexpression auf das Apoptoseverhalten der jeweiligen Zellreihe haben kann. Dabei sollten ebenfalls mögliche konzentrationsabhängige Unterschiede herausgestellt werden.

Für die Untersuchungen wurden die Zellen 48 h mit 100, 500 und 1000 $\mathrm{ng} / \mathrm{ml}$ CsA behandelt. Die zytotoxische Wirkung des CsA war bei allen Zellreihen makroskopisch anhand avitaler, im Medium treibender Zellen und mikroskopisch anhand von Lücken in den jeweiligen Monolayern deutlich zu erkennen. In den Versuchsansätzen mit 1000 ng/ml war dieses Phänomen am stärksten ausgeprägt, so dass teilweise nur noch sehr wenige Zellen im Zellverband integriert waren. Für die geplante FACS-Analyse war die Menge zu gering. Die Zellkulturen, die mit 100 und $500 \mathrm{ng} / \mathrm{ml} \mathrm{CsA}$ über $48 \mathrm{~h}$ behandelt wurden, zeigten ausreichend intakte Monolayer, so dass diese Versuchsansätze für die FACS-Analyse verwendet werden konnten. Bei der Auswertung der mit $100 \mathrm{ng} / \mathrm{ml} \mathrm{CsA}$ behandelten Zellkulturen konnten keine wesentlichen Unterschiede bezüglich des Apoptoseverhaltens gezeigt werden, so dass die Konzentration zur Apoptoseinduktion mutmaßlich zu gering war.

Eindeutige Unterschiede waren allerdings bei den Analysen der Versuchsansätze mit $500 \mathrm{ng} / \mathrm{ml}$ zu beobachten. Hier zeigte sich einerseits ein Unterschied zwischen den HGF-überexprimierenden Zellen und den HGF-negativen Kontrollzellreihen. Sowohl bei den HGFüberexprimierenden Fibroblasten (TFB-HGF), als auch bei den HGFüberexprimierenden Tubulusepithelzellen (NP1-HGF) war die 
Apoptoserate gegenüber den HGF-negativen Zellen geringer. Die TFBHGF zeigten eine 42\% geringere Apoptoserate gegenüber den TFB-3.1. Bei den NP1-HGF war die Apoptoserate um 59\% geringer als bei den NP1-3.1. Verglich man die beiden Zelltypen miteinander, so zeigte sich, dass die Apoptosrate der HGF-überexprimierenden Fibroblasten um 13\% höher lag als bei den Tubulusepithelzellen Die hier vorgelegten Ergebnisse lassen auf einen zytoprotektiven Effekt einer HGFÜberexpression gegenüber einer CsA-induzierten Apoptose schließen.

Diese Ergebnisse unterstützen die von Mizui et al. (2004) beschriebenen protektiven Effekte einer HGF-Überexpression bezüglich einer CsAinduzierten Apoptose. Sie untersuchten in vivo und in vitro die Auswirkung einer HGF-Gentherapie auf die CsA-induzierte Nephropathie. Dabei konnten sie zeigen, dass mittels HGF-Gentransfektion Tubulusepithelzellen vor Apoptose geschützt werden. Sie führten TUNELAssays zur Detektion apoptotischer Zellen durch und demonstrierten dabei einerseits eine zeit- und konzentrationsabhängige Apoptoseindutkion durch CsA und wiesen andererseits eine mehr als 50\% geringere Apoptoserate bei den HGF-transfizierten Zellen als bei den HGF-negativen Kontrollzellen nach. Anhand von Westernblotanalysen konnten sie ferner eine gesteigerte Expression von antiapoptotischen Markerproteinen, wie phosphorylierte Akt-Kinase und Bcl-2 bei HGFpostiven HK-2 Zellen (Tubulusepithelzellen) nachweisen, die bei den HGF-negativen Zellen nach CsA Behandlung supprimiert waren. Mittels immunhistochemischen Färbungen von Rattennieren, die über 2-3 Wochen mit CsA behandelten wurden, zeigten sie eine bis $40 \%$ geringere Ausbreitung der interstitiellen Fibrose. Ähnliche zytoprotektive Effekte duch HGF waren an anderen renalen Epithelzellen beschrieben worden. Die Arbeitsgruppe von Foroni et al. (2001) untersuchte die protektiven Effekte einer systemischen HGF-Substitution vor CsA-induzierter Apoptose, allerdings an glomerulären Epithelzellen. Sie wiesen ebenfalls eine Konzentrations- und Zeitabhängikeit nach. Ferner zeigten sie, dass eine Vorbehandlung mittels systemischen HGF-Gaben glomuläre 
Epithelzellen vor der CsA-induzierten Apoptose schützt. Eine zytoprotektive Wirkung einer HGF-Überexpression wurde an renalen Fibroblasten bisher nicht beschrieben

In-vitro- und in-vivo-Studien zeigten, dass sowohl vermehrtes endogenes und exogenes HGF Tubulusepithelzellen vor Apoptose unterschiedlicher Ursache schützt (Liu 2004; De Souza et al 2003; Foroni et al. 2001, Herrero-Fresneda et al. 2006). Nachdem Yang J und Liu (2001) am Modell der obstruktiven Nephropahtie gezeigt hatten, dass die Injektion eines HGF-cDNA Plamids zur Steigerung endogener HGF-Konzentration und reduzierter Fibrose führt, demonstrierten Gao et al. (2002), dass HGF-Gentransfer die Progression der chronisch obstruktiven Nephropathie verzögert und Tubulusepithelzellen vor Apoptose schützt. Ähnliche Ergebnisse erzielte die Arbeitsgruppe von Dai (2002). Sie untersuchte die protektive Wirkung einer HGF-Gentherapie an Folsäure geschädigten Mäusenieren.

Die antiapoptotische Wirkung von HGF in renalen Epithelzellen und deren zugrunde liegenende Mechanismen sind nicht vollständig geklärt. Die Apoptose ist ein genregulierter Prozess, dem prinzipiell zwei unterschiedliche Signalwege zugrunde liegen. Zum einen die positive Induktion durch Ligandenbindung an einen membrangebundenen „TodesRezeptor“, z.B. Fas-Rezeptor und zum anderen die negative Induktion durch den Verlust von Suppressorsignalproteinen $\mathrm{zu}$ denen im besonderen Maße die der Bcl-2 Proteinfamilie gehören (Itho et al 1991, Yang $E$ und Korsmeyer 1996). Ein anderer wichtiger Aspekt des Zellüberlebens ist das Gleichgewicht zwischen antiapoptotischen und proapoptotischen Proteinen (Liu 1998).

Die Endstrecke der Apoptosekaskade mündet in der Aktivierung von Caspasen, insbeondere der Caspase-3 und -9 (Ortiz et al. 1998, Ortiz 2000). Shiab et al. (1996) demonstrierten, dass CsA die Expression von Caspase-3 und des Fas-Gens induziert und $\mathrm{zu}$ einer Expressionssteigerung von TGF- $\beta 1$ führt (Shiab et al. 1996; Mizui et al. 2004). 
HGF entfaltet, in Abhängigkeit des Apoptose auslösenden Stimulus, seine protektiven und regenerativen Leistungen über unterschiedliche Mechanismen, aber vor allem über eine gesteigerte Expression antiapoptotischer Signalproteine. Einer dieser Mechanismen ist die Phosphorylierung der Akt-Kinase, von der bekannt ist, dass sie vor Apopotose schützt. Mizui et al. (2004) konnten bei ihren Untersuchungen an Tubulusepihelzellen zum einen eine CsA-induzierte Inaktivierung der Akt-Kinase und zum anderen eine durch HGF-Überexpression gesteigerte Akt-Kinase-Aktivität nachweisen. An der Aufrechterhaltung des Zellzyklus und Zellüberlebens sind ebenfalls die der Akt-Kinase nachgeschalteten Signalproteine, wie E2F, c-myc und Bad beteiligt. Die Phosphorylierung von Bad und die darauffolgende Dissoziation vom $\mathrm{Bcl}-\mathrm{xL}$ ist der wichtigste Schritt der antiapoptotischen Akt-Kinase-Kaskade (Mizui et al. 2004). In Untersuchungen, bei denen durch Serumentzug Apoptose induziert wurde, konnte nachgewiesen werden, dass HGF die PI-3-Kinase aktiviert und darüber die Phosphorylierung der Akt-Kinase bewirkt. Daraufhin kommt es zur Phosphorylierung des proapoptotischen Bad-Proteins, das dadurch inaktiviert wird. Gleichzeitig bewirkt HGF die Freisetzung von Bcl$\mathrm{xL}$, einem anderen antiapoptotischen Protein, der Bcl-2 Familie (Liu 1999). In einer Studie an unilateraler Ureterobstruktion konnte Gao et al. (2002) zeigen, dass HGF die Expression von Bcl-2 stimuliert. Bcl-2 ist ein Apoptoseinhibitor, dessen Gegenspieler das Bax-Protein ist. In der Regulation von Zellwachstum und -Tod haben beide Proteine gegenteilige Wirkung. CsA reduziert in Tubulusepithelzellen die Konzentration an Bcl-2 und führt zu einer gesteigerten Expression von Bax (Shiab et al.1999). Die Arbeitsgruppe von Miuzi et al. (2004) demonstrierte neben der Aktivierung von Akt, dass HGF die Expression von $\mathrm{Bcl}-2$ in $\mathrm{CsA}$ geschädigten Tubulusepithelzellen induziert. Ferner konnten sie nachweisen, dass die Hochregulation von Bcl-2 mit der Inhibition der Caspase-3, durch HGF korreliert. CsA induziert die Expression von TGF$\beta 1$. Yazawa et al. (2004) zeigten, dass der Gentransfer von HGF, die 
durch CsA gesteigerte TGF- $\beta 1$ Konzentration reduziert. HGF ist dadurch in der Lage die proapoptotische Wirkung von TGF- $\beta 1$ zu unterdrücken.

\subsection{Schlussfolgerung und Ausblick}

In der vorliegenden Arbeit konnte ein proliferativer, antifibrogener und antiapoptotischer Effekt einer HGF-Überexpression sowohl in Tubulusepithelzellen als auch in renalen Fibroblasten nachgewiesen werden.

In früheren Untersuchungen war eine wichtige Rolle von HGF in der Pathophysiologie der renalen Fibrose beschrieben worden. Die Umwandlung von tubulären Epithelzellen zu mesenchymalen Fibroblasten (EMT) gilt hierbei als eines der charakteristischen Merkmale der chronischen Nierenschädigung. Die Aufrechterhaltung der Matrixsynthese und das Fortschreiten der Fibrose wird hauptsächlich mit der Präsenz profibrogener Zytokine in Verbindung gebracht.

TGF- $\beta 1$ übernimmt dabei eine der Hauptrollen (Strutz und Neilson 2003). Es wirkt chemotaktisch auf Fibroblasten, fördert die Transformation von Fibroblasten zu Myofibroblasten und induziert die Synthese extrazellulärer Matrixproteine, wie Fibronektin und Kollagentyp-I (Strutz et al. 1995). Die Überexpression von TGF- $\beta 1$ in der Niere bewirkt eine rasch fortschreitende Fibrosierung und Funktionsverschlechterung (Liu 2006). Border und Noble (1994) untermauerten die zentrale Rolle von TGF- $\beta 1$ in der Fibrogenese. HGF stellt einen physiologischen Gegenspieler zu TGF$\beta 1$ dar. Eine anhaltende Schädigung des Organs bewirkt eine kontinuierliche Abnahme der HGF-Konzentration. Im Gegenzug dazu wird vermehrt TGF- $\beta 1$ gebildet. In chronisch geschädigtem Gewebe führt das veränderte HGF/TGF- $\beta 1$ Verhältnis zu einer verstärkten Myofibroblastenaktivierung, EMT und damit zu einer exzessiven Matrixakkumulation (Eddy 2000). 
Der Versuch mittels Verabreichung von exogenem HGF die Balance zwischen den beiden Zytokinen wiederherzustellen, um somit die fibrotische Wirkung von TGF- $\beta 1$ zu verhindern, erwies sich in vielen Experimenten als erfolgreich. So gelang es Yang J und Liu (2002) nachzuweisen, dass die durch TGF- $\beta 1$-induzierte Aktivierung interstitieller Fibroblasten zu Myofibroblasten durch die Gabe von exogenem HGF blockiert wird. Anhand weiterer Untersuchungen demonstrierten sie, dass exogenes HGF ebenfalls die durch TGF- $\beta 1$ stimulierte EMT proximaler Tubulusepithelzellen verhinderte (Yang $J$ und Liu 2002). Aufgrund der kurzen Halbwertzeit von exogen zugeführten HGF im Oragnismus, versuchte man mittels Gentransfer in Tiermodellen eine HGFÜberexpression zu erzeugen. Diese alternative HGF-Darreichung erwies sich als eine vielversprechende Methode, die renale Fibrose in chronisch geschädigten Nieren zu minimieren bzw. aufzuhalten. Gao et al. (2002) demonstrierten am Beispiel der chronisch obstruktiven Nephropathie, dass der wiederholte Transfer humaner-HGF cDNA zu einer lokal erhöhten HGF-Konzentration führte. Die HGF-exprimierenden Tiere zeigten im Vergleich zu den Kontrolltieren eine verminderte tubulointerstitielle Schädigung. Ähnliche Ergebnisse erzielten Cruzado et al. (2004) am Modell der fortgeschrittenen diabetischen Nephropathie. Die Arbeitsgruppe von Yazawa et al. (2004) untersuchte den Effekt der HGFGentherapie an der chronischen Cyclosporin A-induzierten Nephropathie. Ihre Ergebnisse konnten, eine deutlich geringere interstitielle Fibrosierung nachweisen. Herrero-Fresneda et al. (2006) untersuchten den Effekt einer HGF-Gentherapie am Modell der chronischen Transplantatniere. Auch sie konnten nachweisen, dass durch die Behandlung mit humaner HGFcDNA der tubulointerstitielle Schaden minimiert und regenerative Prozesse induziert werden können. Bemerkenswert ist, dass sich der antifibrotische Effekt von HGF v.a. in der verzögerten Gabe, d.h. bei schon manifester Fibrosierung als besonders effektiv herausstellte. Diese voneinander unabhängigen Ergebnisse lassen vermuten, dass die HGF- 
Gentherapie als eine mögliche innovative therapeutische Strategie zur Prävention der terminalen Niereninsuffizienz zu betrachten ist.

Das renotrope Potential von HGF im Bezug auf den Erhalt der renalen Struktur und Funktion, ist jedoch auch differenziert zu betrachten. Bei Untersuchungen an transgenen Mäusen, die HGF überexprimierten, beobachteten Takayama et al. (1997a) die Entwicklung einer progressiven polyzystischen Nierenerkrankung. Die autokrine Stimulation der renalen Zellen bewirkte eine gesteigerte zelluläre Proliferation, die zu tubulärer Hypertrophie und Glomerulosklerose führte. Bei weiteren Untersuchungen zeigte sich bei den gleichen Tieren eine deutlich erhöhte Inzidenz für Tumorentwicklung unterschiedlichen Ursprungs (Takayama et al. 1997b). 


\section{Zusammenfassung}

Chronisch progressive Nierenerkrankungen münden, begleitet durch tubulointerstitielle Fibrose, in eine terminale Niereninsuffizienz. Bedingt durch die Ausschüttung von Chemokinen werden Entzündungszellen rekrutiert, proinflammatorische Mediatoren freigesetzt und darüber interstitielle Fibroblasten zur Matrixsynthese angeregt. Im Rahmen der Fibrogenese gehen Tubulusepithelzellen apoptotisch zu Grunde oder durchlaufen via epithelial-mesenchymaler Transition eine phänotypische Umwandlung zu ECM produzierenden Zellen. Durch tubuläre Atrophie und exzessive Matrixsynthese kommt es zur progressiven Fibrosierung und folglich zu renalem Funktionsverlust.

Entscheidend für die Fibrogenese ist die Imbalance zwischen profibrogenen und antifibrogenen Zytokinen. Chronische Schädigungen führen zu einer gesteigerten Expression von TGF- $\beta 1$, dem potentesten profibrogen wirkenden Zytokin. HGF ist ein endogenes Zytokin, mit renoprotektiven Fähigkeiten. Es besitzt als Antagonist von TGF- $\beta 1$ ein hohes antifibrotisches Potential.

In der vorliegenden Arbeit wurden die Effekte einer HGF-Überexpression an murinen Tubulusepithelzellen (NP1) und kortikalen Fibroblasten (TFB) hinsichtlich der Proliferation, Matrixsynthese, -Degeneration, und Apoptose untersucht.

Es konnte gezeigt werden, dass eine HGF-Überexpression die Proliferation proximaler Tubulusepithelzellen und renaler Fibroblasten stimuliert. In den aufgeführten BrdU-Assays steigerte HGF die Proliferation der TFB-Zellen z.B. nach $72 \mathrm{~h}$ um das 1,49fache. Bei den NP1-Zellen zeigte sich nach $72 \mathrm{~h}$ eine 1,38fache Proliferationssteigerung. Anhand von Western Blots und ELISA konnte gezeigt werden, dass eine HGF-Überproduktion die Fibronektinsekretion der TFB-Zellen um bis zu $44 \%$ und die der NP1-Zellen bis zu $40 \%$ senkt. Die Kollagentyp-ISekretion wurde lediglich in geringerem Umfang inhibierend beeinflusst. 
Zur Ermittlung des Einflusses einer HGF-Überexpression auf die Matrixdegeneration wurde die proteolytische Aktivität der Proteasen MMP-2 und MMP-9 in Zellkulturüberständen zymographisch ermittelt. Bei den NP1-Zellen konnte eine durch HGF-Überexpression gesteigerte Aktivität für MMP-2 (28\%) und MMP-9 (32\%) nachgewiesen werden. Im Gegensatz dazu zeigte sich bei den HGF-überexpremierenden TFBZellen eine verminderte Aktivität sowohl von MMP-2 (13\%) als auch MMP-9 (32\%).

Nach Cyclosporin-A-induzierter Apoptose konnte mittels FACS-Analysen, nach Annexin-V- und PI-Färbung, ein zytoprotektiver Effekt durch HGFÜberexpression nachgewiesen werden. Es konnte für die TFB-Zellen eine $42 \%$ geringere und für die NP1-Zellen eine 59\% geringere Apoptoserate gegenüber den HGF-negativen Zellen ermittelt werden.

Diese Beobachtungen sind hinsichtlich zukünftiger Therapiestrategien interessant. In der Literatur wurde das antifibrotische Potential von HGF hinsichtlich Prävention und Regression experimentell induzierter renaler Fibrose sowohl durch systemische Substitution seines Proteins als auch via Gentransfer, beschrieben. Allerdings bedarf es weiterer Untersuchungen, ob die klinische Anwendung von HGF am Menschen eine mögliche Therapiestrategie chronisch progressiver Nierenerkrankungen darstellt. 


\section{Literaturverzeichnis}

Alvarez RJ, Sun MJ, Haverty TP, lozzo RV, Myers JC, Neilson EG (1992): Biosynthetic and proliferative characteristics of tubulointerstitial fibroblasts probed with paracrine cytokines. Kidney Int 41, 14-23

Aumailley M, Gayraud B (1998): Structure and biological activity of the extracellular matrix. J Mol Med $\underline{7}, 253-265$

Batlle D, Ramadugu P, Soler MJ (2006): Progress in retarding the progression of advanced chronic kidney disease: Grounds for optimism. Kidney Int $\underline{70}$, S40-S44

Birkedal-Hanssen H (1995): Proteolytic remodeling of extracellular matrix. Curr Opin Cell Biol $\underline{7}, 728-735$

Bobadilla NA, Gamba G, Tapia E, Garcia-Torres R, Bolio A, LopezZetina P, Herrera-Acosta J (1998): Role of NO in cyclyosporine nephrotoxicity: Effects of chronic NO Inhibition and NO synthases. Am J Physiol 274, F791-F798

Bohle A (1982): Die Bedeutung des Niereninterstitiums für die Nierenfunktion. Klin Wochenschr 60(19), 1186-90

Bohle A, Christ H, Grund KE, Mackensen S (1979): The role of the Interstitium of the renal cortex in renal disease. Contrib Nephrol 16:109114

Bohle A, Strutz F, Müller GA (1994): On the pathogenesis of chronic renal failure in primary glomerulonephropathies: a view from the interstium. Exp Nephrol 2(4), 205-210

Border WA und Noble NA (1994): Mechanisms of disease: Transforming growth factor $\beta$ in tissue fibrosis. N Engl J Med 331, 1286- 1292

Bornstein I, Voyta JC, Lazzari KG, Murphy O, Edwards B, Kricka LJ (1990): Improved chemiluminescent detection of alkaline phosphatase. Biotechniques $\underline{9}, 160-161$

Bradford, M (1976):A Rapid and Sensitive Method for the Quantitation of Microgram Quantities of Protein Utilizing the Principle of Protein-Dye Binding. Anal. Biochem $\underline{72}, 248-254$ 
Bottaro DP, Rubin JS, Faletto DL, Chan AM, Kmiecik TE, Vivande Woude GF, Aronson SA (1991): Identification of hepatocyte growth factor receptor as the c-met protooncogene product. Science $\underline{251}, 802-804$

Chen S, Iglesias-de-la Cruz MC, Jim B, Hong SW, Isono M, Ziyadeh FN (2003): Reversibility of established diabetic glomerulopathy by anti- TGFbeta antibodies in db/db mice. Biochem Biophys Res Commun 으, 16-22 Cruzado J M, Núria L, Torras J, Riera M, Fillat C, Herrero-Fresneda I, Aran J M, Alperovich G, Vidal A, Grinyó J M (2004): Regression of Advanced Diabetic Nephropathy by Hepatocyte Growth Facor Gene Therapy in Rats. Am Diabetes Assoc Inc 모: 1119-1127

Dai C, Yang J, Liu Y (2002): Single injection of naked plasmid encoding hepatocyte growth factor prevents cell death and ameliorates acute renal failure in mice. J Am Soc Nephrol 13, 411-422

De Souza DM Jr, Razvickas CV, Goncalves EA, Okano IR, Camargo SM, Monte JC, dos Santos OF (2003): The role of growth factors on renal tubular cells submitted to hypoxia and deprived of glucose. Ren Fail $\underline{25}$, 341-353

Dworkin LD, Gong R, Tolbert E, Centrecchio J, Yano N, Zanabli A, Esparaza A, Rifai A (2004): Hepatocyte growth factor ameliorates progression of interstitial fibrosis in rats with established renal injury. Kidney Int $\underline{65}, 409-419$

Eddy AA (2000): Molekular basis of renal fibrosis. Pediatr Nephrol $\underline{15}$, 290-301

Eknoyan G, Lameire N, Barsoum R, Eckardt KU, Levin A, Levin N, Locatelli F, MacLeod A, Vanholder R, Walker R, Wang H (2004): The burden of kidney disease: improving global outcomes. Kidney Int $\underline{66}(4)$, 1310-1340

Fava RA und McClure DB (1987): Fibronektin associated transforming growth factor. J Cell Physiol 131, 184-189

Ferguson MW, O'Kane S (2004): Scar-free healing: from embryonic mechanisms to adult therapeutic intervention. Philos Trans R Soc Lon B Biol Sci $\underline{359}, 839-850$

Fiaschi-Taesch NM, Santos S, Reddy V, van Why SK, Philbrick WF, Ortega A, Esbrit P, Orloff JJ, Garcia- Ocana A (2004): Prevention of acute 
ischemic renal failure by targeted delivery of growth factors to the proximal tubule in transgenic mice: the efficacy of parathyroid hormonerelated protein and hepatocyte growth factor. J Am Soc Nephrol $\underline{15}$, 112125

Florquin S, Rouschop KM (2003): Reciprocal functions of hepatocyte growth factor and transforming growth factor-beta 1 in the progression of renal diseases: a role for CD44? Kidney Int Suppl 흐, 15-20

Foroni A, Li H, Foschi A, Striker GE, Striker LJ (2001): Hepatocyte growth factor, but not insulin-like growth factor I, protects podocytes against cyclosporineA-induced apoptosis. Am J Pathol 158, 275-280

Frei U, Schober-Halstenberg HJ (2006), Nierenersatztherapie in Deutschland, Bericht 2005I2006. Quasi Niere 2005/2006, 36

Freshney R: Tierische Zellkulturen; Walter de Gruyter, Berlin 1990

Gao X, Mae H, Ayabe N, Takai T, Oshima K, Hattori M, Ueki T, Fujimoto J, Tanizawa T (2002); Hepatocyte growth factor gene therapy retards the progression of chronic obstructive nephropathy. Kidney Int $\underline{62}, 1238-1248$

Giannopoulou M, Iszkula SC, Dai C, Xiaoyue T, Yang J, Michalopoulos GK, Liu Y (2006): Distinctive role of Stat3 and Erk-1/2 activation in mediating interferon- $\gamma$ inhibition of TGF- $\beta_{1}$ action. Am J Physiol Renal Physiol 290, F1234-1240

Gong R, Rifai A, Tolbert EM, Centracchio JN, Dworkin LD (2003): Hepatocyte Growth Factor Modulates Metalloproteinases and Plasminogen Activator/Plasmin Proteolytic Pathways in Progressive Renal Interstitial Fibrosis. J Am Soc Nephrol 14, 3047-3060

Gratzner HG (1982): Monoclonal antibody to 5-bromo-and 5iododeoxyuridine: A new reagent for detection of DNA replication. Science $\underline{218}, 474-475$

Hartmann G, Naldini L, Weidner KM, Sachs M, Vigna E, Comoglio PM, Birchmeier W (1992): A functional domain in the heavy chain of scatter factor/hepatocyte growth factor binds the c-Met receptor and induces cell dissociation but not mitogenesis. Cell Biol $\underline{89}, 11574-11578$

Healy E, Dempsey M, Lally C, Ryan MP (1998): Apoptosis and necrosis: Mechanisms of cell death induced by cyvlosporine $A$ in a renal proximal tubular cell line. Kidney Int $\underline{54}$, 1955-1966 
Herold G und Mitarbeiter: Innere Medizin, Selbstverlag Köln 2007

Herrero-Fresneda I, Torras J, Franquesa M, Vidal A, Cruzado JM, Lloberas N, Fillat C, Grinyó JM (2006): HGF gene therapy attenuates renal allograft scarring by preventing the profibrotic inflammatory-induced mechanisms. Int Soc Nephrol 70, 265-274

Huynh MN, Fadok VA, Henson PM (2002): Phosphatidylserinedependent ingestion of apoptotic cells promotes TGF- $\beta 1$ secretion and the resolution of inflammation. J Clin Invest $\underline{109}, 41-50$

Isaka Y, Akagi Y, Ando Y, Tsujie M, Sudo T, Ohno N, Border WA, Kaneda $\mathrm{Y}$, Hori M, Imai E: Gene therapy by transforming growth-beta receptor-IgG Fc chimera suppressed extracellular matrix accumulation in experimental glomerulonephritis. Kidney Int $\underline{55}$ (2), 465-75

Itho N, Yonehara S, Ishii A, Yonehara M, Mizuhima S, Sameshima M, Hase A, Seto Y, Nagata S (1991): The polypeptide encoding by the cDNA for human cell surface antigen Fas can mediate apoptosis. Cell $\underline{66}$, 233243

Iwano M, Plieth D, Danoff TM, Xue C, Okada H, Neilson EG (2002): Evidence that fibroblasts derive from epithelium during tissue fibrosis. $\mathrm{J}$ Clin Invest 110, 341-350

Jernigan SM, Eddy AA: Experimental insights into the mechanisms of tobulointerstitial scarring. In: Mechanisms and Clinical Management of Chronic Renal Failure, $2^{\text {nd }}$ Ed., El Nahas AM, Oxford University Press, Oxford 2000, 104-145

Kaissling B, Le Hir M (1994): Characterization and distribution of interstitial cell types in renal cortex of rats. Kidney Int $\underline{45}, 709-720$

Kalluri R, Neilson EG (2003): Epithelial-mesenchymal transition and its implications for fibrosis. J Clin Invest 112, 1776-1784

Kawaida K, Matsumoto K, Shimazu H, Nakamura T (1994): Hepatocyte growth factor accelerates prevents failure and accelerates renal regeneration in mice. Proc Natl Acad Sci USA 91, 4357-4361

Kofler S, Nickel T, Weis M (2004): The role of cytokines in cardiovascular diseases. Focus on endothelial response to inflammation. Clin Sci (Lond) 2004 
Kopp JB, Klotmann PE (1990): Cellular and molecular mechanisms of cyclosporin nephrotoxicity. J Am Nephrol 1:162-179

Krammer PH (2000): Apoptose. Dtsch Ärztebl 97, B-1481-1488

Laemmli UK (1970): Cleavage of structural proteins during the assembly of the head of bacterioge. Nature 227, 680-85

Lee MJ, Shoukat D, Kalluri R, Thompson EW (2006): The epithelialmesenchymal transition: new insights in signaling, development, and disease. J Cell Biol ㄱ, 973-981

Lemley KV, Kritz W (1991): Anatomy of the renal interstitium. Kidney Int $\underline{39}, 370-381$

Liu Y (1999): Hepatocyte growth factor promotes renal epithelial cell survival by dual mechanisms. Am J Physiol Renal Physiol 277, F624-633

Liu Y (2003): Hepatocyte growth factor in kidney fibrosis: therapeutic potential and mechanisms of action. Am J Renal Physiol 287: F7-F16

Liu Y (2004a): Epithelial to mesenchymal transition in renal fibrogenesis: pathologic significance, molecular mechanism, and therapeutic intervention. J Am Soc Nephrol 15 (1), 1-12

Liu Y (2004b): Hepatocyte growth factor in kidney fibrosis: therapeutic potential and mechanisms of action. Am J Physiol Renal Physiol 287, F7F16

Liu Y (2006): Renal fibrosis: New Insights into pathogenesis and therapeutics. Kidney Int $\underline{69}$, 213-217

Liu Y, Yang J (2006): Hepatocyte Growth Factor: new arsenal in the fight against renal Fibrosis? Kidney Int $\underline{70}$, 238-240

Liu Y, Sun AM, Dworkin LD (1998): Hepatocyte growth factor protects renal epithelial cells from apoptotic cell death. Biochem Biophy Res Commun $\underline{246}, 821-6$

Liu Y, Tolbert EM, Lin L, Thursby MA, Sun AM, Nakamura T, Dworkin LD (1999): Up-regulation of hepatocyte growth factor receptor: An amplification and targeting mechanism for hepatocyte growth factor in acute renal failure. Kidney Int 55, 442-453 
Liu Y, Rajur K, Tolbert E, Dworkin LD (2000): Endogenous hepatocyte growth factor ameliorates chronic renal injury by activating matrix degradation pathways. Kidney Int $\underline{58}$, 2028-2043

Löffler G, Petrides PE: Biochemie und Pathobiochemie, 6. Auflage; Springer Verlag, Berlin 1998

Matsumoto K, Nakamura T (2001): Hepatocyte growth factor: Renotropic role and potential therapeutics for renal diseases. Kidney Int $\underline{59}$, 20232038

Matsumoto K, Matsumoto K, Nakamura T, Kramer RH (1994) Hepatocyte growth factor/scatter factor induces tyrosine phophorylation of focal adhesion kinase (p125FAK) and promotes migration and invasion by oral squamous cell carcinoma cells. J Biol Chem 269(50), 31807- 31813 Menè $\mathbf{P}$, Amore A (1998): Apoptosis: potential role in renal diseases. Nephrol Dial Transplant 13, 1936-1943

Miller SB, Martin DR, Kissane J, Hammerman MR (1994): Hepatocyte growth factor accelerates recovery from acute ischemic renal injury in rats. Am J Physiol Renal Fluid Electrolyte Physiol 266, F129-F134

Mizui M, Isaka Y, Takabatje Y, Mizuno S, Nakamura T, Ito T, Imai E, Hori M (2004): Elektroporation-mediated HGF gene transfer ameliorated cyclosporine nephrotoxicity. Kidney Int $\underline{65}$, 2041-2053

Mizuno S, Kurosawa T, Matsumoto K, Mizuno-Horikawa Y, Okamoto M, Nakamura T (1998): Hepatocyte growth factor prevents renal fibrosis and dysfunction in a mouse model of chronic renal disease. J Clin Invest $\underline{101}, 1827-1834$

Mizuno S, Matsumoto K, Kurosawa T, Mizuno-Horikawa Y, Nakamura T (2000): Reciprocal balance of hepatocyte growth factor and transforming growth factor- $\beta 1$ in renal fibrosis in mice. Kidney Int $\underline{57}$, 937-948

Mizuno S, Matsumoto K, Nakamura T (2001): Hepatocyte growth factor suppresses interstitial fibrosis in a mouse model of obstructive nephropathy. Kidney Int $\underline{59}, 1304-1314$

Montesano R, Soriano JV, Pepper MS, Orci L (1997): Induction of epithelial branchiching tubulogenesis in vitro. J Cell Physiol $\underline{173}, 152-61$ 
Müller GA, Markovic-Lipovski J, Frank J und Rodemanne HP (1992): The role of interstitial cells in the progresssion of renal diseases. J Am Soc Nephrol $\underline{2}, 198-205$

Mullis K, Faloona F, Scharf S, Saiki R, Horn G, Ehrlich H (1986): Specific enzymatic amplification of DNA in vitro: the polymerase chain reaction. Cold Spring Harb Symp Quant Biol 51, 263-73

Nakamura T, Nawa K, Jichihara A (1984): Partial purification and characterization of hepatocate growth factor from serum of hepatectomized rats. Biochem Biophys Res Commun 122, 1450- 1459

Nakamura T, Katsuhiko N, Ichihara A, Kaise N, Nichino T (1987): Purification and subunit structure of hepatocyte growth factor from rat platelets. FEBS Letters, 224 (2) 311- 316

Nakamura T, Nichizawa T, Hagiya M, Seki T, Shimonishi M, Sugimura A, Tashiro K, Shimizu S (1989): Molecular Cloning and Expression of Human Hepatocyte Growth Factor. Nature 342, 440-44

Negri AL (2004): Prevention of renal fibrosis in chronic renal diseases: Antifibrotic agents. J Nephrol 17, 496-503

Neilson EG (2005): Setting a trap for tissue fibrosis. Nat Med 11, 373-374 Okada H, Innoue T, Suzuki H, Strutz F, Neilson EG (2000): Epithelialmesenchymal transformation of renal tubular epithleal cells in vitro and in vivo. Nephrol Dial Transplant 15, 44-46

Opelz G, Dohler B (2001): Cyclosporine and long-term kidney graft survival. Transplantation $\underline{72}, 1267-1273$

Ortiz A (2000): Apoptotic regulatory proteins in renal injury. Kidney Int $\underline{58}$, 467-485

Ortiz A, Lorz C, Catalán MP, Ortiz A, Coca S, Edigo J (1998): Cyclosporine A induces apoptosis in murine tubular epithelial cells: Role of caspases. Kidney Int Suppl $\underline{68}$, S25-S29

Palmer BF (1997): The renal tubule in the progression of chronic renal failure. J Invest Med $\underline{45}$, 34-43

Park M, Dean M, Kaul K, Braun MJ, Gonda MA, Vande Woude G (1987) Sequence of MET protooncogene cDNA has features characteristics of the tyrosine kinase family of growth- factor receptors. Proc Natl Acad Sci USA 84 (18), 6379-6383 
Ponzetto C, Bardelli A, Zehn Z, Maina F, dalla Zonca P, Giordano S, Graziani A, Panayotou G, Comoglio PM (1994) A multifunctional docking site mediates signalling and transformation by hepatocyte growth factor/ scatter factor receptor family. Cell Press $\underline{77}(2), 261$ - 271

Quesada AR, Barbacid MM, Mira E, Fernandez-Resa P, Marquez G, Aracil M (1997): Evaluation of fluorometric and zymographic methods as activity assays for stromelysins and gelatinases. Clin Exp Metastasis $\underline{15}$, 339-344

Remuzzi G, Bertani T (1998): Pathophysiology of progressive nephropathies. New Engl J Med $\underline{339}, 1448-1456$

Ruiz-Ortega M und Edigo J (1997): Angiotensin II modulates cell growthrelated events and synthesis of matrix proteins in renal interstitial fibroblasts. Kidney Int $\underline{52}, 1497-510$

Ruiz-Ortega M, Ruperez M, Lorenzo O, Esteban V, Blanco J, Mezzano S, Edigo J (2002): Angiotensinll regulates the synthesis of proinflammatory cytokines and chemokines in the kidney. Kidney Int Suppl, 82, 12-22

Scheaper U, Gehring NH, fuchs KP, Sachs, Kempkes B, Birchmeier W (2000): Coupling of Gab1 to c-Met, Grb2, and Shp2 Mediates Biological Responses. J Cell Biol 149, 1419-1432

Schiffer M, Gersdorff G von, Bitzer M , Susztak K, Bottinger EP (2000): Smad proteins and transforming growth factor beta-signaling. Kidney Int $\underline{58}$ [Suppl 77], S45-52

Schmidt C, Bladt F, Goedecke S, Brinkmann V, Zschiesche W, Sharpe M, Gherardi E, Birchmeier C (1995): Scatter factor/ hepatocyte growth factos is essential for liver development. Nature $\underline{373}, 699-702$

Shamara AK, Mauer SM, Kim Y, Michael AF (1995): Altered expression of matrix metalloproteinase-2, TIMP, and TIMP2 in obstructive nephropathy. J Lab Clin Med 125, 754-61

Shiab FS (1996): Cyclosporine nephropathy: pathophysiology and clinical impact. Semin Nephrol 16, 536-547

Shiab FS, Andoh TF, Tanner AM, Noble NA, Border WA, Franceschini N, Bennett WM (1996): Role of transforming growth factor-beta 1 in experimental chronic cyclosporine nephropathy. Kidney Int $\underline{49}, 1141-1151$ 
Shiab FS, Andoh TF, Tanner AM, Yi H, Bennett WM (1999): Expression of apoptosis regulatory genes in chronic cyclosporine nephrotoxicity favors apoptosis. Kidney Int $\underline{56}$ : 2147-59

Strutz F (2004): Fibrose und potentielle Reversibilität: Bedeutung von BMP-7. Spek Nephrol 17, 17-27

Strutz F, Müller GA (2000): Transdiffertiation comes of age. Nephrol Dial Transpl 15, 1729-1731

Strutz F, Neilson EG (2003): New insights into mechanisms of fibrosis in immune renal injury. Springer Semin Immunopathol 24, 459-476

Strutz F, Okada H, Lo CW, Danoff T, Carone RL, Tomaszewski JE, Neilson EG (1995): Identification and characterization of a fibroblast marker: FSP-1. J Cell Biol 130, 393-405

Strutz F, Heeg M, Kochsiek T, Siemers G, Zeisberg M, Müller GA (2000a): Effects of pentoxifylline, pentyfilline and $\mathrm{Y}$-Interferon on proliferation, differentiation, and matrix synthesis of human renal fibroblasts. Nephrol Dial Transplant 15, 1535-1546

Strutz F, Zeisberg M, Hemmerlein B, Sattler B, Hummel K, Becker V, Müller GA (2000b): Basic Fibroblast growth factor is increased in human renal fibrogenesis and may mediate autocrine fibroblast proliferation. Kidney Int $\underline{57}$, 1521-1538

Strutz F, Renziehausen A, Dietrich M, Amin J, Becker V, Heeg M, Rastaldi MP, Müller GA (2001): Cortical fibroblasts culture from human biopsies. J Nephrol 14, 190-7

Takayama H, Larochelle WJ, Sabins SG, Otsuka T, Merlino G (1997a): Renal tubular hyperplasia, polycystic disease, and glomerulosklerosis in transgenic mice overexpressing hepatocyte growth factor/ scatter factor . Lab Invest $\underline{77}, 131-138$

Takayama H, LaRochelle WJ, Sharp R, Otsuka T, Kriebel P, Anver M, Aaronson SA, Merlino G (1997b): Diverse tumorogenesis associated with aberrant development in mice overexpressing hepatocyte growth factor/ scatter factor. Proc Natl Acad Sci USA 94, 701-706

Thiery JP (2002): Epithelial-mesenchymal transition in tumor progression. Nat Rev Cancer $\underline{2}$ (6), 442-54 
Thomas SE, Andoh TF, Pichler RH, Shankland SJ, Couser WG, Benett WM, Johson RJ (1998): Accelrated apoptosis charcterizes cyclosporineassociated interstitail fibrosis. Kidney Int $\underline{53}, 897-908$

Timpl R (1996): Macromolecular organization of basement membranes. Curr Opin Cell Biol $\underline{8}, 618-624$

Towbin H, Staehelin T, Gordon J (1979): Electrophoretic transfer of proteins from polyacrylamid gels to nitrocellulose sheets: procedure and some applications. Biotechnology 24, 145-149

Vargas GA, Hoeflich A, Jehle P (2000): Hepatocyte growth factor in renal failure: Promise and reality. Kidney Int $\underline{57}$, 1426-1236

Vermes I, Haanen C, Steffens-Nakken H, Reutelingsperger (1995): A novel assay for apoptosis. Flow cytometric detection of phosphatiylserine expression on early apoptotic cells using fluorescein labelled Annexin V. J Immonol Methods 184, 39-51

Vijayan A, Martin DR, Sadow JL, Kissane J, Miller SB (2001): Hepatocyte growth factor inhibits apoptosis after ischemic renal injury in rats. Am J Kidney Dis $\underline{38}$, 274-278

Wahab NA, Mason RM (2006): A critical look at growth factors and epithelial-to-mesenchymal transition in the adult kidney. Nephron Exp Nephrol $\underline{104}$, e129-134

Watabe M, Matsumoto K, Nakamura T, Takeichi M (1993): Effect of Hepatocyte Growth Factor on Cadherin- Mediated Cell- Cell Adhesion. Cell Struct Func $\underline{18}, 117-124$

Weidner KM, Di Cesare S, Sachs M, Brinkmann, Behrens J, Birchmeier W (1996): Interactioon between Gab1 and the c- Met receptor tyrosine kinase is responsible for epithelial morphogenesis. Nature $\underline{384}, 173-176$ Wu MS (2007): From beside to bench drug-induced tubulointerstitial disease cyclosporine nephropathy study from models of cultured renal epithelial cells. Chang Gung Med J $\underline{30}(1), 7-16$

Yang CW, Faulkner GR, Whaba IM, Christianson TA, Bagby GC, Jin DC, Abboud HE, Andoh TF, Bennett WM (2002): Expressions of apoptosis- 
related genes in chronic cyclosporine nephrotoxicity in mice. Am $J$ Transplant 2, 391-399

Yang E and Korsmeyer SJ (1996): Molecular thanaopsis: a discourse on the BCL2 family and cell death. Blood $\underline{88}$, 386-401

Yang J, Liu Y (2002): Blockage of tubular epithelial to myofibroblast transition by hepatocyte growth factor prevents renal interstitial fibrosis. J Am Soc Nephrol 13, 96-107

Yang J, Liu Y (2003): Delayed administration of hepatocyte growth factor reduces renal fibrogenesis in obstructive nephropathy. Am J Physiol 284: F349-57

Yang J, Dai C, Liu Y (2001): Systemic administration of naked plasmid encoding hepatocyte growth factor ameliorates chronic renal fibrosis in mice. Gene Ther $\underline{8}$ (19), 1470-9

Yang J, Shultz RW, Mars WM, Wegner RE, Li Y, Dai C, Nejak K, Liu Y (2002): Disruption of tissue-type plasminogen activator gene in mice reduces renal interstitial fibrosis in obstructive nephropathy. J Clin Invest $\underline{110}(10), 1525-1538$

Yang J, Dai C, Liu Y (2003): HGF suppresses renal interstitial myofibroblast activation and intercepts Smad signal transduction. Am J Pathol $\underline{163}, 621-632$

Yazawa K, Isaka y, Takahara S, Imai E, Ichimau N, Shi Y, Namba Y,Okuyama A (2004): Direct Transfer of hepatocyte growth factor into kidney suppresses cyclosporin A nephrotoxicity in rats. Nephrology Dialysis Transplantation $\underline{19}, 812-816$

Zhang et al 2000

Zeisberg M, Kalluri R (2004): The role of epithelial-to-mesenchymal transition in renal fibrosis. J Mol Med $\underline{82}, 175-181$

Zeisberg M, Strutz F, Müller GA (2001): Renal Fibrosis: an update. Curr Opin Nephrol Hypertens $\underline{10}, 315-320$

Zeisberg M, Maeshima Y, Mostermann B, Kalluri R (2002): Extrazellular matrix microenvironment regulates migratory behaviour of activated tubular epithel cells. Am J Pathol 160, 2001-2008). 


\section{Abbildungs- und Tabellenverzeichnis}

\subsection{Abbildungsverzeichnis}

Abb.1.1 Struktur von Pro-HGF und HGF Seite 13

Abb. 1.2 Hauptsignalwege von HGF in Nierenzellen Seite 14

Abb. 1.3 Antagonismus zwischen HGF und TGF- $\beta 1$ Seite 16

Abb. 2.1 pcDNA3.1/Hygro (+) Vektorkarte Seite 26

Abb. 3.1 PCR-Gelelektrophorese auf HGF Seite 46

Abb.3.2 HGF-Westernblot Seite 47

Abb. 3.3 BrdU-Proliferationsassay von TFB Seite 49

Abb. 3.4 BrdU-Proliferationsassay von NP1 Seite 50

Abb. 3.5 Proliferationsassay (Zellzählung) von TFB Seite 51

Abb. 3.6 Proliferationsassay (Zellzählung) von NP1 Seite 52

Abb. 3.7 Fibronektin-Westernblot Seite 53

Abb. 3.8 Dichteanalyse des Fibronektin-Westernblot Seite 54

Abb. 3.9 Fibronektin ELISA Seite 56

Abb. 3.10 Kollagentyp-I ELISA Seite 57

Abb. 3.11 Zymographische Analyse MMP-2 und Seite 59 MMP-9

Abb. 3.12 MMP-9 Enzymaktivität $\quad$ Seite 60

Abb. 3.13 MMP-2 Enzymaktivität Seite 61

Abb. 3.14 Apoptoserate Seite 63 


\subsection{Tabellenverzeichnis}

Tab. 1.1

Tab. 2.1

Tab. 2.2

Tab. 2.3

Tab. 2.4

Tab. 2.5

Tab. 2.6

Tab. 2.7

Tab. 2.8

Tab. 2.9

Tab. 2.10

Tab. 2.11

Tab. 2.12

Tab. 2.13

Tab. 2.14
Mechanismen der renalen Fibrose

Seite 7

Phosphat-gepufferte Lösung

Tris-gepufferte Lösung

10x DNA-Probenpuffer

1x TAE-Laufpuffer

Maße und Volumina zur Subkultivierung Seite 33 von Zellen

Lysispuffer

Zusammensetzung der Gele

Transferpuffer

Blockierlösung

Primärantikörper

Sekundärantikörper

Probenpuffer

Laufpuffer

Entwicklungspuffer, $\mathrm{pH} 7,5$
Seite 36

Seite 24

Seite 24

Seite 28

Seite 29

Seite 37

Seite 38

Seite 39

Seite 39

Seite 40

Seite 41

Seite 41

Seite 42 


\section{Danksagung}

An dieser Stelle möchte ich allen, die mich bei meiner Arbeit unterstützt haben ganz herzlich danken.

Mein Dank gilt zunächst Herrn Prof. Dr. med. G.A. Müller als Leiter der Abteilung Nephrologie und Rheumatologie, für die Ermöglichung dieser Arbeit. In besonderer Weise möchte ich mich bei Herrn Prof Dr. med. F. Strutz für die interssante Themenstellung, die stete Diskussionsbereitschaft und die gute Betreuung, sowohl während des experimentellen Teils, als auch im Anschluss bei der Abfassung dieser Arbeit, bedanken.

Ein weiterer Dank gilt den Mitarbeitern der Arbeitsgruppe, Frau Diana Lichtblau und Frau Swantje Wehn und Christina Lauterberg, die mir immer mit Rat und Tat zur Seite standen. Die gute Arbeitsatmosphäre und die Kollegialität haben sehr zum Gelingen der Arbeit beigetragen.

Herrn Prof. Dr. E. Brunner sei stellvertretend für die Abteilung „Medizinische Statistik“ für die Hilfe bei der statistischen Auswertung meiner Daten gedankt. 